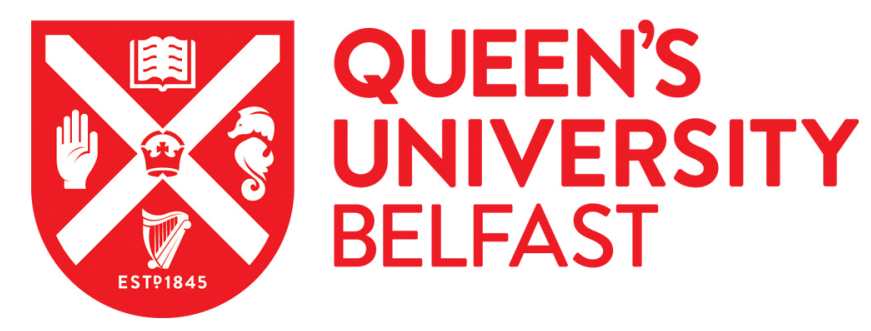

\title{
State-of-the-art on the production and application of carbon nanomaterials from biomass
}

Wang, Z., Shen, D., Wu, C., \& Gu, S. (2018). State-of-the-art on the production and application of carbon nanomaterials from biomass. Green Chemistry, 20,5031-5057. https://doi.org/10.1039/c8gc01748d

\author{
Published in: \\ Green Chemistry
}

Document Version:

Peer reviewed version

Queen's University Belfast - Research Portal:

Link to publication record in Queen's University Belfast Research Portal

Publisher rights

Copyright 2018 Royal Society of Chemistry. This work is made available online in accordance with the publisher's policies. Please refer to any applicable terms of use of the publisher.

\section{General rights}

Copyright for the publications made accessible via the Queen's University Belfast Research Portal is retained by the author(s) and / or other copyright owners and it is a condition of accessing these publications that users recognise and abide by the legal requirements associated with these rights.

Take down policy

The Research Portal is Queen's institutional repository that provides access to Queen's research output. Every effort has been made to ensure that content in the Research Portal does not infringe any person's rights, or applicable UK laws. If you discover content in the Research Portal that you believe breaches copyright or violates any law, please contact openaccess@qub.ac.uk. 


\title{
State-of-the-Art on the Production and Application of
}

\section{Carbon Nanomaterials from Biomass}

\author{
Zhanghong Wang ${ }^{\mathrm{a}, \mathrm{b}}$, Dekui Shen ${ }^{\mathrm{a}}$, Chunfei $\mathrm{Wu}^{\mathrm{c}^{*}}, \mathrm{Sai} \mathrm{Gu}^{\mathrm{d}}$ \\ ${ }^{a}$ Key Laboratory of Energy Thermal Conversion and Control of Ministry of Education, Southeast \\ University, Nanjing 210096, PR China \\ ${ }^{\mathrm{b}}$ School of Engineering and Computer Science, University of Hull, Hull HU6 7RX, United \\ Kingdom \\ c School of Chemistry and Chemical Engineering, Queen's University Belfast, Belfast BT7 1NN, \\ United Kingdom \\ ${ }^{\mathrm{d}}$ Faculty of Engineering and Physical Sciences, University of Surrey, Guilford, GU2 7XH, United \\ Kingdom
}

\begin{abstract}
Biomass is a type of low-cost, readily available, widely distributed, environmentally friendly and renewable carbon sources. How to realize its reasonable disposal is plaguing us especially as it acts as a by-product/bio-waste of agriculture, industry and forestry. Carbon nanomaterials (CNMs), especially for carbon nanotubes (CNTs), carbon nanofibers (CNFs), graphene, conventionally prepared from fossil fuel are the most demanding carbon materials at present due to the outstanding characteristics and extensive applications. The purpose of this review is to overview the progress on the technologies for CNMs preparation from biomass in the latest few decades. The production of these high value-added CNMs from biomass is intensively investigated, together with the biomass serving as catalyst and catalyst support during the preparation of CNMs. Finally, the advances in the application of biomass-based CNMs in terms of ecological remediation, photocatalysis, electrode materials for supercapacitor and battery, chemical catalysis and composites are briefly summarized for developing the potential market of biomass-based CNMs.
\end{abstract}

Key words: Biomass, Carbon Nanomaterials, Catalyst Support, Application

\section{Contents}

1 Introduction

\footnotetext{
* Corresponding authors:

Dekui Shen, Tel:+86-13851706572; E-mail: 101011398@seu.edu.cn;

Chunfei Wu, Tel: 44-2890975573; E-mail: c.wu@qub.ac.uk.
} 


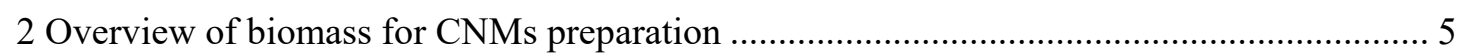

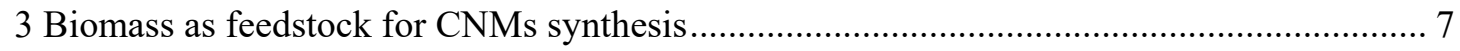

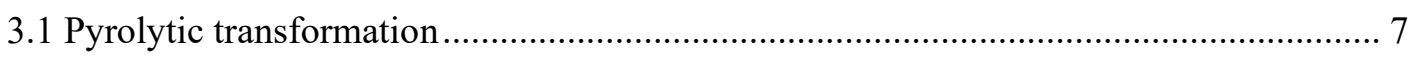

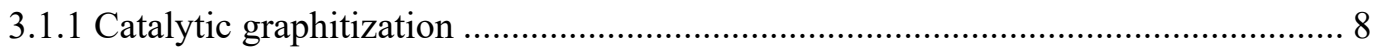

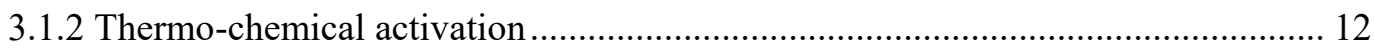

3.1.3 Catalytic graphitization coupled with thermo-chemical activation ....................... 13

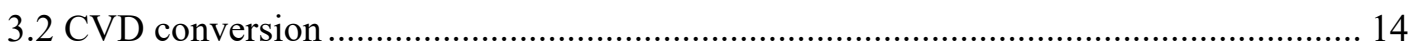

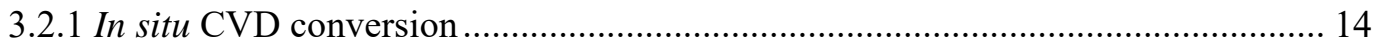

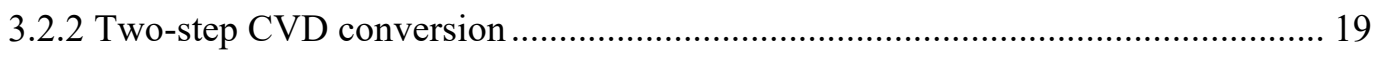

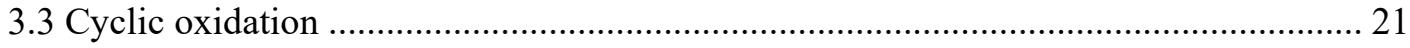

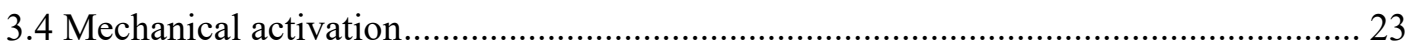

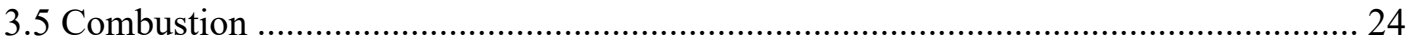

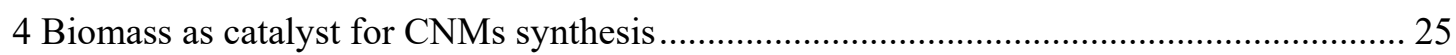

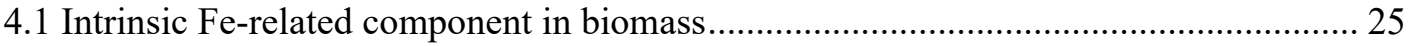

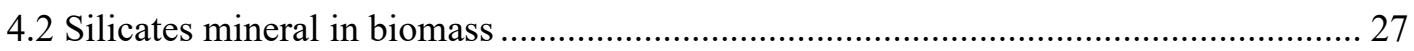

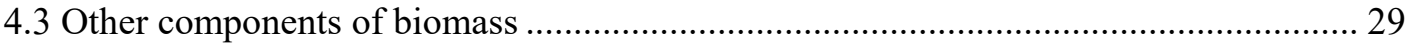

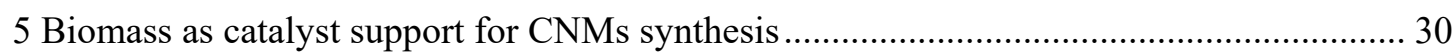

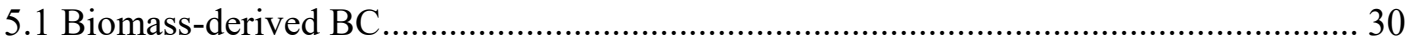

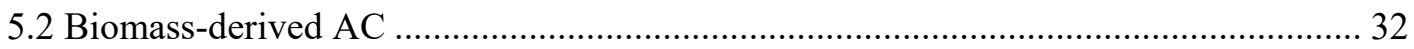

5.3 Roles of surface functional groups of biomass-derived carbon material on CNMs

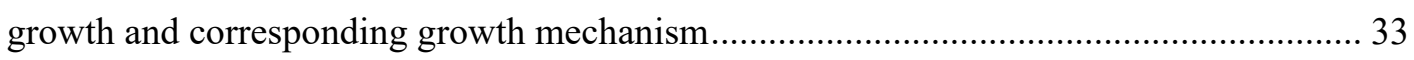

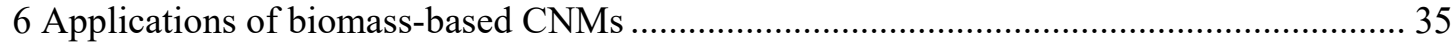

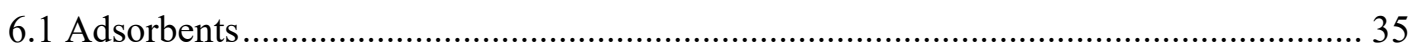

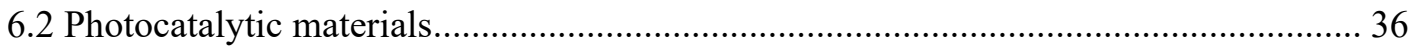

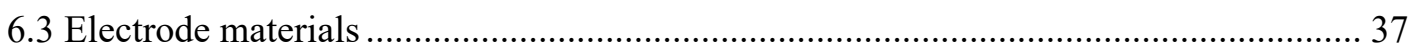

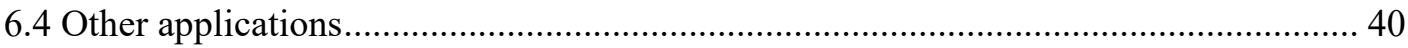

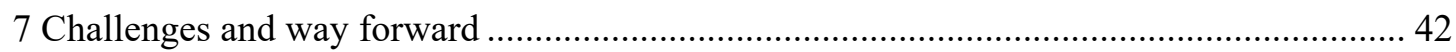




\section{Introduction}

It is well-established that carbon materials play an important role in promoting social development and technological progress. Graphite, diamond, activated carbon (AC) and carbon fibers, some of the typical carbon materials extensively employed in the last century, had brought great development to human society in energy, environment and technology. With the discovery of new-generation carbon materials (i.e., carbon nanomaterials, CNMs) at the end of the last century, such as fullerenes (spherical carbon cages built up of carbon atoms with $\mathrm{sp}^{2}$ hybridization via Euler's theorem), CNTs (onedimensional carbon nanostructures made of cylinders of $\mathrm{sp}^{2}$-hydbridized carbon atoms with several nanometers in diameter and many microns in length) and graphene (twodimensional monolayer of $\mathrm{sp}^{2}$-hydbridized carbon atoms in a honey comb lattice), carbon materials have once again been bringing rapid development to human civilization ${ }^{1,2}$. For instance, multi-walled CNTs discovered by Iijima in 1991 possess unique structure and fascinating properties such as high tensile strengths, high moduli, large aspect ratios, low densities, good chemical and environmental stabilities, and high thermal and electrical conductivities. These unique properties of CNTs give rise to their far-ranging applications in conductive and high-strength composites; energy storage and energy conversion devices ${ }^{3,4}$; sensors ${ }^{5-7}$; field emission displays ${ }^{8,9}$ and radiation sources; hydrogen storage media; and nanometer-sized semiconductor devices ${ }^{10}$, probes ${ }^{11,12}$, and wind blades ${ }^{13}$. Since then, researchers are in the ascendant of developing CNMs and exploiting their applications. Up to date, numerous methods including chemical vapor deposition (CVD) ${ }^{14}$, arc discharge ${ }^{1,15}$, laser ablation ${ }^{16}$, pyrolysis ${ }^{17,18}$, template methods ${ }^{19}$, flame synthesis ${ }^{20-22}$ and electrolysis ${ }^{23}$ have been successfully developed for preparing CNMs with individually special properties. However, carbon sources for the preparation of CNMs mainly focus on non-renewable petroleum and coal products, such as methane $\left(\mathrm{CH}_{4}\right)$, ethylene $\left(\mathrm{C}_{2} \mathrm{H}_{4}\right)$ and benzene, which have been giving rise to many serious social problems such as energy shortage and environmental crisis. Therefore, to seek new, environmentally friendly, low-cost and renewable carbon sources and explore corresponding preparation methods towards CNMs are the key factors that constrain the CNMs in making contributions in the development of human society.

Biomass originated from the photosynthesis of carbon dioxide, water and solar light is the richest renewable carbon source in nature. According to statistics, the world's annual biomass production is about 146 billion tons, of which carbon accounts for 20 billion tons ${ }^{24}$. On the other hand, biomass as a by-product of industry, agriculture and forestry such as bioethanol fermentation, pulp and paper manufacturing, grain planting, and forest mining, also has a large production every year ${ }^{25}$. It is estimated that as many as 30 billion tons of biomass waste are produced each year along with agricultural production and that from pulp and paper industry can reach 70 million tons as well ${ }^{26}$. To develop and utilize such a large amount of natural biomass and waste biomass is not only a resource problem but also an urgent environmental problem. 
The current research suggested that the preparation of bio-fuels and chemicals are two of the most promising applications of biomass ${ }^{27}$. $\mathrm{CH}_{4}$, ethanol, hydrogen-rich syngas, benzene, phenol as well as their derivatives can be readily obtained from biomass. At the same time, biomass is an important raw material for the preparation of carbon materials such as biochar (BC), coke and AC. In particular, BC contained limited specific surface area and underdeveloped porous structure while AC possessed uncontrollable pore size distribution and irregular three-dimensional structure, which greatly limited their applications. Driven by the huge demand for new generation of CNMs, researchers have made great efforts in the preparation of CNMs from biomass with excellent properties such as high thermal and electrical conductivities and good chemical and environmental stabilities. For example, graphene-like nanosheets with large specific surface area and pore volume, and good electrical conductivity were successfully prepared from waste coconut shell via a graphitization approach ${ }^{28}$. Wang et al. found that microwave plasma irradiation of rice husk can result in the formation of graphenated CNT hybrids ${ }^{29}$.

It is worth noting that the utilization of biomass for the preparation of high performance CNMs is still difficult due to biomass possesses complex three-dimensional structure, strong chemical bonding and high oxygen content. However, due to biomass is the only renewable carbon-containing source in the world and the development of biomassbased CNMs will make great contributions to the progress of other renewable energies such as wind power and solar energy ${ }^{13}$. Therefore, the continuous efforts for the preparation of CNMs from biomass in the future is of great significance.

Herein, the objective of the present work is to highlight the latest development in CNMs synthesis (e.g. CNTs, CNFs, graphene) from biomass (Fig. 1). Various techniques with biomass as a carbon source for the preparation of CNMs are extensively presented including pyrolytic transformation (catalytic graphitization, thermo-chemical activation, and catalytic graphitization coupled with thermo-chemical activation), CVD (in situ CVD and two-stage CVD), cyclic oxidation, mechanical activation and combustion. Attention is also paid to the studies using biomass as low-cost sustainable catalyst and catalyst support to make contributions in CNMs production. Afterward, the latest applications of the biomass-based CNMs (biomass acting as carbon source, catalyst and catalyst support) are investigated as well. Finally, current challenges and future strategies for the preparation of CNMs from biomass and their applications are discussed. 


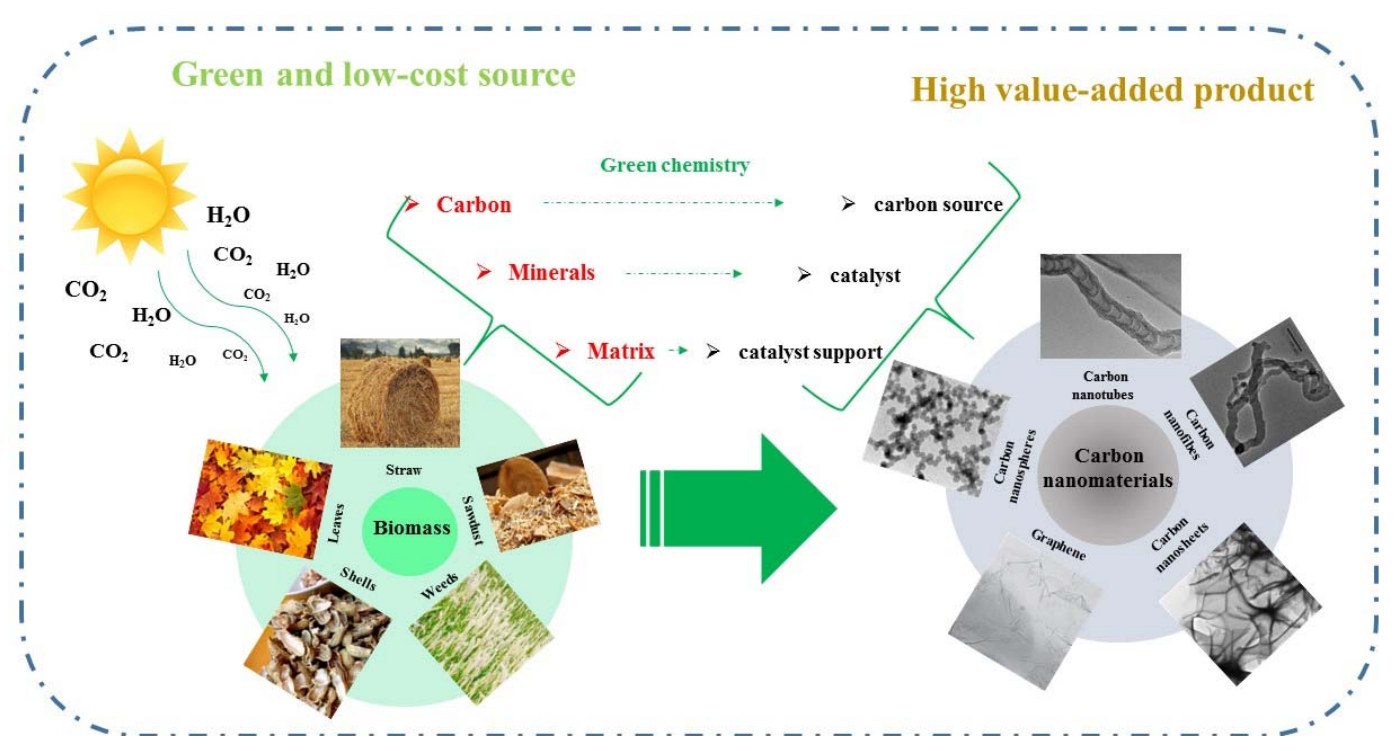

Fig. 1 Production of CNMs from biomass

\section{Overview of biomass for CNMs preparation}

Biomass is a sustainable and renewable carbon-rich material mainly composed of hemicellulose, cellulose and lignin, which has been widely employed as feedstock for the preparation of various high value-added carbon containing products like carbon materials, chemicals and bio-fuels ${ }^{30-32}$. Nowadays, extensive attention is obtained in the application of biomass acting as low cost and green carbon sources for the production of CNMs such as graphene, fullerene, CNFs and CNTs ${ }^{33}, 34$. These high value-added carbon materials (CNMs) predominantly consist of pure $\mathrm{C}$ element. By comparison, biomass contains abundant $\mathrm{H}, \mathrm{O}, \mathrm{N}$ and $\mathrm{S}$ besides $\mathrm{C}$. It thus appears that the cleavage of chemical bonds, the removal of $\mathrm{H}, \mathrm{O}, \mathrm{N}$ and $\mathrm{S}$ and the retention of $\mathrm{C}$ are the key for the preparation of CNMs from biomass. Thermal conversion involving pyrolysis, incineration or gasification is considered as one of the most universal methods for the removal of $\mathrm{H}, \mathrm{O}, \mathrm{N}$ and $\mathrm{S}$ from biomass. It is reported that the aromaticity of pyrolysis product evaluated by means of the ratio of $\mathrm{H} / \mathrm{C}$ and $\mathrm{O} / \mathrm{C}$ increased with the enhancement of pyrolysis temperature, indicating that $\mathrm{H}$ and $\mathrm{O}$ can be detached from C-related structure ${ }^{35}$. As demonstrated by Keiluweit et al., biomass was suffered some physical-chemical transitions as charring temperature increased from 100 to $700{ }^{\circ} \mathrm{C} \quad{ }^{36}$. These changes suggested the existence of four distinct categories of char consisting of a unique mixture of chemical phases and physical states: i) in transition chars, the crystalline character of the precursor materials is preserved; ii) in amorphous chars, the heat-altered molecules and incipient aromatic polycondensates are randomly mixed; iii) composite chars consist of poorly ordered graphene stacks embedded in amorphous phases; and iv) turbostratic chars are dominated by disordered graphitic crystallites ${ }^{36}$. Meanwhile, the involvement of metals such as rare earth (e.g. $\mathrm{La}$ ), $\mathrm{Mg}$ and $\mathrm{Fe}$, was found favorable for the carbonization of biomass, producing high aromatic carbon material ${ }^{37-39}$. On the other hand, chemicals and fuels derived from 
biomass are mainly abundant in $\mathrm{CO}$, hydrocarbon $\left(\mathrm{C}_{\mathrm{x}} \mathrm{H}_{\mathrm{y}}\right)$, alcohol and phenol ${ }^{31}$. It is reported that these chemicals with high purity obtained from fossil fuel have been widely used as carbon sources for the production of CNMs via a CVD process ${ }^{40-43}$. Consequently, the application of biomass as feedstock to prepare high-carbon-purity CNMs possesses tremendous possibility.

Apart from $\mathrm{C}, \mathrm{H}, \mathrm{O}$, biomass is also abundant in mineral elements including major elements (macronutrients) of $\mathrm{K}, \mathrm{Na}, \mathrm{Ca}, \mathrm{Mg}$, Si and trace elements (micronutrents) of $\mathrm{Fe}, \mathrm{Cu}, \mathrm{Mn}, \mathrm{Mo}, \mathrm{Zn}$ and other heavy metals ${ }^{44,45}$. The amount of each mineral element varies with the type of biomass and the ambient environment biomass growing. For example, ash related elements in herbaceous plant are much higher than that in wood plant ${ }^{46}$. While biomass growing in saline-alkali land or tailing region possesses much more mineral elements in relation to the soil circumstance where it grows. Furthermore, the content of mineral elements in biomass also differs from biomass organs (e.g. stem, leaf, root and shell). But in one organ, the distribution of each mineral is generally homogeneous. The existence of these elements not only makes dramatically effect on the growth of biomass but also the application of biomass ${ }^{47}$. Recently, much attention has been focused on the special catalytic function of mineral elements during thermal conversion process regarding pyrolysis, gasification and incineration ${ }^{47}$. It is reported that $\mathrm{Ca}, \mathrm{Mg}, \mathrm{Ca}$ or $\mathrm{Fe}$ in a coconut shell and bamboo serving as catalyst played an important role in the synthesis of $\mathrm{SiC}$ whiskers, $\mathrm{SiO}_{2}$ and $\mathrm{SiC}$ nanowires under high temperature (1200-1400 $\left.{ }^{\circ} \mathrm{C}\right){ }^{48,49}$. Biomass can be used as an effective catalyst for the preparation of functional materials since it contains many active catalytic mineral elements, especially for transition metal such as Fe. Meanwhile, the distribution of each active element is uniformly dispersed in individual organs and cells. As a result, increasing interest has been attracted in the application of biomass as a low cost and green catalyst for CNMs synthesis.

Biomass has the relatively stable three-dimensional structure, enabling it withstand a certain degree of mechanical, biological and chemical attack. Its structure will become much more stable after it subjects to a chemical, thermochemical or biological treatment for the removal of readily degradable constituents (all of hemicellulose and most of cellulose as well as partial lignin). As a result of the removal of those readily degradable constituents, channels and pores are widely formed in resulting matrix. Based on its abundant channels and pores structure, biomass without the easy degradable constituents has been considered as an ideal catalyst support employing extensively in catalytic reaction, such as hydrolysis, degradation and synthesis techniques ${ }^{50}$. It is worth mentioning that its ample functional groups inheriting from pristine biomass also has an important impact on its property in immobilizing and dispersing catalyst, which in turn plays a crucial role in catalytic reaction ${ }^{51}$. For example, in the process of CNMs preparation, especially for CVD method, it is essential to immobilize and disperse the catalyst onto a porous substrate, otherwise the catalyst will easily aggregate and agglomerate, which not only result in a low utilization efficiency and catalytic activity of catalyst but also make negative influence on the properties of as-synthesized CNMs. 
It is reported that the aggregation and agglomeration of catalyst were either unable to prepare CNMs or only little CNMs with large diameter and defect obtained ${ }^{52}$. Additionally, there are interactions existed between catalyst and support during the immobilization and dispersion of catalyst onto the support. The intense of these interactions is responsible for the properties and the growth mode of CNMs. In distance, catalyst particles readily detach from support leading to the growth of CNTs following "tip growth" mechanism as the catalyst and support gather in weak interactions ${ }^{53}$. Furthermore, the detached catalyst would aggregate together to form catalyst clusters or lumps which make the diameter of CNTs significantly increased. On the contrary, strong interactions occurred in catalyst and support cause a "base growth" mode for CNTs growth and with small diameters ${ }^{54}$. In brief, catalyst support developed from biomass with abundant pores and specific functional groups is found to be favorable for the synthesis of CNMs via a CVD method.

\section{Biomass as feedstock for CNMs synthesis}

\subsection{Pyrolytic transformation}

Conventional pyrolysis performed under an inert atmosphere at moderate temperature $\left(\sim 500{ }^{\circ} \mathrm{C}\right)$ is a well-developed method for the conversion of biomass into carbonaceous materials such as BC and AC. While the as-obtained carbonaceous materials are mainly made of anomalous amorphous carbon with low crystallinity, porosity and specific surface area due to biomass contains complex three-dimensional matrix, abundant heteroatoms besides $\mathrm{C}$ and strong interlinkages such as $\beta-\mathrm{O}-4$ which can be hardly cut off and rearranged in an orderly and regular arrangement (CNMs). Only a few studies have shown the feasibility of using pyrolysis to prepare CNMs from biomass. For example, Liu and co-workers reported that flat and wrinkled carbon nanosheets with a thickness of $30-40 \mathrm{~nm}$ and $120 \mathrm{~nm}$, respectively, as well as carbon nanorods could be collected from Perilla frutescens leaves after pyrolysis under $600-800{ }^{\circ} \mathrm{C}{ }^{55}$. And the pyrolysis of Camphor leaves at $1200{ }^{\circ} \mathrm{C}$ can result in the formation of few layer graphene with a thickness of $2.37 \mathrm{~nm}{ }^{56}$. Actually, most studies consistently showed that CNMs can hardly be obtained from the pyrolysis of biomass unless catalyst was added or the pyrolysis was combined with another process (a developed pyrolysis). Barin and co-workers found that highly curved graphitic nanostructured carbons with high degree of crystallinity can be easily derived from the pyrolysis of coconut coir dust after the involvement of a hydrothermal carbonization process in pretreating the dust prior to pyrolysis ${ }^{57}$. The existence of nickel salt (a type of graphitic catalyst) was regarded to play an important role in the formation of graphitic carbon nanostructures from cellulose via pyrolysis ${ }^{58}$. Herein, the preparation of CNMs from the developed pyrolysis is summarized, which is schematically presented in Fig. 2. 


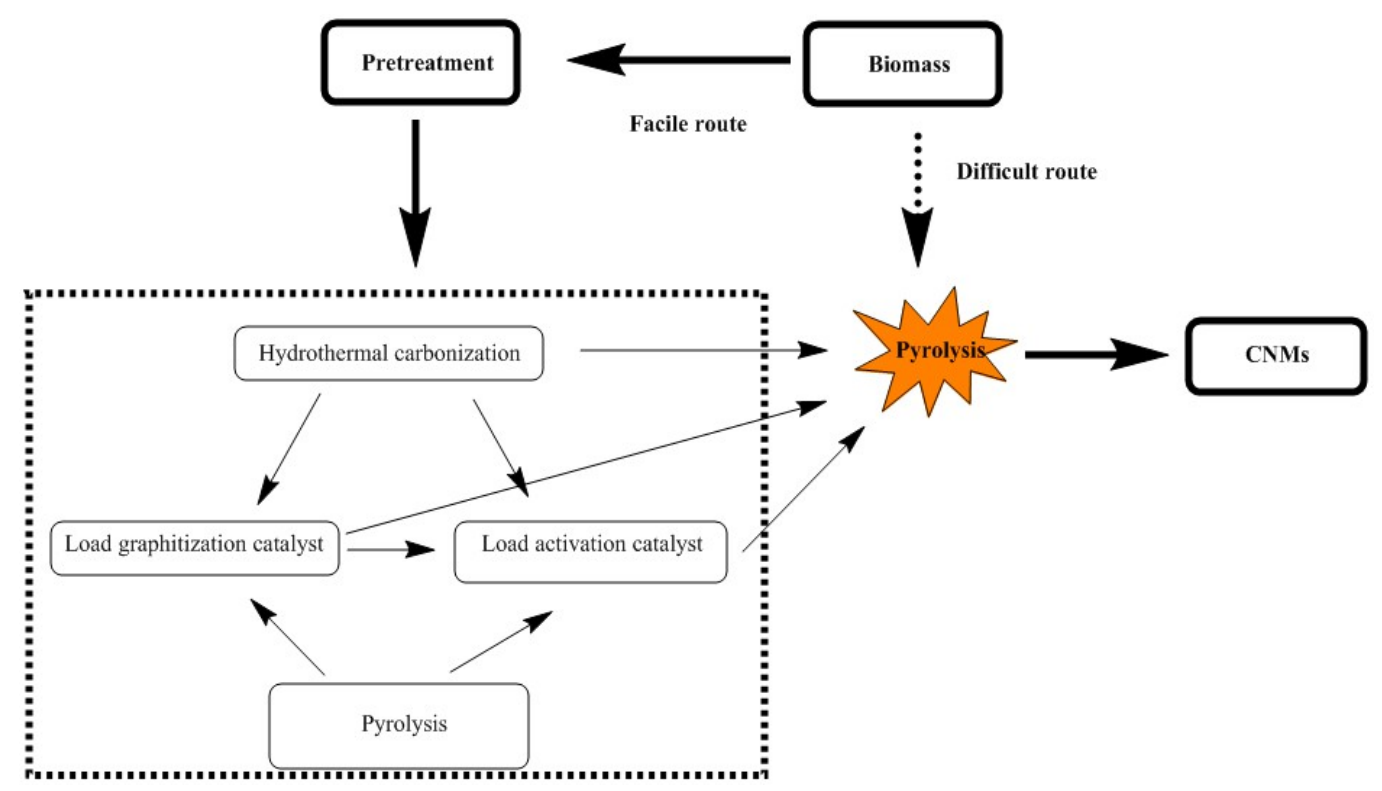

Fig. 2 Synthesis of CNMs from biomass via pyrolysis

\subsubsection{Catalytic graphitization}

Graphitization can be considered as a type of pyrolysis conducting at high temperature, which has been confirmed as an effective process to transform amorphous and turbostratic carbon materials into three-dimensional graphitic carbon materials such as CNTs, CNFs, nanocapsules ${ }^{59}$. While the temperature requested in conventional graphitization is rather high, usually above $2000{ }^{\circ} \mathrm{C}$. It results in an expensive cost and safety hazard, which has greatly limited its industrial application. The involvement of catalyst mainly consisted of group 4-7 metals could decrease the activation energy during the conversion of amorphous carbon to graphitic carbons hence decreasing the cost of preparation graphitic carbons. Group 4-7 metals (Fe, cobalt (Co), nickel (Ni), $\mathrm{Mn}$, etc.) are considered as ideal graphitization catalysts because they have 2-5 electrons in the $d$-shell orbital, making them capable of forming strong bonds between metal carbides and carbon-based materials ${ }^{60}$. Much interest therefore has focused on the development of catalytic graphitization for the preparation of CNMs. In addition to decreasing the activation energy during graphitic carbon formed, catalytic graphitization also can transform both graphitizable and non-graphitizable carbons into crystalline materials at moderate temperatures (below $1000{ }^{\circ} \mathrm{C}$ ) ${ }^{61}$. The following procedure is usually involved: i) impregnation of the precursor with catalyst like $\mathrm{Fe}$ or $\mathrm{Ni}$, ii) carbonization of the impregnated material at a certain temperature ${ }^{59,62}$.

Recently, catalytic graphitization has also been widely applied to the preparation of graphitic CNMs using biomass precursor. Sevilla et al. ${ }^{59}$ provided a research about the fabrication of graphitic CNMs from pine wood sawdust via this method. In detail, sawdust was impregnated into a solution of metal nitrate ( $\mathrm{Fe}$ or $\mathrm{Ni}$ ) in ethanol (2.5 or 5 mmol metal $/ \mathrm{g}$ ) through grinding and washing treatment. The precursor was heattreated under $\mathrm{N}_{2}$ at $900-1000{ }^{\circ} \mathrm{C}$ for $3 \mathrm{~h}$. Afterward, the material was washed with $20 \%$ 
$\mathrm{HCl}$ in order to remove the metals. The carbon samples obtained consisted of a mixture of amorphous carbon and graphitic nanostructures. In order to extract pure graphitic CNMs, the as-prepared carbons were oxidized in an acid solution with a molar composition of $\mathrm{H}_{2} \mathrm{O}: \mathrm{H}_{2} \mathrm{SO}_{4}: \mathrm{KMnO}_{4}=1: 0.02: 0.006$. In brief, samples were firstly treated with certain ratio of the acid solution then separated, followed by washing with $10 \% \mathrm{HCl}$. At last, the residue was collected and characterized by TEM/SAED, XRD and Raman analysis. The results indicated that the obtained materials were composed of graphitic carbon nanocapsules, nanocoils and nanoribbons with high crystallinity. This method was further verified in other studies ${ }^{63}$, where a variety of saccharides regarding to glucose, sucrose and potato starch and nitrate metallic salts including $\mathrm{Ni}$ and Fe were used as precursors and graphitization catalyst, respectively. As a result, bamboo-like nanopipes, nanocoils and nanocapsules were obtained, depending on the type of catalyst used. A research from Thompson et al. ${ }^{64}$ used $\mathrm{Fe}\left(\mathrm{NO}_{3}\right)_{3}$ as graphitization catalyst to prepare graphitic CNMs from softwood sawdust at $800{ }^{\circ} \mathrm{C}$. It was revealed that straight or bamboo-like graphitic CNTs were obtained which were different from that reported by Sevilla et al., though the same catalyst and similar graphitization temperature were applied. The detailed comparison of CNMs production from catalytic graphitization of biomass is presented in Table 1. Additionally, a treatment of oxidation in the liquid phase to selectively remove amorphous carbons was avoided in the work of Thompson et al. ${ }^{64}$. Petala et al. found that the carbon materials derived from the pyrolysis of pine resin loaded with $\mathrm{Fe}\left(\mathrm{NO}_{3}\right)_{3}$ under $1000{ }^{\circ} \mathrm{C}$ were mainly made of magnetic carbon nanocages ${ }^{65}$.

Table 1 Characteristics of CNMs prepared through pyrolysis

\begin{tabular}{|c|c|c|c|c|c|}
\hline Feedstock & $\begin{array}{l}\text { Graphitic } \\
\text { catalyst }\end{array}$ & $\begin{array}{l}\text { Activating } \\
\text { catalyst }\end{array}$ & Preparation process & Products & Reference \\
\hline $\begin{array}{l}\text { Perilla } \\
\text { frutescens } \\
\text { leaves }\end{array}$ & - & - & $\begin{array}{l}\text { Directly pyrolyzed } \\
\text { under } 600-800{ }^{\circ} \mathrm{C}\end{array}$ & $\begin{array}{l}\text {-O/N-co-doped porous } \\
\text { carbon nanosheets with } \\
\text { thickness in the range of } \\
30-120 \mathrm{~nm} \\
\text {-Carbon nanorods }\end{array}$ & 55 \\
\hline $\begin{array}{l}\text { Camphor } \\
\text { leaves }\end{array}$ & - & - & $\begin{array}{l}\text { Directly pyrolyzed } \\
\text { under } 1200{ }^{\circ} \mathrm{C}\end{array}$ & $\begin{array}{l}\text {-Few layer graphene } \\
\text { with a thickness of } 2.37 \\
\mathrm{~nm}\end{array}$ & 56 \\
\hline $\begin{array}{l}\text { Coconut coir } \\
\text { dust }\end{array}$ & - & - & $\begin{array}{l}\text { Hydrothermal } \\
\text { carbonized at } \\
250 \quad{ }^{\circ} \mathrm{C} \\
\text { pyrolyzed then } \\
1500{ }^{\circ} \mathrm{C}\end{array}$ & $\begin{array}{ll}\text {-Highly } & \text { curved } \\
\text { graphitic } & \text { carbon } \\
\text { nanostructures } & \end{array}$ & 57 \\
\hline $\begin{array}{l}\text { Pine wood } \\
\text { sawdust }\end{array}$ & $\begin{array}{l}\mathrm{Ni}\left(\mathrm{NO}_{3}\right)_{2} \\
\text { or } \\
\mathrm{Fe}\left(\mathrm{NO}_{3}\right)_{3}\end{array}$ & - & $\begin{array}{l}\text { Pyrolyzed the Ni or } \\
\text { Fe-loaded sawdust } \\
\text { at } 900 \sim 1000{ }^{\circ} \mathrm{C}\end{array}$ & $\begin{array}{l}\text {-Graphitic carbon } \\
\text { nanocapsules, } \\
\text { nanocoils, nanoribbons }\end{array}$ & 59 \\
\hline $\begin{array}{l}\text { Softwood } \\
\text { sawdust }\end{array}$ & $\mathrm{Fe}\left(\mathrm{NO}_{3}\right)_{3}$ & - & $\begin{array}{l}\text { Pyrolyzed the Fe- } \\
\text { loaded sawdust at }\end{array}$ & $\begin{array}{l}\text { Straight and bamboo- } \\
\text { like graphitic nanotubes }\end{array}$ & 64 \\
\hline
\end{tabular}




\begin{tabular}{|c|c|c|c|c|c|}
\hline Pine resin & $\mathrm{Fe}\left(\mathrm{NO}_{3}\right)_{3}$ & - & $\begin{array}{l}800{ }^{\circ} \mathrm{C} \\
\text { Pyrolyzed the Fe- } \\
\text { loaded sawdust at } \\
1000{ }^{\circ} \mathrm{C}\end{array}$ & $\begin{array}{l}\text { Magnetic carbon } \\
\text { nanocages }\end{array}$ & 65 \\
\hline $\begin{array}{l}\text { Dry elm } \\
\text { samaras }\end{array}$ & - & $\mathrm{KOH}$ & $\begin{array}{l}\text { Pyrolyzed the } \\
\mathrm{KOH} / \text { elem samaras } \\
\text { mixture at } 1000{ }^{\circ} \mathrm{C}\end{array}$ & $\begin{array}{l}\text { Highly porous carbon } \\
\text { nanosheets }\end{array}$ & 66 \\
\hline $\begin{array}{l}\text { Willow } \\
\text { catkin }\end{array}$ & - & $\mathrm{KOH}$ & $\begin{array}{l}\text { Pyrolyzed the } \\
\mathrm{KOH} / \text { willow catkin } \\
\text { mixture at } 850{ }^{\circ} \mathrm{C}\end{array}$ & $\begin{array}{l}\text { Interconnected porous } \\
\text { carbon nanosheets }\end{array}$ & 67 \\
\hline $\begin{array}{l}\text { Sugarcane } \\
\text { bagasse }\end{array}$ & - & $\mathrm{KOH}$ & $\begin{array}{l}\text { Sugarcane bagasse } \\
\text { was firstly } \\
\text { carbonized under } \\
700{ }^{\circ} \mathrm{C} \text { and then } \\
\text { pyrolyzed at } 600- \\
900{ }^{\circ} \mathrm{C} \text { after mixed } \\
\text { with a } \mathrm{KOH} \\
\text { solution }\end{array}$ & $\begin{array}{l}\text { Larger size graphene- } \\
\text { like porous carbon } \\
\text { nanosheets }\end{array}$ & 68 \\
\hline Reed & - & $\mathrm{KOH}$ & $\begin{array}{l}\text { Reed was subjected } \\
\text { to a hydrothermal } \\
\text { treatment and then } \\
\text { pyrolyzed at } 700 \text { - } \\
900{ }^{\circ} \mathrm{C} \text { after mixed } \\
\text { with a } \mathrm{KOH} \\
\text { solution }\end{array}$ & $\begin{array}{l}\text { Interconnected porous } \\
\text { carbon nanosheets }\end{array}$ & 69 \\
\hline Spruce bark & - & $\mathrm{KOH}$ & $\begin{array}{l}\text { Spruce bark was } \\
\text { subjected to a } \\
\text { hydrothermal } \\
\text { treatment and then } \\
\text { pyrolyzed at } 800- \\
1000 \text { }{ }^{\circ} \text { after } \\
\text { mixed with } \mathrm{KOH} \\
\text { via grinding }\end{array}$ & $\begin{array}{l}\text { Vertically } \quad \text { aligned } \\
\text { graphene nanosheet } \\
\text { arrays }\end{array}$ & 70 \\
\hline Wheat stalk & - & $\mathrm{KOH}$ & $\begin{array}{l}\mathrm{KOH} \text { immersed } \\
\text { wheat straw was } \\
\text { hydrothermally } \\
\text { treated and then } \\
\text { pyrolyzed at } \\
800{ }^{\circ} \mathrm{C} \text {, followed } \\
\text { by treating at } \\
2600{ }^{\circ} \mathrm{C}\end{array}$ & $\begin{array}{ll}\text { Interconnected } & \text { highly } \\
\text { graphitic } & \text { carbon } \\
\text { nanosheets } & \end{array}$ & 71 \\
\hline Wheat straw & - & $\mathrm{KOH}$ & $\begin{array}{l}\mathrm{KOH} \text { immersed } \\
\text { wheat straw was } \\
\text { hydrothermally }\end{array}$ & Few-layer graphene & 72 \\
\hline
\end{tabular}




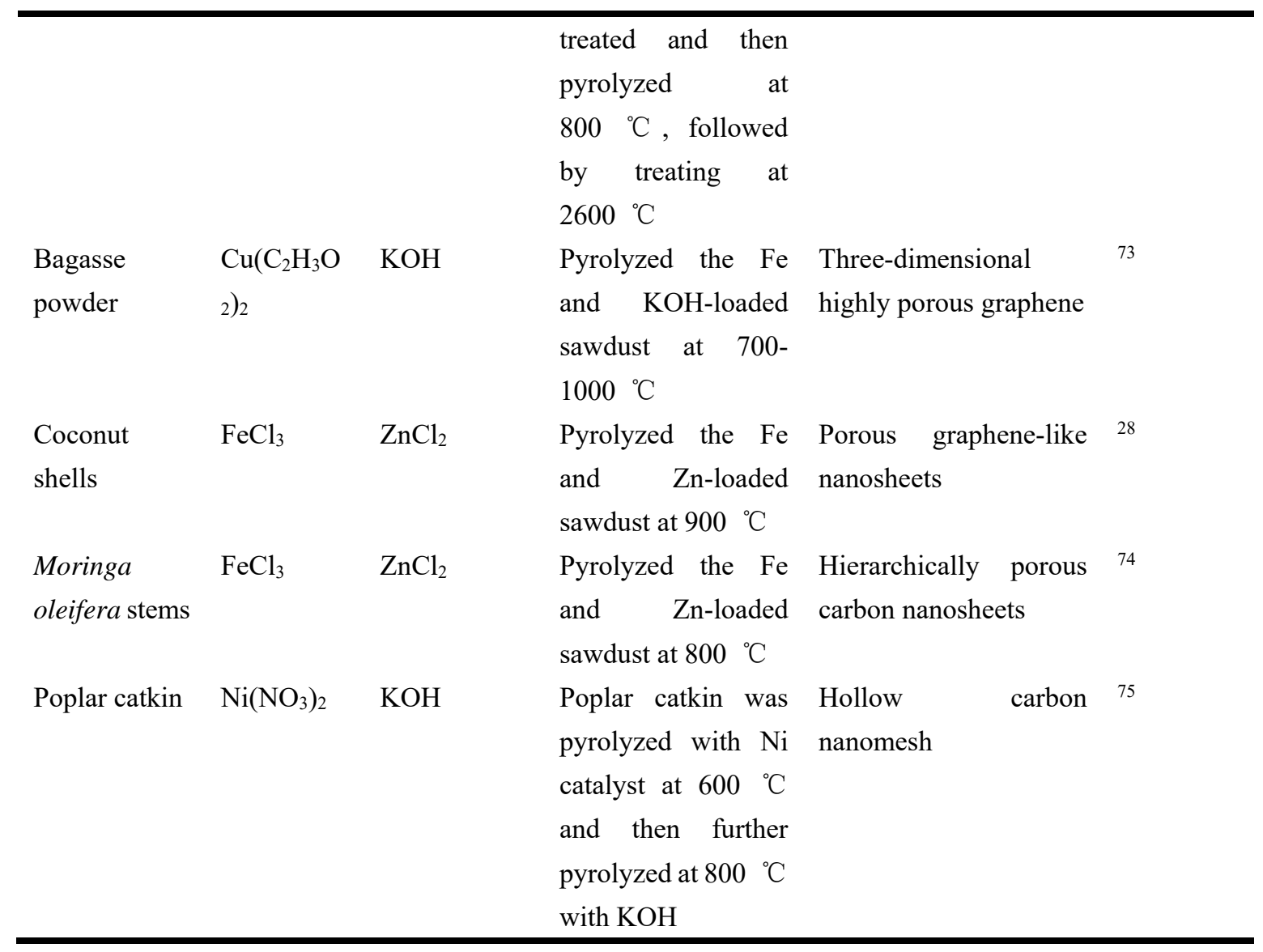

Two mechanisms have been proposed to explain the process of catalytic graphitization: i) the dissolution-precipitation mechanism, whereby amorphous carbons are first dissolved into the metal particles, then precipitate to graphitic carbons and ii) the formation-decomposition of carbide intermediates, whereby the carbons form carbides with the metal, then are decomposed at a certain temperature, leaving behind graphitic carbons ${ }^{60,76}$. In Sevilla et al. ${ }^{59,63}$ study, they are inclined to dissolution-precipitation mechanism. They considered that when biomass impregnated with a metallic salt were heat-treated under an inert atmosphere, the salt decomposed into corresponding metallic oxides, which were subsequently reduced by the carbon into metal nanoparticles (i.e., Ni, Fe). Graphitic CNMs were then formed around the metallic nanoparticles through a catalytic mechanism that involved the dissolution of amorphous carbon into catalyst particles followed by the precipitation of graphitic carbons. Apart from reduced metal particle $(\mathrm{Fe}), \mathrm{Fe}$ carbide $\left(\mathrm{Fe}_{3} \mathrm{C}\right)$ also had been proposed as the active catalyst in graphitic $\mathrm{CNMs}$ formation ${ }^{64}$. $\mathrm{Fe}$ and $\mathrm{Fe}_{3} \mathrm{C}$ resulted in the formation of straight and bamboo-like nanotubes, respectively. Sun et al. proposed that the porous graphene-like nanosheets derived from the coconut shell by the catalytic graphitization of $\mathrm{Fe}$ are mainly dominated by the formation-decomposition mechanism involving the formation of $\mathrm{Fe}_{3} \mathrm{C}$ and their subsequent transformation to $\mathrm{Fe}^{28}$. Active carbon atoms in the $\mathrm{Fe}_{3} \mathrm{C}$ layers could diffuse out from the dense $\mathrm{Fe}_{3} \mathrm{C}$ layer to form the dense twodimensional carbon atom layers on both surfaces of the self-generating Fe template. In addition, the excess amount of carbon atoms would precipitate on the formed nanosheets. 


\subsubsection{Thermo-chemical activation}

Pyrolysis process using a chemical activation agent such as $\mathrm{KOH}, \mathrm{ZnCl}_{2}$, and $\mathrm{H}_{3} \mathrm{PO}_{4}$ (thermo-chemical activation) is a well-developed approach for the preparation of AC from biomass with high specific surface area and developed porosity. Additionally, chemical activation agent plays a vital role in the evolution of carbon matrix and the formation of porous structure. Recently, some studies revealed that CNMs could be obtained through a thermo-chemical activation treatment of biomass (Table 1). For example, Chen et al. reported that the pyrolysis of elm samaras after treated with a $\mathrm{KOH}$ aqueous solution based on a mass ration of 1:1 resulted in the formation of threedimensional scaffolding frameworks of highly porous carbon nanosheets with a thickness down to $1-2 \mathrm{~nm}^{66}$. An interconnected porous carbon nanosheets was obtained as willow catkin was employed as biomass feedstock in the same preparation method ${ }^{67}$. It was believed that willow catkin with a unique hollow and multilayered structure could readily interact with $\mathrm{KOH}$ which was favorable for CNMs synthesis. However, Niu et al. considered that in addition to the introduction of chemical activation agent $(\mathrm{KOH})$, a pre-carbonization treatment at $700{ }^{\circ} \mathrm{C}$ was also necessary to produce the carbon nanosheets with large-size multiscale wrinkled nanosheets architecture and high surface area from sugarcane bagasse pith ${ }^{68}$. Meanwhile, a hydrothermal carbonization of spruce bark at $180{ }^{\circ} \mathrm{C}$ in a stainless steel autoclave was conducted prior to the thermo-chemical activation ${ }^{70}$. A three-dimensional interconnected structure was observed with ultrahigh specific surface area $\left(2385 \mathrm{~m}^{2} / \mathrm{g}\right)$, large volume of hierarchical pore volume and easily accessible open surfaces of graphene nanosheets. Interestingly, Zhou group introduced $\mathrm{KOH}$ during the hydrothermal carbonization of wheat stalk and inferred that high concentrated hot $\mathrm{KOH}$ solution can gradually saponify the wax and dissolve hemicellulose and linin. After the removal of hemicellulose and lignin, cellulose microfibrils with weak linkage were collected. When the as-derived cellulose microfibrils were subjected to a pyrolysis and graphitization process (see Fig. 3), interconnected highly graphitic carbon nanosheets with 2-10 atomic layers were readily obtained $^{71}$.

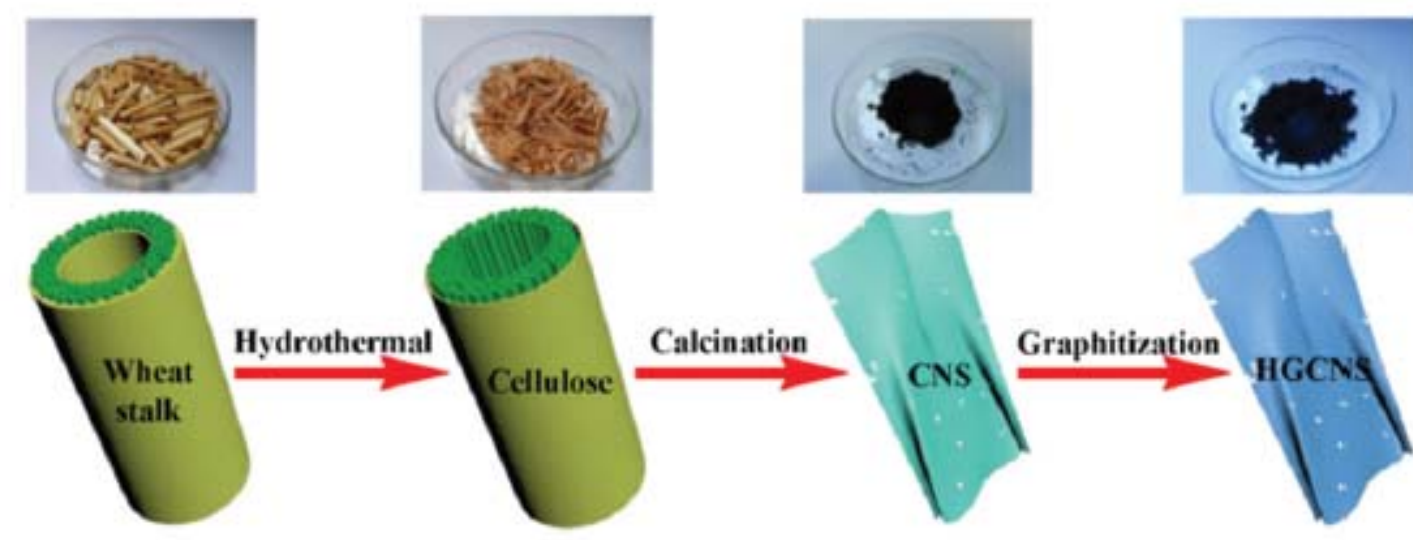

Fig. 3 Schematic diagram for the preparation of CNMs from wheat stalk proposed by Zhou group ${ }^{71}$. Reproduced from ${ }^{71}$ with permission from the Royal Society of Chemistry 


\subsubsection{Catalytic graphitization coupled with thermo-chemical}

\section{activation}

As mentioned above, a catalytic graphitization was in favor of the formation of high graphited CNMs while layered porous CNMs can be readily derived after a thermochemical activation. Naturally, much attention is attracted to the combination of these two methods for the preparation of carbon materials. Su and co-workers presented a study on the production of carbon materials from poplar catkin through a combination of graphitization with chemical activation process, in which $\mathrm{Ni}\left(\mathrm{NO}_{3}\right)_{2}$ and $\mathrm{KOH}$ were employed as a catalyst, respectively. It was confirmed from SEM and TEM images that hollow carbon nanomesh was successfully obtained and their further investigation revealed that the as-synthesized CNMs possessed a large specific surface area $\left(1893 \mathrm{~m}^{2} / \mathrm{g}\right)$ and a high total pore volume $\left(1.495 \mathrm{~cm}^{3} / \mathrm{g}\right){ }^{75}$. Both $\mathrm{Ni}\left(\mathrm{NO}_{3}\right)_{2}$ and $\mathrm{KOH}$ were considered playing important roles in chemical etching of raw material, resulting in the formation of nanomesh morphology. Instead of $\mathrm{Ni}\left(\mathrm{NO}_{3}\right)_{2}, \mathrm{Cu}\left(\mathrm{C}_{2} \mathrm{H}_{3} \mathrm{O}_{2}\right)_{2}$ was employed coupling with $\mathrm{KOH}$ to simultaneously activate bagasse powder under 700$1000{ }^{\circ} \mathrm{C}$ in Mahmoudian et al. research ${ }^{73}$. It was found that three-dimensional highly porous graphene was prepared with a specific surface area of almost $3000 \mathrm{~m}^{2} / \mathrm{g}$. Typical graphitization and activation catalyst of $\mathrm{FeCl}_{3}$ and $\mathrm{ZnCl}_{2}$ were also investigated for the preparation of carbon materials via the combination of graphitization and activation process ${ }^{74}$. Sun et al. ${ }^{28}$ reported that Fe components can catalyze graphitization of the carbon source, and meanwhile, chemical activation of $\mathrm{ZnCl}_{2}$ can make the carbon source have a porous structure. As a result, porous graphene-like nanosheets were obtained with a specific surface area of $1281-1874 \mathrm{~m}^{2} / \mathrm{g}$ corresponding to the graphitization temperature range of 700-1000 ${ }^{\circ} \mathrm{C}$. Therefore, it can be concluded that the combination of catalytic graphitization and thermos-chemical activation procedure is an effective and promising way to prepare graphitic porous CNMs. According to the aforementioned summary, the morphology and properties of CNMs are greatly dependent on the type of raw material, pretreatment (such as the introduction of catalyst and pre-hydrothermal carbonization) and operating parameters (especially for temperature) (Table 1). For example, Chen et al. revealed that the thickness was greatly reduced by increasing the $\mathrm{KOH}$ concentration applied. The thickness of the CNMs was $1-2 \mathrm{~nm}$ when a $\mathrm{KOH}$ concentration of $6 \mathrm{~mol} / \mathrm{L}$ was used. The layer of the CNMs became too thin to hold the three-dimensional frameworks when the $\mathrm{KOH}$ concentration was higher than $8 \mathrm{~mol} / \mathrm{L}$ resulting in a collapse morphology ${ }^{66}$. This observation suggested that the dosage of the activation agent made important influences on the properties of CNMs. Accordingly, it is necessary to take all factors concerning the type of raw material, pretreatment and operating parameters into account as intend to design a wellorganized CNMs from pyrolysis. 


\subsection{CVD conversion}

CVD method is one of the most typical and well-developed technique for CNMs synthesis, where carbon source, catalyst and catalyst support are generally needed ${ }^{77-79}$. Carbon source offers carbon atom for the formation of CNMs after a decomposition process. Catalyst provides active sites to prompt the decomposition of a carbon source to generate carbon atom and acts as a template for CNMs growth. And catalyst support would support and disperse catalyst to maintain its high activation and efficiency. Up to date, the most commonly used carbon sources for the preparation of CNMs are purified $\mathrm{CO}, \mathrm{CO}_{2}$ and hydrocarbons (such as $\mathrm{CH}_{4}, \mathrm{C}_{2} \mathrm{H}_{4}$, benzene, naphthalene) ${ }^{40,42,80 \text {, }}$ ${ }^{81}$. On the other hand, biomass can be converted to various $\mathrm{C}$-containing products such as $\mathrm{CO}, \mathrm{CO}_{2}$, light hydrocarbons (e.g. $\mathrm{CH}_{4}, \mathrm{C}_{2} \mathrm{H}_{4}$ ), aromatic hydrocarbons (e.g. benzene, toluene) and their corresponding derivatives (e.g. $\mathrm{CH}_{3} \mathrm{OH}$, phenol) by means of pyrolysis, incineration or gasification ${ }^{31,82,83}$. Hence, biomass can be considered as a potential starting material for the preparation of CNMs via CVD method. It was found that considerable achievements have been attained for the preparation of CNMs from CNMs, which can be generally divided into in situ CVD and two-stage CVD in terms of the location of the catalyst employed during the CNMs preparation procedure. The relationships of conventional CVD, in situ CVD and two-stage CVD are presented in Fig. 4.

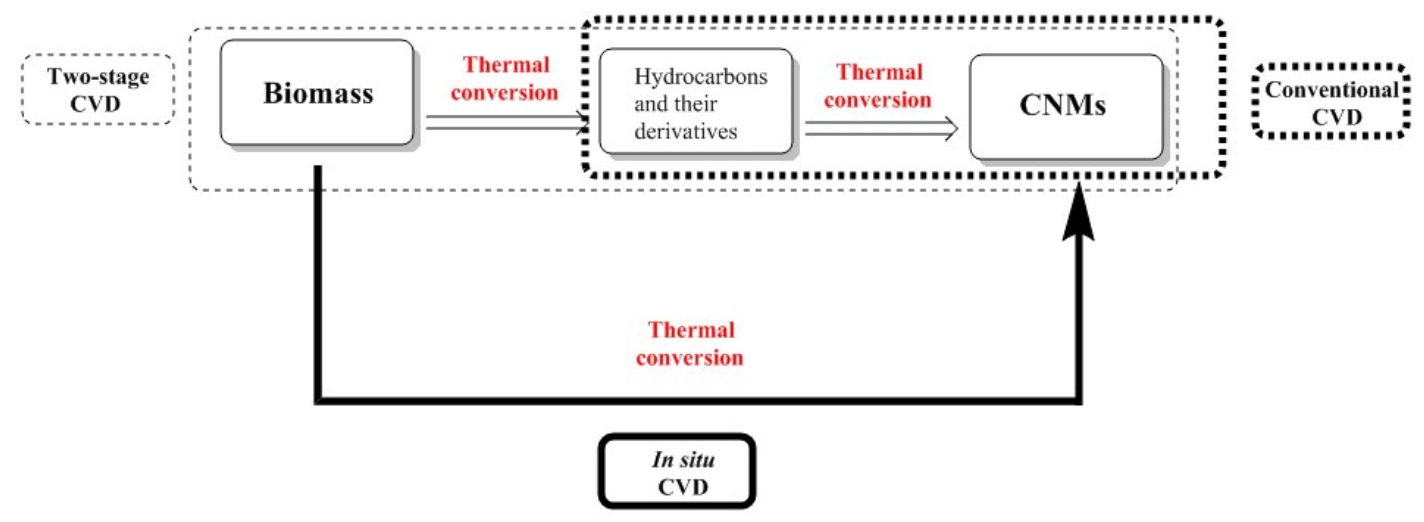

Fig. 4 Relationships of conventional CVD, in situ CVD and Two-step CVD

\subsubsection{In situ CVD conversion}

In an in situ CVD process for the preparation of CNMs from biomass, the conversion of biomass into carbon sources, the decomposition of carbon sources into carbon atoms and the fabrication of CNMs from the decomposed carbon atoms were occured at the same interface. One of the most critical points of the process is to prepare the homogeneous system of biomass-catalyst (or biomass-catalyst precursor). A homogeneous system can ensure the adequate supply of carbon sources and sufficient active catalytic sites, which is beneficial to the effective conversion of biomass into desired CNMs. For example, Liu et al. mixed fir sawdust with Fe-containing precursor 
by an impregnation method. Briefly, sawdust was immersed into a $\mathrm{FeCl}_{3}$ solution and kept shaking in an oscillator for $5 \mathrm{~h}$. After that, the suspension was evaporated under reduced pressure and the solid residue was collected. High-yield harvest of CNFs consequently can be obtained after a fast pyrolysis of the oven-dried solid residue in a vertical fixed bed ${ }^{84}$. Liu et al. considered that during the pyrolysis, the fir sawdust was firstly decomposed into abundant small-molecular hydrocarbons such as $\mathrm{CH}_{4}, \mathrm{C}_{2} \mathrm{H}_{4}$ and $\mathrm{C}_{2} \mathrm{H}_{2}$. These compounds were further decomposed into carbon atoms on the surface of Fe-containing catalyst, then the as-decomposed carbon atoms deposited on the surface of the catalyst and precipitated to form CNFs. Different from the impregnation method of Liu et al., Debalina et al. employed commercial Fe and Co powder as catalysts and mixed them with sugarcane bagasse through grinding. A homogeneous system was obtained as well as the CNTs as the products of microwave assisted pyrolysis ${ }^{85}$. It is well known that impregnation method is a process to take the advantage of biomass bio-sorption. Due to the presence of abundant homogeneous-distributed O-containing functional groups and porous structures, biomass can efficiently adsorb and homogeneously fix catalyst to obtain a homogeneous biomass-catalyst system to avoid the sintering and agglomeration of catalyst ${ }^{50}$. On the other hand, grinding also is a conventional way to mix biomass and catalyst into a homogenous sample through a mechanical force. It is worthwhile to note that there are various intrinsic minerals in natural biomass which are homogeneously distributed in every cell ${ }^{86}$. Natural biomass with homogeneous targeted intrinsic minerals may be a better catalyst than the homogeneous biomass-catalyst system derived from impregnation or grinding. This assumption was evident in the research from Shi et al., where multi-walled CNTs were obtained from microwave-induced processing of minerals-rich gumwood ${ }^{87}$. Shi et al. assumed that the $\mathrm{Si}$ and $\mathrm{Ca}$ related nanoparticles in gumwood played key roles in CNTs formation during microwave treatment. Interestingly, a home-made nickel case was employed to load rice husks and then acted as catalyst sources during the preparation of graphene and CNTs composites from microwave plasma irradiation ${ }^{29}$. This result indicated that in addition to the homogeneous biomass-catalyst system, there are other factors affecting the synthesis of CNMs via in situ CVD.

It is well-established that the preparation of CNMs from conventional CVD process is significantly affected by carbon sources, catalyst, support and operating parameters (such as atmosphere, operating temperature) ${ }^{79,88}$. Similarly, these factors also play important roles in in situ CVD technique ${ }^{89,90}$. The type and amount of carbon sources employed in the production of CNMs in conventional CVD can be controlled accurately 77. However, it is difficult to verify the carbon sources involved in an in situ CVD process of the preparation of CNMs from biomass due to the composition of the volatiles (a mixture of bio-oil and non-condensable gases) from the pyrolysis of biomass is extremely complex. For example, the major components of the bio-oil originated from the pyrolysis of wheat straw were phenols, methoxyphenols, and substituted methoxyphenols while the non-condensable gases mainly consisted of $\mathrm{CO}$, $\mathrm{H}_{2}, \mathrm{CO}_{2}, \mathrm{CH}_{4}, \mathrm{C}_{2} \mathrm{H}_{4}, \mathrm{C}_{2} \mathrm{H}_{6}$, and $\mathrm{C}_{4} \mathrm{H}_{10}{ }^{91}$. Most studies for the preparation of CNMs from biomass via in situ CVD considered that light hydrocarbons such as $\mathrm{CH}_{4}, \mathrm{C}_{2} \mathrm{H}_{4}$ 
and $\mathrm{C}_{2} \mathrm{H}_{2}$, played crucial roles in the formation of CNMs ${ }^{50,51}$. In addition to hydrocarbons, Shi et al. considered hydrocarbon derivatives like phenol in bio-oil originated from gumwood also were responsible for the CNTs synthesis during microwave induced pyrolysis ${ }^{87}$. Zhang et al. believed that $\mathrm{CO}$ and $\mathrm{CO}_{2}$ in bio-gas originated from the microwave pyrolysis of pine nut shell made partly contributions in the formation of hollow CNFs ${ }^{92}$. Apart from volatiles mainly concerning hydrocarbons and their derivatives, Wang et al. considered that carbon radicals of char made an important contribution to the synthesis of shape-edge graphene during microwave plasma irradiation pyrolysis of rich husk ${ }^{29}$. More details about the carbon sources of CNMs in an in situ CVD process and other parameters as well as the characteristics of as-prepared CNMs are presented in Table 2.

Table 2 Biomass-based CNMs obtained from in situ CVD process.

\begin{tabular}{|c|c|c|c|c|c|c|}
\hline Biomass & Carbon source & Substrate & Catalyst & Method & Products and characteristics & Reference \\
\hline $\begin{array}{l}\text { Fir } \\
\text { sawdust }\end{array}$ & $\begin{array}{l}\text { Small-molecular } \\
\text { hydrocarbons } \\
\text { from the } \\
\text { decomposition of } \\
\text { fir sawdust }\end{array}$ & $\begin{array}{l}\text { Fir } \\
\text { sawdust } \\
\text { char }\end{array}$ & $\mathrm{FeCl}_{3}$ & Fast pyrolysis & $\begin{array}{l}\text { Magnetic CNFs/mesoporous } \\
\text { carbon composites }\end{array}$ & 84 \\
\hline $\begin{array}{l}\text { Fir } \\
\text { sawdust }\end{array}$ & $\begin{array}{l}\text { Small-molecular } \\
\text { hydrocarbons } \\
\text { from the } \\
\text { decomposition of } \\
\text { fir sawdust }\end{array}$ & $\begin{array}{l}\text { Fir } \\
\text { sawdust } \\
\text { char }\end{array}$ & $\begin{array}{l}\mathrm{FeCl}_{3} \text { plus } \\
\mathrm{NiCl}_{2}\end{array}$ & Fast pyrolysis & $\mathrm{Ni}-\mathrm{NiFe}_{2} \mathrm{O}_{4} / \mathrm{CNFs}$ & 50 \\
\hline Rice husk & $\begin{array}{l}\mathrm{CH}_{4} \text { from the } \\
\text { decomposition of } \\
\text { rice husk and } \\
\text { carbon radicals } \\
\text { from rice husk- } \\
\text { derived char }\end{array}$ & $\begin{array}{l}\text { Rice husk } \\
\text { char }\end{array}$ & $\begin{array}{l}\mathrm{Ni} \text { from } \\
\text { nickel } \\
\text { case }\end{array}$ & $\begin{array}{l}\text { Microwave } \\
\text { plasma } \\
\text { irradiation }\end{array}$ & $\begin{array}{l}\text { Graphene, CNTs and } \\
\text { graphenated CNTs }\end{array}$ & 29 \\
\hline Gumwood & $\begin{array}{l}\mathrm{CH}_{4} \text {, naphthalene } \\
\text { and benzene based } \\
\text { derivatives from } \\
\text { the decomposition } \\
\text { of gumwood }\end{array}$ & $\begin{array}{l}\text { Gumwood } \\
\text { char }\end{array}$ & $\begin{array}{l}\text { Mineral } \\
\text { matters in } \\
\text { char }\end{array}$ & $\begin{array}{l}\text { Microwave- } \\
\text { induced } \\
\text { pyrolysis }\end{array}$ & $\begin{array}{l}\text { CNTs with a diameter of } 50 \text { - } \\
100 \mathrm{~nm} \text {, a length ranging from } \\
600 \text { to } 1600 \mathrm{~nm} \text { and a wall } \\
\text { thickness around } 5 \mathrm{~nm}\end{array}$ & 87 \\
\hline $\begin{array}{l}\text { Wood } \\
\text { sawdust }\end{array}$ & $-^{\mathrm{a}}$ & - & $\begin{array}{l}\text { Ferrocene } \\
\text { or } \\
\mathrm{Fe} / \mathrm{Mo} / \mathrm{M} \\
\mathrm{gO}\end{array}$ & & $\begin{array}{l}\text { CNTs with a thickness of } 25- \\
50 \mathrm{~nm}\end{array}$ & 93 \\
\hline $\begin{array}{l}\text { Sugarcane } \\
\text { bagasse }\end{array}$ & - & $\begin{array}{l}\text { Sugarcane } \\
\text { bagasse } \\
\text { char }\end{array}$ & $\begin{array}{l}\text { Commerc } \\
\text { ial Fe and } \\
\text { Co metal }\end{array}$ & $\begin{array}{l}\text { Microwave } \\
\text { assisted } \\
\text { pyrolysis } \\
16\end{array}$ & CNTs and graphitic flakes & 85 \\
\hline
\end{tabular}




\begin{tabular}{|c|c|c|c|c|c|c|}
\hline \multirow[b]{2}{*}{ Bamboo } & & & powders & & & \\
\hline & $\begin{array}{l}\text { Light } \\
\text { hydrocarbons } \\
\text { such as } \mathrm{CH}_{4} \text {, } \\
\mathrm{C}_{2} \mathrm{H}_{4}, \mathrm{C}_{2} \mathrm{H}_{6} \text { and } \\
\mathrm{C}_{3} \mathrm{H}_{6} \text { obtained } \\
\text { from the } \\
\text { thermoconversion } \\
\text { of bamboo }\end{array}$ & $\begin{array}{l}\text { Bamboo } \\
\text { char }\end{array}$ & $\mathrm{Fe}\left(\mathrm{NO}_{3}\right)_{3}$ & $\begin{array}{l}\text { Pyrolysis- } \\
\text { gasification- } \\
\text { carbonization }\end{array}$ & $\begin{array}{l}\text {-Carbon nanoribbons } \\
\text {-CNFs } \\
\text {-hollow carbon nanospheres } \\
\text { (HCs) } \\
\text {-bamboo/herringbone } \\
\text { shaped (BCNTs/ HCNTs) }\end{array}$ & 51 \\
\hline $\begin{array}{l}\text { Reed } \\
\text { bristles }\end{array}$ & $\begin{array}{l}\text { Volatiles from the } \\
\text { thermolysis of the } \\
\text { reed bristles }\end{array}$ & - & $\begin{array}{l}\text { Oxides } \\
\text { originated } \\
\text { from } \\
\text { biomass }\end{array}$ & $\begin{array}{l}\text { Carbonizatio } \\
\mathrm{n}\end{array}$ & CMTs and CNTs & 94 \\
\hline $\begin{array}{l}\text { Palm } \\
\text { kernel } \\
\text { shell }\end{array}$ & $\begin{array}{l}\text { Volatiles and bio- } \\
\text { liquid release from } \\
\text { microwave } \\
\text { pyrolysis of palm } \\
\text { kernel shell }\end{array}$ & $\begin{array}{l}\text { Palm } \\
\text { kernel } \\
\text { shell- } \\
\text { derived } \\
\text { char }\end{array}$ & $\begin{array}{l}\mathrm{Fe}, \\
\mathrm{CaSiO}_{4}, \\
\mathrm{CaCO}_{3}, \\
\mathrm{KO}_{2} \\
\text { originated } \\
\text { from palm } \\
\text { kernel } \\
\text { shell }\end{array}$ & & $\begin{array}{l}\text { Hollow CNFs with a diameter } \\
\text { around } 50-100 \mathrm{~nm} \text { and a length } \\
\text { of } 600-1600 \mathrm{~nm}\end{array}$ & 95 \\
\hline $\begin{array}{l}\text { Pine nut } \\
\text { shell }\end{array}$ & $\begin{array}{l}\text { Hydrocarbons } \\
\text { (benzene and } \\
\text { alkenes) in bio-oil } \\
\text { and } \mathrm{CO}, \mathrm{CO}_{2}, \\
\text { methane and } \\
\text { ethane in bio-gas }\end{array}$ & $\begin{array}{l}\text { Pine nut } \\
\text { shell- } \\
\text { derived } \\
\text { char }\end{array}$ & $\begin{array}{l}\mathrm{K}, \mathrm{Si}, \mathrm{Ca} \text {, } \\
\mathrm{Mg} \text { and } \mathrm{Al} \\
\text { related } \\
\text { minerals }\end{array}$ & $\begin{array}{l}\text { Microvave } \\
\text { pyrolysis }\end{array}$ & $\begin{array}{l}\text { Hollow CNFs with a diameter } \\
\text { of about } 400 \mathrm{~nm} \text { and a length } \\
\text { of } 1400-5000 \mathrm{~nm}\end{array}$ & 92 \\
\hline
\end{tabular}


The catalyst employed is considered as an important factor affecting CNMs synthesis from biomass via an in situ CVD technique. It was found that not all ferric salts and chloride can catalyze the formation of magnetic CNFs/mesoporous carbon composites ${ }^{84}$. The results of carbonaceous materials produced by fast pyrolysis of the biomass loaded with different metal salts were exhibited in Fig. $5^{84}$. CNFs were not formed by the pyrolysis of biomass preloaded with $\mathrm{Fe}\left(\mathrm{NO}_{3}\right)_{3}$ (Fig. 5b) and $\mathrm{Fe}_{2}\left(\mathrm{SO}_{4}\right)_{3}$ (Fig. 5c) or $\mathrm{CuCl}_{2}$ (Fig. 5d) and $\mathrm{NiCl}_{2}$ (Fig. 5e). Further investigation revealed that the formation of the CNFs structure was the combined catalytic effects of both $\mathrm{Fe}$ and $\mathrm{Cl}$. In detail, for $\mathrm{Fe}\left(\mathrm{NO}_{3}\right)_{3}$ and $\mathrm{Fe}_{2}\left(\mathrm{SO}_{4}\right)_{3}$, despite their catalysis on the CNFs growth, they could not catalyze the formation of small-molecular-weight hydrocarbons, which were the carbon source for the growth of CNFs. While for $\mathrm{CuCl}_{2}$ and $\mathrm{NiCl}_{2}$, they had the similar effects on the catalytic formation of the small-molecular-weight hydrocarbons in biomass pyrolysis process, but could not catalyze the deposition and growth of the CNFs ${ }^{84}$. Debalina et al. found that the composition of bio-oil and the evolution of the concentration of non-condensable gases were apparently affected by the type and amount of catalysts during the microwave assisted pyrolysis of sugarcane bagasse, which directly resulted in the formation of different CNMs in terms of types and characteristics ${ }^{85}$. The catalysts employed in the preparation of CNMs from biomass via in situ CVD are summarized in Table 2.
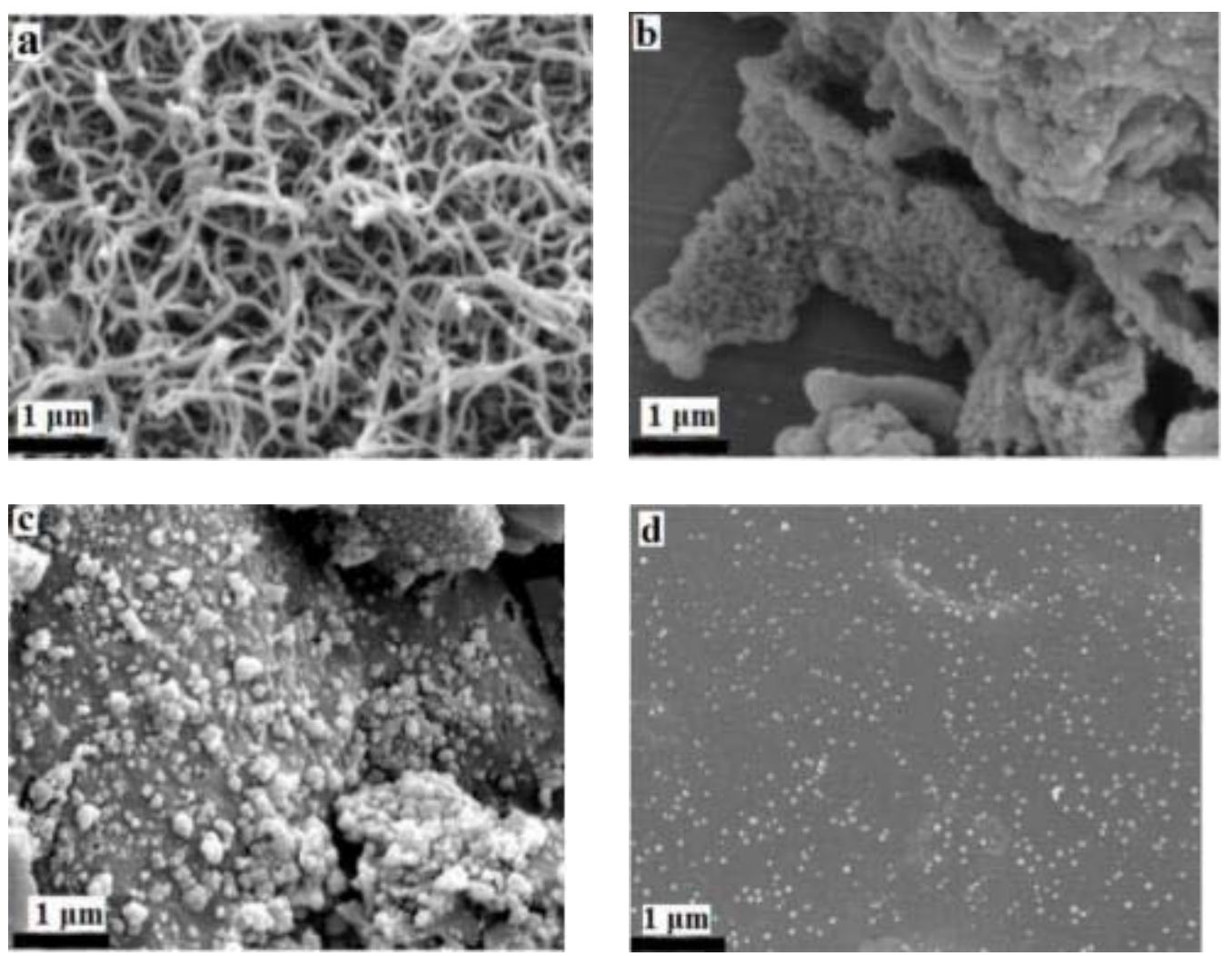


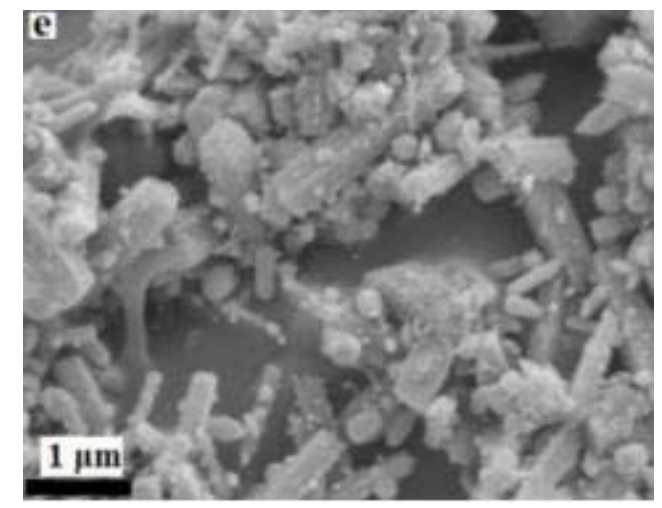

Fig. 5 SEM images of carbonaceous materials produced by pyrolysis of the biomass loaded with different metal salts: a) $\mathrm{FeCl}_{3}$, b) $\left.\mathrm{Fe}\left(\mathrm{NO}_{3}\right)_{3}, \mathrm{c}\right) \mathrm{Fe}_{2}\left(\mathrm{SO}_{4}\right)_{3}$, d) $\mathrm{CuCl}_{2}$, e) $\mathrm{NiCl}_{2}$ reported by Liu group ${ }^{84}$. Reproduced from ${ }^{84}$ with permission from the American Chemical Society.

On the other hand, pyrolysis temperature not only remarkably affected catalyst species such as $\mathrm{Fe}(\mathrm{OH})_{3}, \mathrm{FeO}(\mathrm{OH}), \mathrm{Fe}_{2} \mathrm{O}_{3}, \mathrm{Fe}_{3} \mathrm{O}_{4}, \mathrm{Fe}_{3} \mathrm{C}$ but also determined the composition of small-molecular hydrocarbons released during pyrolysis, which hence played key roles in the preparation of CNMs ${ }^{84}$. It was reported by Liu et al. that no CNFs could be formed at low pyrolysis temperature $\left(350-400{ }^{\circ} \mathrm{C}\right)$ while as the temperature was increased to $500{ }^{\circ} \mathrm{C}$, some small CNFs were observed. When the temperature was further increased to $600-800{ }^{\circ} \mathrm{C}$, the CNFs continuously grew to several micrometers long. Zhang et al. found that the yield of hollow CNFs prepared from pine nut shell at microwave pyrolysis temperatures of $400,500,600$ and $700{ }^{\circ} \mathrm{C}$ was calculated to be $1.72 \%, 3.76 \%, 4.69 \%$ and $3.21 \%$, respectively, according to isothermal oxidation ${ }^{92}$. A study from Shi et al. ${ }^{87}$ demonstrated that the heating method also made an influence on the preparation of CNMs. For example, conventional pyrolysis and microwaveinduced pyrolysis were comparatively investigated by Wang et al. ${ }^{29}$. It was found that no CNMs were formed on the surface of the conventional pyrolyzed char while there were a number of nanowire materials grown on the surface of the microwave-induced pyrolyzed char with a diameter ranging of 50-100 $\mathrm{nm}$. They attributed this observation to the difference in components of the bio-oil and bio-gas derived from two heating methods. Comparing with conventional pyrolytic bio-oil, microwave induced pyrolysis oil contained less phenol and corresponding derivatives and more naphthalene, benzene, alkene, and corresponding derivatives. In other words, the microwave-induced processing of gumwood produced more favorable carbon sources for the formation of CNMs compared to the conventional pyrolysis.

\subsubsection{Two-step CVD conversion}

A two-step CVD technique for the production of CNMs from biomass generally includes two processes, i.e., thermal conversion of biomass into vapors and catalytic conversion of the vapors into CNMs in the presence of a catalyst. These two steps are normally performed in two reactors separately. As shown in Table 2 and discussed in to 
3.2.1 In situ CVD, the vapors of biomass consist of abundant carbon-containing compounds such as $\mathrm{CO}, \mathrm{CH}_{4}, \mathrm{C}_{2} \mathrm{H}_{4}$, benzene and their derivatives which have been identified as desirable and efficient carbon sources for CNMs fabrication ${ }^{85,96}$. When these carbon-rich vapors pass through a catalyst bed, they would be decomposed into carbon atoms to form CNMs with similar mechanisms of conventional CVD. For example, Alves et al. employed a two-section quartz laminar-flow muffle furnace consisting of a pyrolyzer and a catalyzer to prepare CNMs from sugarcane bagasse. A schematic diagram of the experimental system used is presented in Fig. $6 \mathrm{a}^{97}$. Sugarcane bagasse was placed in the first section of the furnace to generate vapors via a pyrolysis process. The pyrolyzed vapors subsequently passed through the stainless steel screen bed which was acted as a catalyst. As a result, CNMs in the form of long, straight, tubular structures with smooth walls and axially-uniform diameters (CNTs) eventually were collected on the surface of stainless steel screen, which possessed a typical length of $50 \mu \mathrm{m}$ and a diameter in the range of $20-50 \mathrm{~nm}$.

It is worthwhile to note that the synthesis of CNMs from biomass in terms of a twostep CVD technique is quite similar to the production of syngas from biomass via pyrolysis-gasification process ${ }^{98}$. The key difference is that the carbon product called coke is unpopular in syngas preparation due to the formation of coke would poison the catalyst and promote the polycondensation of intermediates, resulting in the reduction of syngas yield ${ }^{99}$. However, $\mathrm{Wu}$ et al. found that the coke from the pyrolysisgasification of toluene was composed of amorphous carbons and filamentous carbons 100. Particularly, the formation of amorphous carbons during pyrolysis-gasification process could be partly inhibited and the formed amorphous carbon in coke could be significantly eliminated via controlling the catalyst and operating conditions such as modifying the catalyst component and injecting suitable water. Afterward, the asobtained filamentous carbons without amorphous carbons were identified as wellstructured CNTs. In this way, the pyrolysis-gasification process can realize the coproduction of syngas and CNTs. Subsequently, Wu et al. group conducted a series of study on the preparation of CNMs and hydrogen-rich syngas based on this method using a two-stage vertical fixed-bed reaction system, which is shown in Fig. $6 b^{83,101-103}$. A typical CNTs in $\mathrm{Wu}$ et al. group was in a diameter of 10-20 nm derived from the pyrolysis-gasification of wood sawdust ${ }^{102}$. Another study from $\mathrm{Wu}$ et al. group employed a two-stage continuous screw-kiln reactor (see Fig. 6c) for the production of syngas from the pyrolysis of waste wood coupling with catalytic reforming of the pyrolysis vapours, where CNMs also can be obtained on the catalyst bed ${ }^{104}$. 

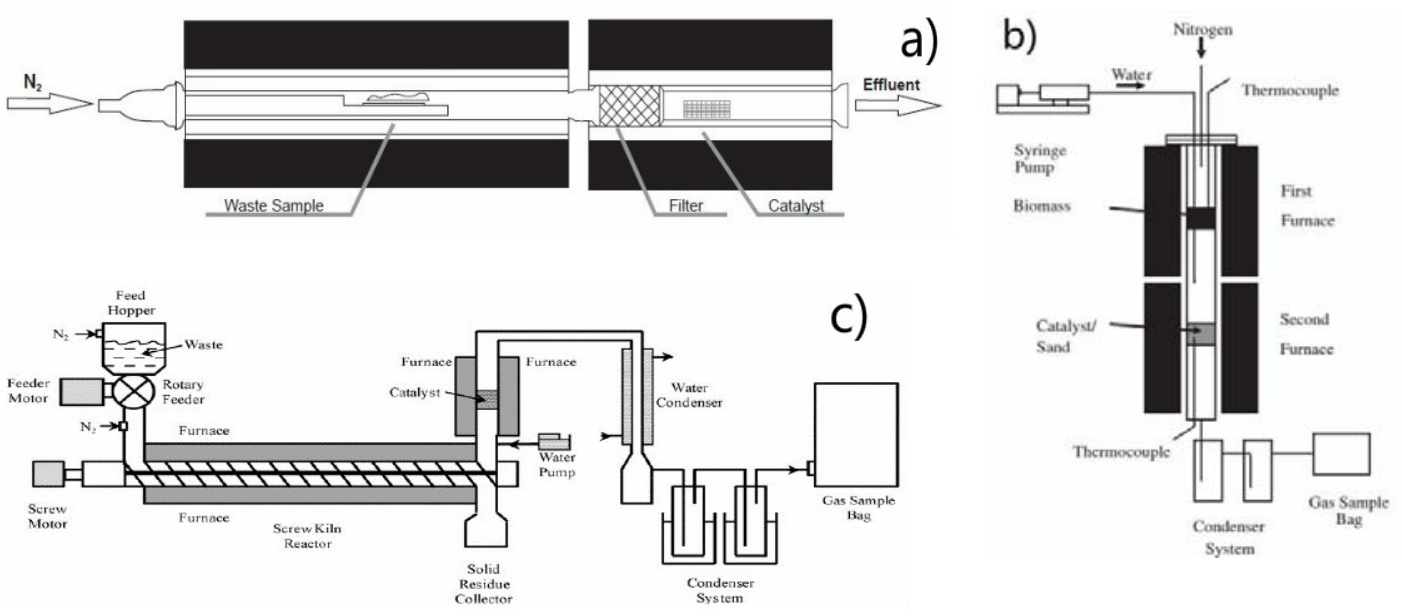

Fig. 6 Schematic diagram of an experimental system employed in Alves et al. ${ }^{105}$ (a), Wu et al. ${ }^{106}$ (b), and Efika et al. ${ }^{104}$ (c) study. Reproduced from ${ }^{105,106,104}$ with permission from the Elsevier.

Similar to in situ CVD, the preparation of CNMs from biomass via two-step CVD is also determined by several factors, such as the composition of carbon source, type of catalyst, operating temperature. The type of biomass feedstock and the pyrolysis conditions in the first stage made important influences on the composition of the pyrolysis vapors which are the carbon source during CNMs synthesis at the next stage. Different catalysts have been used at the second stage for the formation of CNMs. For example, stainless steel screen ${ }^{97}$, nickel oxide with or without support and assistant ${ }^{104}$, multi-metal catalysts ${ }^{101,103}$ were referred. On the other hand, the component and the preparation method of catalyst also played important roles in the growth of CNMs. In Efika et al. research, $\mathrm{NiO} / \mathrm{Al}_{2} \mathrm{O}_{3}$ catalyst was more favorable for the growth of $\mathrm{CNMs}$ during pyrolysis-gasification of wood sawdust compared to $\mathrm{NiO} / \mathrm{CeO}_{2} / \mathrm{Al}_{2} \mathrm{O}_{3}$ catalyst, because the addition of $\mathrm{CeO}_{2}$ to catalyst would suppress the formation of coke ${ }^{104}$. CNMs were also observed on the surface of a $\mathrm{Ni}-\mathrm{Ca}-\mathrm{Al}$ catalyst rather than $\mathrm{Ni}-\mathrm{Mg}-\mathrm{Al}$ after the pyrolysis-gasification of lignin ${ }^{98}$. In addition to the influence of catalyst, the injection of water was identified as an important factor affecting the fabrication of CNMs. It was found that the amount of coke (the mixture of amorphous carbon and CNMs) deposited on the catalyst presented a decreasing trend from $33.8 \%$ to $2.6 \mathrm{wt} \%$ with the increase of water injection rate from 1.90 to $1.42 \mathrm{~g} / \mathrm{h}$. SEM results further confirmed that fewer CNMs were observed on the catalyst surface at the water injection rate of $14.20 \mathrm{~g} / \mathrm{h}{ }^{107}$. Furthermore, a research on investigating the influence of the temperature of the second stage on the preparation of CNMs revealed that a smaller fraction of straighter CNTs was obtained at $1000{ }^{\circ} \mathrm{C}$ than that at $600{ }^{\circ} \mathrm{C}$, suggesting that the formation of CNMs was affected by pyrolysis temperature as well ${ }^{97}$.

\subsection{Cyclic oxidation}

Cyclic oxidation method for the preparation of CNMs from biomass mainly refers to a technique that involves reduplicative oxidation processes to convert three-dimensional 
biomass into tubular CNMs (such as CNTs). Kang et al. ${ }^{108}$ firstly reported the use of cyclic oxidation technique to prepare CNMs. Detailed steps are as follows. Grass, the biomass feedstock for preparation of CNMs, was heated at about $250{ }^{\circ} \mathrm{C}$ in air after dried and crumbled. The resulting residue then was subjected to rapid heating at about $600{ }^{\circ} \mathrm{C}$ and hold $20 \mathrm{~min}$ with a controlled amount of oxygen. After that, the heated system was cooled to room temperature and equivalent oxygen was re-injected. The heat treatment at about $600{ }^{\circ} \mathrm{C}$ was repeated in about 50 times and the product was collected. TEM images revealed that the as-prepared product exhibiting a middlehollow structure was multi-walled CNTs with the inner and outer diameters range of 10-30 and 30-50 $\mathrm{nm}$, respectively. In this technique, there are three critical factors, i) the feedstock with three integrated dimensional structure directly originated from biomass, ii) the preheating of biomass in air at low temperature prior to the cyclic oxidation process, iii) reduplicative oxidation of as-preheated biomass in many times via the involvement of suitable oxygen. CNMs were hardly observed as carbonhydrates powders such as glucose, saccharose, faecula and cellulose were employed as feedstock in the cyclic oxidation. Apart from vascular bundles, grass contains many protein and grease in the stem and nervation. The heat pretreatment at about $250{ }^{\circ} \mathrm{C}$ was in favor of the removal of those unrelated components (protein and grease) to expose vascular bundles. The following reduplicative treatment by involving suitable amount of oxygen to rapidly heat at about $600{ }^{\circ} \mathrm{C}$ was helpful to the dehydration of cellulose, so that resulting in the formation of CNMs. According to Kang et al. research, Goodell et al. 109 investigated the fabrication of CNMs using six different carbon feedstock including wood fiber, organosolv lignin, ashless filter paper, avicel, alpha-cellulose and bamboo through similar method. The samples were preheated and cyclic oxidation temperature at $240{ }^{\circ} \mathrm{C}$ and $400{ }^{\circ} \mathrm{C}$, respectively. Results indicated that tubular CNMs were hardly obtained from lignin, delignified filter paper, and two purified cellulose samples while that can be confirmedly observed in the samples made from wood fiber, with inside and outside diameter range of 4-5 $\mathrm{nm}$ and 10-20 nm, respectively. This further verified that original biomass feedstock structure played an important material base role in the preparation of CNMs from biomass via cyclic oxidation method. Goodell and coworkers considered that the carbonization at low temperature was a stepwise process, which was responsible for the formation of nanoscale channels. And then the nanochannels acted as a template to mediate the production of CNTs. At the same time, an environment of low pressure combined with air as a result of the formation of nanochannels to greatly facilitate cellulose ablation, also make contributes to the synthesis of CNTs ${ }^{109}$.

In another work reported by Goodell group ${ }^{110}$, the effect of heat pretreatment on the preparation of CNMs was investigated. The result demonstrated that heat pretreatment was favorable for the retention of the nano-architecture of the cell wall which was responsible for the formation of tubular CNMs after cyclic heat treatment. The low temperature pretreatment promoted i) the dehydration of cellulose resulting in increased carbon yield through gradual carbonization, ii) the stabilization of lignin limiting the flow of lignin in the later higher temperature processing. Additionally, cyclic oxidation 
affecting the formation of CNMs was studied and the result revealed that the cyclic oxidation procedure was effective for the ablation of cellulose microfibril in plant cell walls. A series of researches derived from Qu group revealed that cyclic oxidation method has been successfully developed in the synthesis of tubular CNMs from absorbent cotton, poplar leaves and hyperaccumulators ${ }^{111-113}$. Apart from tubular CNMs, graphene sheets and carbon nanospheres can also be obtained from biomass using cyclic oxidation method in Qu et al. studies as well ${ }^{114,115}$.

Although cyclic oxidation has been widely applied in the synthesis of CNMs from biomass, the potential mechanism dominating the formation of CNMs is still under debate. Kang et al. ${ }^{108}$ considered that the involvement of a suitable amount of oxygen during cyclic oxidation procedure was helpful for the dehydration of the vascular bundles in biomass structure, which caused the formation of carbon skeleton. In other words, the formation of tubular CNMs was ascribed to the contraction or shrinkage of vascular bundles. However, this hypothesis then suffered a question from Goodell group 109, 110, 116 and a new mechanism was proposed. Goodell group proposed that cyclic oxidation process was in favor of the formation of nanoscale channels via the ablation of cell wall microfibrils, which located and oriented in a pattern corresponding to the location of the cellulose microfibrils originally located with the cell wall. The asformed nano-channels and the carbon vapors from the ablation of cellulose microfibrils would separately acted as a template and a gas phase carbon source to mediate the synthesis of tubular CNMs ${ }^{117}$. It should be noted that the natural three dimensional structure of biomass concerning the presence of vascular bundles played a crucial role in both Kang et al. and Goodell group studies. Tubular CNTs could not be observed as a purified lignocellulosic component of biomass such as lignin or cellulose was used. It was reported that the minerals like Fe particle and silicates in biomass were crucial for CNMs synthesis from biomass, which acted as catalysts ${ }^{87,118}$. According to Qu et al. ${ }^{112}$ report, the poplar derived $\mathrm{CNM}$ s contained not only $\mathrm{C}$ but also $\mathrm{O}, \mathrm{Na}, \mathrm{Zn}, \mathrm{Cu}$, $\mathrm{Ca}, \mathrm{K}, \mathrm{Cl}$ and $\mathrm{S}$. It is therefore unclear that whether minerals in biomass feedstock also made some contributions to the preparation of CNMs via cyclic oxidation method. In spite of Qu group has successfully synthesized different kinds of CNMs from biomass, the mechanisms of CNMs formation were not reported. It would be interesting and urgent to further explore the potential mechanism controlling the formation of CNMs from biomass via cyclic oxidation method.

\subsection{Mechanical activation}

Mechanical activation partly introduced into the preparation of CNMs was firstly conducted by Chen et al., where they found that aligned CNTs were readily obtained by pyrolysis of iron phthalocyanine after ball milling treatment ${ }^{119}$. The key of the asemployed mechanical activation in Chen group was to prepare a homogeneous mixture of carbon source and catalyst via ball milling ${ }^{120}$. After that, various methods of ball millings were directly developed in the preparation CNMs ${ }^{121,122}$. Typically, biomass 
sample was mixed with steel balls and placed in a ball mill. After a period of grinding, the biomass was totally converted to CNMs which can be readily collected from the ball mill. Apart from the grinding time, other parameters such as atmosphere, reaction temperature could be generally neglected. It was reported that Onishchenko group has successfully produced CNTs from a large amount of natural biomass such as sphagnum moss and agricultural wastes based on this technique ${ }^{123-125}$. Differently, the biomass was first subjected to carbonize at $950{ }^{\circ} \mathrm{C}$ to produce amorphous carbon, followed by washing to remove mineral impurities using a mixed acid solution, then the precursors were ground in a planetary mill in many times to produce CNMs with different diameters and textural morphologies ${ }^{126}$. It seems that the type of biomass feedstock remarkably determines the products and their corresponding properties via this method. For example, oat, millet and buckwheat wastes were unsuitable as sources for CNMs synthesis. On the other hand, the CNMs derived from corn wastes with bamboo and embedded nanocones structures were more defective than those from sphagnum moss ${ }^{126}$. In addition, the duration of mechanical treatment in the planetary mill plays a vital role in the properties of CNMs, which was found to exhibit a linear relationship with the volume of the formed CNMs ${ }^{126}$. It was found that the pristine amorphous carbons were represented in the form of fractal structure in a broad range of particle dispersion. Sample with $6 \mathrm{~h}$ of mechanical activation preserved its lamellar shape. Upon $8 \mathrm{~h}$ of processing, a nanofiber structure with a diameter of 10-20nm was observed inside carbon particles. Increasing the mechanical activation up to $10 \mathrm{~h}$, all the bulk material composed of CNTs with a diameter of 10-70 nm. The CNTs formed after mechanical activation for $36 \mathrm{~h}$ were abundant. The sample after mechanical activation for $46 \mathrm{~h}$ looked like aggregates consisting of CNTs and amorphous carbons. The aggregates were evidently formed on account of the electrostatic interaction of the CNMs ${ }^{127,} 128$. Corn CNMs content in the carbon composite prepared at a mechanical duration of 7 , 10,16 and 27 were $11.52 \mathrm{wt} \%, 24.45 \mathrm{wt} \%, 34.06 \mathrm{wt} \%$ and $42.75 \mathrm{wt} \%$, respectively ${ }^{129}$.

It should be noted that no catalyst was involved in the preparation of CNMs from biomass via mechanical activation. Mineral particles which were considered as the effective catalyst in the CVD method have been rinsed with acidic solution ${ }^{130}$, suggesting that the preparation process was independent on the catalyst. On the other hand, the amorphous carbons acting as the precursor of CNMs before mechanical activation were readily obtained from biomass. In other words, the use of mechanical activation may be considered as a promising technique for CNMs preparation due to the low cost of feedstock (biomass) and technology (pyrolysis and grinding), and it is catalyst-free.

\subsection{Combustion}

Combustion is a high-temperature exothermic redox chemical reaction between a fuel and an oxidant, usually atmospheric oxygen, which produces oxidized, often gaseous products. Apart from application in producing heat, it has been involved in the preparation of well refined materials such as carbon nanoparticles ${ }^{131-133}$. Raju group 
134, 135 further promoted this method to produce graphitic-carbon nanoparticles from camphor, a natural eco-friendly hydrocarbon obtained from the tree Cinnamomum camphora ${ }^{136-138}$. Afterward, the successful production of CNMs from grass Desmostachya bipinnata via this method was also reported in their recent research ${ }^{139}$. In detail, sun-dried Desmostachya bipinnata grass was directly subjected to a complete incineration in atmospheric oxygen. During the burning process, burning parameters such as temperature, pressure, time, were not controlled except camphor powder was added as a fuel to realize the complete combustion of grass. After the burning reaction, a variety of CNMs concerning CNTs, micro-rod and CNFs could be collected from the resulting residue ash as confirmed by field emission scanning electron microscopy. The as-synthesized CNMs characterized a large amount of O-containing surface functional groups like carboxyl $(-\mathrm{COOH})$ and hydroxyl $(-\mathrm{OH})$ which were related to the abundant presence of oxygen in preparation process (burning under an air atmosphere). In addition to combustion, Muramastu et al. introduced a chemical activation using solid $\mathrm{KOH}$ as activation agent to treat the burnt rice husk residue at $850{ }^{\circ} \mathrm{C}$ in air ${ }^{140}$. At last, nano-sized crystalline graphene and corrugated graphene with a yield of ca. $10 \mathrm{wt} \%$ was obtained. TEM and XRD analyses revealed that the nano-sized crystalline graphene contained a monolayer or multilayer structure with clean edges and the corrugated graphene composed of domains with a few nanometers in size. The authors considered that the chemical activation by $\mathrm{KOH}$ after combustion was a key factor for the formation of high-quality graphene, where $\mathrm{KOH}$ efficiently etched amorphous carbon and penetrated the amorphous carbon into crystalline graphene. Afterward, some research works provided by Muramastu group further confirmed that the combination of chemical activation with combustion was an efficient and scalable technique to produce graphene-based materials from low-cost wastes ${ }^{141,142}$. The authors found that $\mathrm{KOH}$ dosage and the combustion temperature played vital roles in the fabrication of corrugated paper-like graphene with large specific surface area ${ }^{143}$. A graphene with a maximum specific surface area of $2274 \mathrm{~m}^{2} / \mathrm{g}$ can be collected as the $\mathrm{KOH}$ dosage and combustion temperature were controlled as $12.5 \mathrm{~g}$ and $550{ }^{\circ} \mathrm{C}$, respectively. On the other hand, using the same method and the same feedstock, the combustion temperature and chemical activation temperature were individually set as 500 and $700{ }^{\circ} \mathrm{C}$, respectively, resulting in the formation of crumpled silk-veil-wave graphene nanosheets with a specific surface area of $1225 \mathrm{~m}^{2} / \mathrm{g}$. It appears that the combustion technique is a simple and available technique to produce valuable CNMs. While the potential mechanism for CNMs growth was not stated which may obtain dramatically interest for researchers in future work.

\section{Biomass as catalyst for CNMs synthesis}

\subsection{Intrinsic Fe-related component in biomass}

It is well-established that $\mathrm{Fe}$ and Fe-containing composites are effective catalysts in 
preparing CNMs ${ }^{144,145}$. At the same time, $\mathrm{Fe}$ is ubiquitous in biomass matrix due to it is one of the essential trace elements for plant growth. Fe is also an important component of cytochrome and non heme ferritin which play important roles in photosynthesis, biological nitrogen fixation and respiration ${ }^{146}$. Therefore, it is feasible to develop Fe-containing biomass as a catalyst source for CNMs preparation. Chen et al. ${ }^{118}$ employed ACs produced from palm kernel shell, coconut and wheat straw with a certain $\mathrm{Fe}$ content (Fig. 7a-b) as catalysts to decompose $\mathrm{C}_{2} \mathrm{H}_{4}$ at $700{ }^{\circ} \mathrm{C}$ for the fabrication of CNMs. It was found that tangled CNFs were obtained on the surface of the AC (Fig. 7c). Further high resolution transmission electron microscopy (HRTEM) image presented that the tip of a CNF containing a Fe particle with a diameter about $100 \mathrm{~nm}$ (Fig. 7d). Consequently, Fe particles originated from the AC precursor hence were considered to play a catalyst role in the CNFs preparation and a tip-growing model was proposed to explain the growth mechanism of CNFs. It was inferred that the iron particles of the $\mathrm{AC}$ were firstly reduced by $\mathrm{H}_{2}$ then melted to form a liquid droplet at high temperature. Carbon source $\left(\mathrm{C}_{2} \mathrm{H}_{4}\right)$ consequently was dissociated on the surface of the reduced iron, dissolved and diffused into it and last precipitated to create CNFs. It is worth mentioning that during the CVD processing, the weight of the kernel shell, coconut and wheat straw derived ACs increased from 200 to 270, 271 and $296 \mathrm{mg}$, respectively, while the iron content in corresponding ACs were $2.91 \%, 0.17 \%$ and $1.79 \%$, respectively. In other words, the yield of CNFs was found not to be proportional to the amount of iron in the starting activated carbons.

Fe also existed in black jew's-ear fungus and black sesame seeds which were conducted to fabricate CNMs based on a CVD process of liquefaction petroleum gas at $800{ }^{\circ} \mathrm{C}$ 147, 148. Due to the homogenous content of $\mathrm{Fe}$ in a single cell of the precursor, the distribution of catalyst particles was uniform and their size and composition were almost identical. As a result, CNTs with uniform diameters were attained when black sesame seeds were used as catalyst precursor. An adsorption-diffusion-deposition model was employed to describe the growth mechanism of CNTs: i) Liquefaction petroleum gas was adsorbed on the active crystal surface of the Fe catalyst, ii) Chemical reactions occurred between Fe and liquification petroleum gas at high temperature to form carbides, iii) Extra supply of liquification petroleum gas led to over-saturation of carbon atoms in the carbide and then the over-saturated carbon atoms diffused through Fe particles to the other side of the active crystal surface, depositing to form CNTs. The diameter of black jew's-ear fungus and black sesame seeds derived CNTs were 80 and $100 \mathrm{~nm}$, respectively, which are negatively related to the iron content, indicating that higher content of iron was responsible for the large size of CNTs, whereas the lower content of iron led to small sizes of CNTs. 

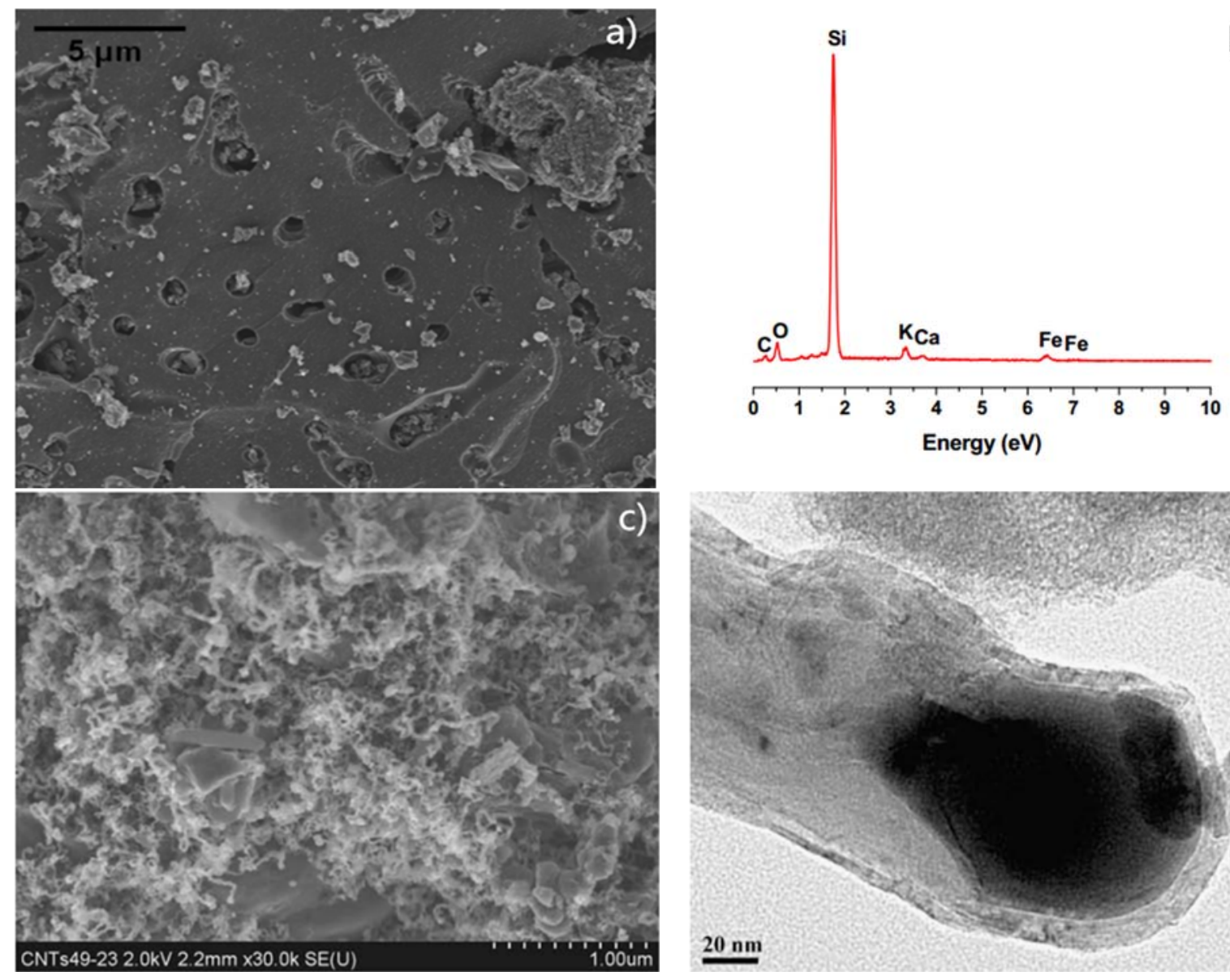

b)

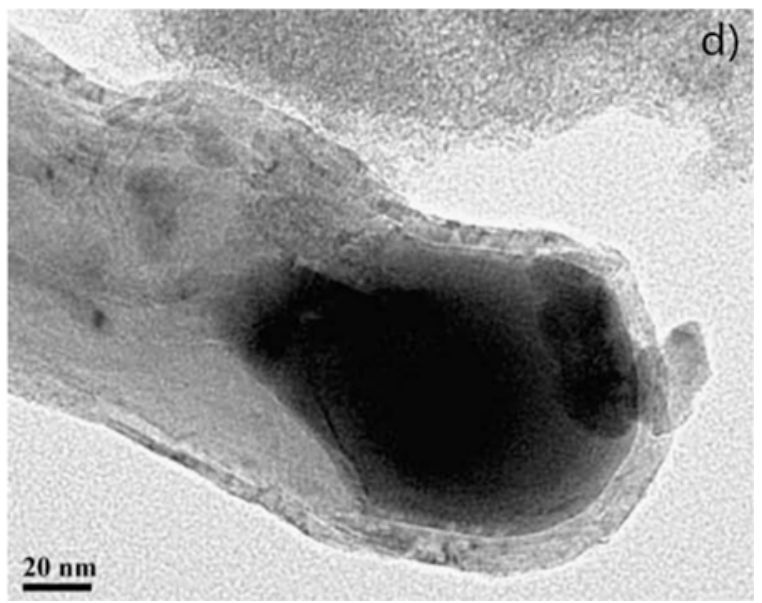

Fig.7 a) Scanning electron microscopy (SEM) image of coconut $\mathrm{AC}$ after calcination at $400{ }^{\circ} \mathrm{C}$, b) Elementary analysis of a selected area of a) using energy dispersive X-ray detector, c) SEM image of as-synthesized CNFs supported on the surface of coconut activated carbon, d) HRTEM image of a CNF with an iron particle on the tip ${ }^{118}$. Reproduced from ${ }^{118}$ with permission from the Elsevier.

\subsection{Silicates mineral in biomass}

Apart from $\mathrm{Fe}$, other mineral elements in biomass also have been found to possess catalytic capability for the preparation of CNMs. It is reported that mineral matters composed of $\mathrm{Si}$ and $\mathrm{Ca}$ in gumwood were regarded as catalysts for the synthesis of CNTs in a microwave-induced pyrolysis process ${ }^{87}$. During this process, these Si and Ca related minerals can decompose the volatiles derived from the microwave-induced pyrolysis of gumwood mainly involving $\mathrm{CH}_{4}$, naphthalene and benzene-based derivatives, leading to the formation of CNTs with a diameter between 50 and $100 \mathrm{~nm}$ and a length ranging from 600 to $1600 \mathrm{~nm}$. Further analysis according to EDX revealed that the catalyst neither existed on the tip nor fill inside of CNTs but embedded in CNTs structure. Zhu et al. ${ }^{130}$ found that silicates in bamboo derived charcoal, especially for $\mathrm{Mg}$ and Ca-related silicates, played a crucial role to synthesize CNTs via a CVD process. And catalytic performance of the silicates in the preparation of CNTs were significantly determined by their composition and phase, which were greatly depended on the employed temperature in turn. For example, silicates identified as $\mathrm{Mg}_{2} \mathrm{SiO}_{4}$ were 
presented the plate-like crystal on the charcoal as treated at $1200{ }^{\circ} \mathrm{C}$ resulting in the formation of cluster-like CNTs (Fig. 8a). The enhancement of treated temperature to 1300-1400 ${ }^{\circ} \mathrm{C}$ gave rise to the transformation of main component of minerals to calcium silicates and occurred a sphere appearance (Fig. 8b-c). As a result, CNTs with length ranging from several nanometers up to micrometers and a wall of 100 layers were obtained. By increasing temperature to $1500{ }^{\circ} \mathrm{C}$, whiskers were formed on the charcoal and made up of $\mathrm{SiC}$ doped with $\mathrm{Al}$, Ca and $\mathrm{K}$ (Fig. 8d). No CNTs were observed in this regard, indicating that the whiskers were not in favor of CNTs formation. It can be concluded that the yield of CNTs was associated with the carbon solubility of silicates, which were subjected to the order of $\mathrm{Mg}_{2} \mathrm{SiO}_{4}$ nanocrystal< calcium silicate spheres. In addition, CNTs formed on the charcoal at $1200{ }^{\circ} \mathrm{C}$ and $1400{ }^{\circ} \mathrm{C}$ had no droplet tips while those at $1300{ }^{\circ} \mathrm{C}$ possessed droplet tips. This observation further demonstrated that the employed temperature affected not only the composition and phase of silicates but also the growth model of CNTs. Nersisyan et al. reported that spherical particles originated from spherical seeds of Andropogon virginicus reed bristles were also found to act as catalysts for generating carbon microtubes and CNTs via a novel method ${ }^{94}$. The spherical particles were mainly composed of the oxide form of $\mathrm{Si}, \mathrm{Mg}, \mathrm{P}$ and $\mathrm{O}$, regarding to $\mathrm{MgO}, \mathrm{SiO}_{2}, \mathrm{SiO}$, and $\mathrm{P}_{2} \mathrm{O}_{5}$. These oxides were effective in the catalytic decomposition of gaseous hydrocarbons formed by thermolysis of the reed bristles. As a result, CNTs with an outer diameter of about 10-15 nm were collected.
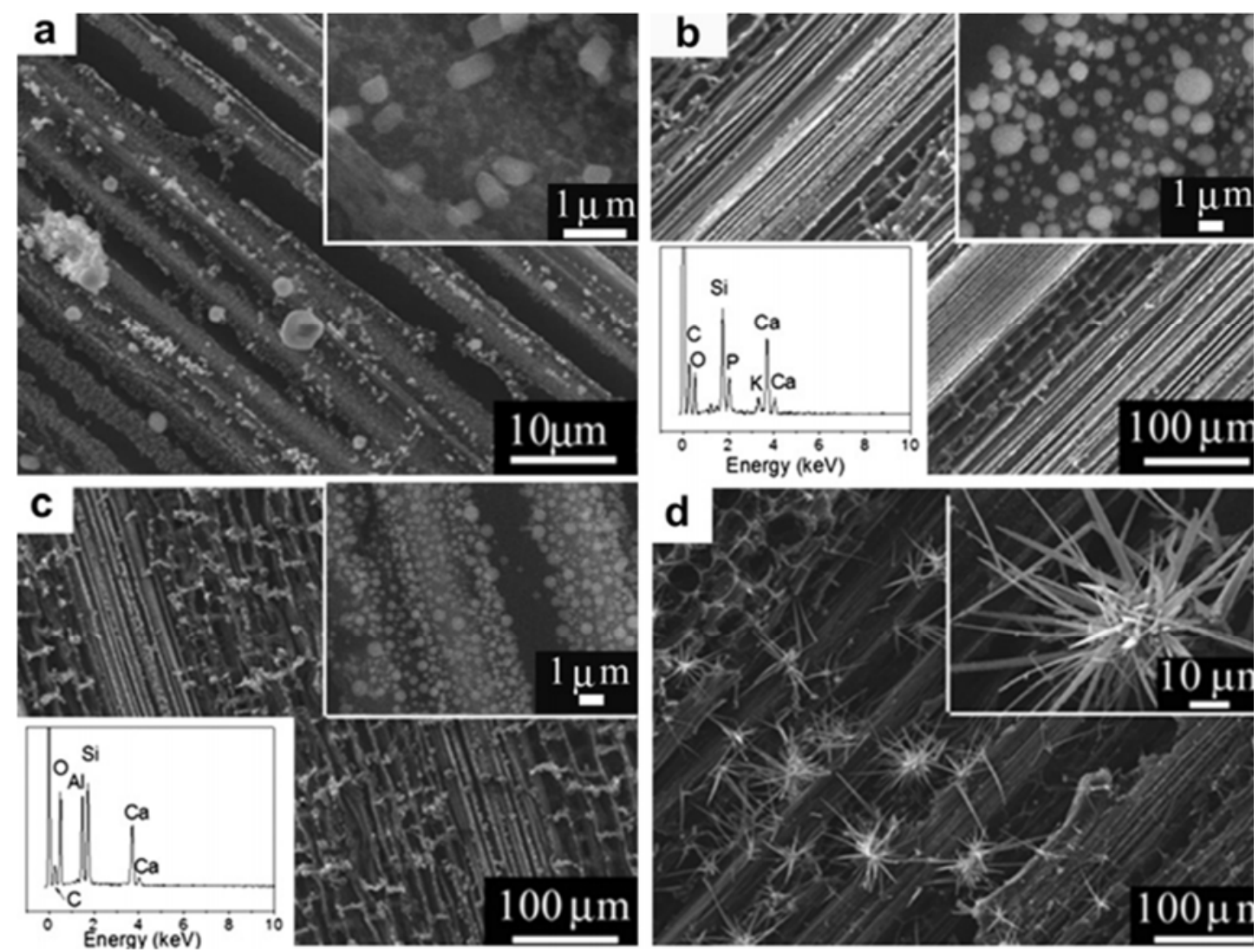

Fig. 8 SEM images of bamboo samples treated at different temperature reported by Zhu et al. ${ }^{130}$ : a) $1200{ }^{\circ} \mathrm{C}$, b) $1300{ }^{\circ} \mathrm{C}$, c) $1400{ }^{\circ} \mathrm{C}$, d) $1500{ }^{\circ} \mathrm{C}$. Top right insets are magnified images and Left bottom 
insets are EDX spectra. Reproduced from ${ }^{130}$ with permission from the Elsevier.

In Zhu et al. ${ }^{130}$ work, they considered that the growth of CNTs was followed vaporliquid-solid mechanism due to silicates exhibited a catalytic activity which was similar to that of transition metals for the nucleation of nanotubes. During the pyrolysis at high temperature, minerals in the bamboo derived charcoal melted initially and formed droplets on the surface of the charcoal. The melt mainly consisted of calcium silicate but also contained other elements, such as S, P, and K. Subsequently, carbon feedstock decomposed on the silicate droplet surfaces, dissolved inside and formed CNTs when the carbon supersaturation was reached. The growth mechanism of CNTs in Shi et al. ${ }^{87}$ work was found to subject to a vapor-solid phase growth model instead of a liquid phase growth model, which included three key steps: i) the microwave-induced pyrolysis of biomass to generate biogas, bio-oil and char products, ii) the decomposition of the carbon sources (biogas and bio-oil) on the char surface to form carbon nanospheres, iii) the growth of multi-walled CNTs via self-assembling of these carbon nanospheres in the electromagnetic field. It is well known that catalyst-prepared CNTs would have at least one particle at each end of the nanotube (top or bottom). In the work from Nersisyan et al., CNTs were formed around spherical particles, but no liquid droplets could be found on the tubes ${ }^{94}$. Therefore, the authors assumed that the formation of CNTs occurred through a new mechanism.

\subsection{Other components of biomass}

As discussed above, the intrinsic Fe-related components and silicates of biomass were generally considered as efficient catalytic components during CVD-involved preparation of CNMs. In terms of the abundant mineral components of biomass, the roles of the other components except for $\mathrm{Fe}$ and silicates during the production of CNMs were also aroused extensive interest. For example, it was reported that the minerals of palm kernel shell played a catalytic role in the formation of hollow CNFs from palm kernel shell via microwave pyrolysis ${ }^{95}$. Further investigation of XRD results indicated that the minerals were mainly composed of $\mathrm{Fe}, \mathrm{CaSiO}_{4}, \mathrm{CaCO}_{3}$ and $\mathrm{K}_{2} \mathrm{O}$. The authors hence deduced that in addition to Fe and silicates, other minerals $\left(\mathrm{CaCO}_{3}\right.$ and $\mathrm{K}_{2} \mathrm{O}$ ) were also in favor of the synthesis of CNMs, acting as catalysts. For the preparation of multi-walled CNTs via a plasma enhanced CVD, minerals of coconut shell including $\mathrm{Al}, \mathrm{Ca}, \mathrm{Na}, \mathrm{K}$ and $\mathrm{Mg}$ were found to be serving as catalyst except $\mathrm{Fe}^{149}$. In the study from Zhang et al., $\mathrm{K}$ in pine nut shell (account for $0.37 \%$ of the shell) was inferred to act as a catalytic role during the formation and growth of hollow CNFs partly because it could vaporize as volatile content and hence possess highly migration ability at high temperature ${ }^{92}$. Interestingly, Lin et al. considered that the fullerene-like positions and nanoscale curvatures of biomass-derived char also could act as efficient catalysts to decompose carbon sources into carbon atoms and hydrogen, and provide stack-up sites for the self-assembling of the carbon atoms to form CNMs ${ }^{150,151 .}$ Consequently, it appears that the preparation of CNMs using biomass as catalyst is a complicated process, more works are urgently needed to make it clear. 


\section{Biomass as catalyst support for CNMs synthesis}

\subsection{Biomass-derived BC}

Biomass served as a catalyst support for the preparation of CNMs via a CVD method has been successfully developed, when it was pretreated through a thermal conversion process such as pyrolysis, carbonization sintering or hydrothermal carbonization ${ }^{118,152}$. The thermally converted biomass is usually referred to as charcoal, black carbon or BC. The derived BC can be impregnated with catalyst and used in a CVD process to generate CNMs in a variety of morphologies depending on such factors as the type of catalyst, the properties of $\mathrm{BC}$ and the growth temperature employed. In detail, the following processes for the application of biomass as catalyst support in CNMs synthesis are generally involved: i) Convert biomass into a carbon material (BC) by a thermal treatment, ii) Remove the impurities on the surface of $\mathrm{BC}$ using an acidic solution, iii) Load catalyst by means of wet-impregnation or adsorption, iv) Reduce catalyst by $\mathrm{H}_{2}$, v) Introduce carbon source gas in certain concentration and ambient temperature. For example, in the study from Zhou et al., biomass was first sintered in a vacuum atmosphere to obtain a $\mathrm{BC}$ and then the as-prepared $\mathrm{BC}$ was subjected to a treatment with a concentrated $\mathrm{HNO}_{3}$ to eliminate inorganic impurities ${ }^{152}$. Afterwards, Ni catalyst was supported on the washed BC by means of a wet-impregnation method, obtaining a composite of $\mathrm{Ni} / \mathrm{BC}$ catalyst precursor. The composite was placed in a single quartz tubular reactor and a mixture of $\mathrm{Ar} / \mathrm{H}_{2}$ was introduced in the apparatus to reduce the catalyst. At last, the CNTs growth was carried out under a gas mixture of $\mathrm{H}_{2}$ and $\mathrm{CH}_{4}(1: 1)$ at $850{ }^{\circ} \mathrm{C}$. It is well-known that the support employed for CNMs production predominantly depends on the porous texture ${ }^{153}$. However, the pore structure of BC generally seems not developed well in comparison with other conventional porous supports such as AC, as shown in Table 3. For instance, the specific surface area of a bamboo-derived BC reported in Zhou et al. work ${ }^{152}$ was moderate as $491 \mathrm{~m}^{2} / \mathrm{g}$ (Table 3). While, another bamboo-derived BC with a very low specific surface area of $7.0 \mathrm{~m}^{2} / \mathrm{g}$ was also conducted as a catalyst support for the preparation of CNTs 154,155 . It was believed that BC with poor porosity was hardly favorable for the homogeneous distribution of catalyst, which resulted in the aggregation and agglomeration of the excess catalyst. Huang et al. ${ }^{155}$ investigated moso bamboo derived $\mathrm{BC}$ supported with different amount of catalyst $(2,3$, and $5 \mathrm{wt} \% \mathrm{Fe})$ for CNTs synthesis using xylene as a carbon source. A large number of CNTs grew uniformly and tightly on the surface of the BC when $3 \mathrm{wt} \% \mathrm{Fe}$ was loaded. However, the loading of $2 \mathrm{wt} \%$ Fe led to sparse CNTs growth and the grown CNTs were longer than that of $3 \mathrm{wt} \%$ loading. No CNTs can be observed on the BC surface as the Fe loading was increased to $5 \mathrm{wt} \%$, mainly attributing to the agglomeration of $\mathrm{Fe}$ into large particles. In addition to specific surface area, the source of biomass and the condition of CNMs growth were also found to play important roles in the preparation of CNMs from biomass-based BC. Zhou et al. investigated the application of four kinds of BCs originated from coconut 
shell, bamboo, hemp straw and lauan as catalyst support for CNMs synthesis, respectively ${ }^{152}$. Results showed that among these BCs, the bamboo derived BC showed the most uniform pore size and relative regular pore distribution. As a result of this property, it resulted in a uniform catalyst distribution while a hierarchical pore structure of the other three kinds of BCs resulted in a partly aggregation of the catalyst. After $\mathrm{CVD}$ of $\mathrm{CH}_{4}$, it was found that only the bamboo derived $\mathrm{BC}$ was observed to be uniformly covered by a CNTs layer which is $5 \sim 10 \mu \mathrm{m}$ in length and around $85 \mathrm{~nm}$ in diameter. In comparison, only a few CNTs were dispersed on the coconut shell derived $\mathrm{BC}$ and no CNTs but carbon aggregations in a state of chunks or clusters were observed on hemp straw and lauan derived BCs. Zhang et al. employed BCs derived from the pyrolysis of bamboo under 700-900 ${ }^{\circ} \mathrm{C}$ to support ferrocene for the synthesis of CNMs. The result indicated that smaller quantities of CNTs with shorter length were obtained at $700{ }^{\circ} \mathrm{C}$. The density of CNTs increased when the temperature increased to 800 or $900{ }^{\circ} \mathrm{C}$. This observation may be related to carbonization degree of BCs determined by the pyrolysis temperature ${ }^{154}$. Moreover, the pore size distribution, particles size and the content of catalyst may play key roles in the preparation of CNMs as BC was employed as the catalyst support ${ }^{156}$.

Table 3 Porosity characteristics of biomass derived carbon material before and after being employed as catalyst support for the preparation of CNMs

\begin{tabular}{|c|c|c|c|c|c|c|c|c|c|}
\hline \multirow[t]{2}{*}{ Substrate } & \multicolumn{2}{|c|}{$\mathrm{SSA}^{\mathrm{a}}\left(\mathrm{m}^{2} / \mathrm{g}\right)$} & \multicolumn{2}{|c|}{$\mathrm{TPV}^{\mathrm{d}}\left(\mathrm{cm}^{3} / \mathrm{g}\right)$} & \multicolumn{2}{|c|}{$\operatorname{MiPV}^{\mathrm{e}}\left(\mathrm{cm}^{3} / \mathrm{g}\right)$} & \multicolumn{2}{|c|}{$\operatorname{MePV}^{\mathrm{f}}\left(\mathrm{cm}^{3} / \mathrm{g}\right)$} & \multirow[t]{2}{*}{ References } \\
\hline & Before $^{b}$ & After ${ }^{c}$ & Before & After & Before & After & Before & After & \\
\hline $\begin{array}{c}\text { Bamboo derived } \\
\text { BC } \\
\left(850{ }^{\circ} \mathrm{C}\right)\end{array}$ & 491 & 92 & 0.233 & 0.094 & 0.199 & 0.008 & 0.034 & 0.085 & 152 \\
\hline $\begin{array}{c}\text { Bamboo derived } \\
\text { BC } \\
\left(800{ }^{\circ} \mathrm{C}\right)\end{array}$ & 7.0 & 3.2 & -g & - & - & - & - & - & 154 \\
\hline $\begin{array}{c}\text { Bamboo derived } \\
\text { BC } \\
\left(800{ }^{\circ} \mathrm{C}\right)\end{array}$ & 7.0 & 4.0 & - & - & - & - & - & - & 155 \\
\hline $\begin{array}{c}\text { Palm kernel } \\
\text { shells derived } \\
\text { AC }\end{array}$ & 1490 & 305 & 0.551 & 0.289 & - & - & - & - & 153 \\
\hline $\begin{array}{c}\text { Palm kernel } \\
\text { shells derived } \\
\text { AC }\end{array}$ & 1490 & $\begin{array}{l}32.4 \\
20.5\end{array}$ & - & - & - & - & - & - & 157 \\
\hline $\begin{array}{l}\text { Palm kernel } \\
\text { shells derived }\end{array}$ & 1237 & $\begin{array}{l}17.7 \\
91.5\end{array}$ & 0.547 & $\begin{array}{l}0.009 \\
0.078\end{array}$ & - & - & - & - & 158 \\
\hline $\mathrm{AC}$ & & 56.0 & & 0.080 & - & - & - & - & \\
\hline $\begin{array}{c}\text { Palm kernel } \\
\text { shells derived } \\
\text { AC }\end{array}$ & 1273 & 15 & 0.601 & 0.035 & 0.522 & 0.013 & - & - & \\
\hline Coconut derived & 1189 & 32 & 0.495 & 0.055 & 0.422 & 0.025 & - & - & 118 \\
\hline
\end{tabular}


$\mathrm{AC}$

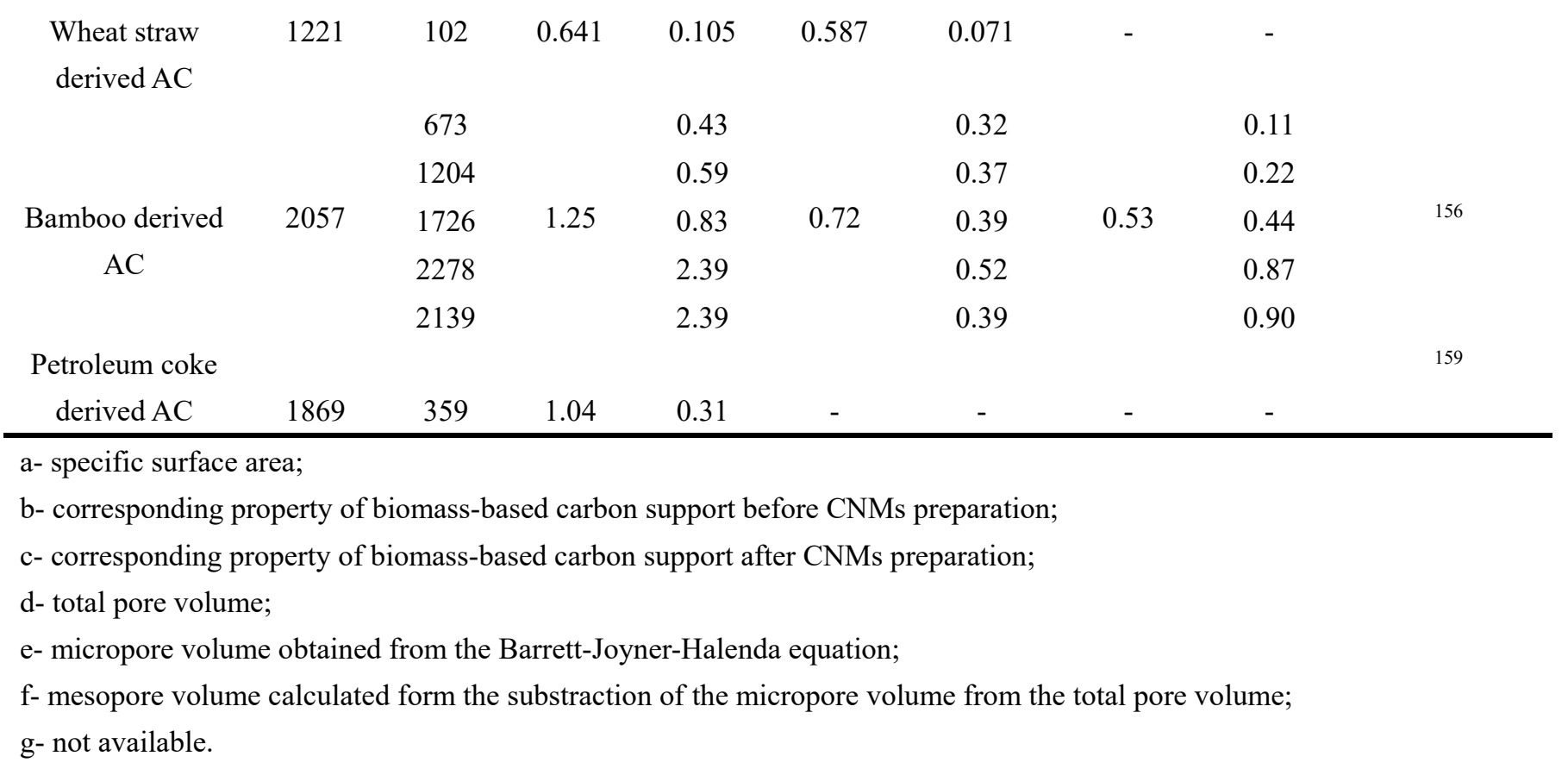

\subsection{Biomass-derived AC}

As discussed-above, it seems that the pore characteristics is a crucial parameter for the synthesis of CNMs using biomass-derived carbon material as a catalyst support. Chemical and physical activation is normally used to enhance the porosity of the biomass-derived carbon materials. As shown in Table 3, all of the biomass-derived AC show much higher specific surface areas and pore volumes than biomass-derived BC ${ }^{153,160}$. Su and his co-workers reported that palm kernel shell could be employed as an outstanding catalyst support precursor in CNMs synthesis as it was converted into AC by carbonizing in $\mathrm{N}_{2}$ at $350{ }^{\circ} \mathrm{C}$ and subsequently activating in steam at $600{ }^{\circ} \mathrm{C}{ }^{153}$. The as-derived palm kernel shell-based $\mathrm{AC}$ had well-developed pore structures with a specific surface area and pore volume of $1081 \mathrm{~m}^{2} / \mathrm{g}$ and $0.365 \mathrm{~cm}^{3} / \mathrm{g}$, respectively. After Fe impregnation, the specific surface area of the AC was still over $1000 \mathrm{~m}^{2} / \mathrm{g}$, which indicated that Fe-related catalyst particle was highly dispersed on the surface of the AC. Afterward, the Fe-impregnated $\mathrm{AC}$ was suffered from a $\mathrm{C}_{2} \mathrm{H}_{2} \mathrm{CVD}$ process at $700{ }^{\circ} \mathrm{C}$. According to SEM analysis, it was found that entangled CNFs with a diameter of 20 $300 \mathrm{~nm}$ was luxuriantly covered on the surface of the AC (Fig. 9a). Further study shown in Fig. $9 \mathrm{~b}$ revealed that CNFs not only immobilized onto the surface of the AC but also nested inside the pores of the AC. The growth of CNFs on the surface or in the pore of the AC gave rise to a significant decrease of its specific surface area from 1490 to 305 $\mathrm{m}^{2} / \mathrm{g}$. A similar result was reported in Chen et al. work, where CNTs were obtained both on the surface and inside the pores of a coconut and wheat straw-derived support ${ }^{118}$. As a result, the specific surface area of the coconut and wheat straw-derived AC decreased from 1189 to $32 \mathrm{~m}^{2} / \mathrm{g}$ and 1121 to $102 \mathrm{~m}^{2} / \mathrm{g}$, respectively, after CNTs growth. It is notable that the activation method applied in $\mathrm{Su}$ et al. work was steam activation 
which was corresponded to a physical activation method. By comparison, chemical activation-derived $\mathrm{AC}$ also has been extensively used as support for CNMs preparation. In Zhou et al. study, they found that the specific surface area and total pore volume of a bamboo-derived BC were considerably increased by 4 folds to $2057 \mathrm{~m}^{2} / \mathrm{g}$ and 1.25 $\mathrm{cm}^{3} / \mathrm{g}$, respectively as an activation process using $\mathrm{KOH}$ was employed ${ }^{156}$. After the introduction of $\mathrm{Co}$ as catalyst and a carbon monoxide CVD process, intertwined CNTs possessed a diameter and length in the range of 5-12 and $<100 \mathrm{~nm}$, respectively, can be observed on the bamboo-derived AC surface. It is worth noting that after the growth of CNTs, the specific surface area and total pore volume of the bamboo-derived AC did not sharply decrease as general biomass-based AC performed (as mentioned above) but further enhanced to $2278 \mathrm{~m}^{2} / \mathrm{g}$ and $1.39 \mathrm{~cm}^{3} / \mathrm{g}$. A possible explanation is that the formation of CNTs can provide abundant mesoporous channels.
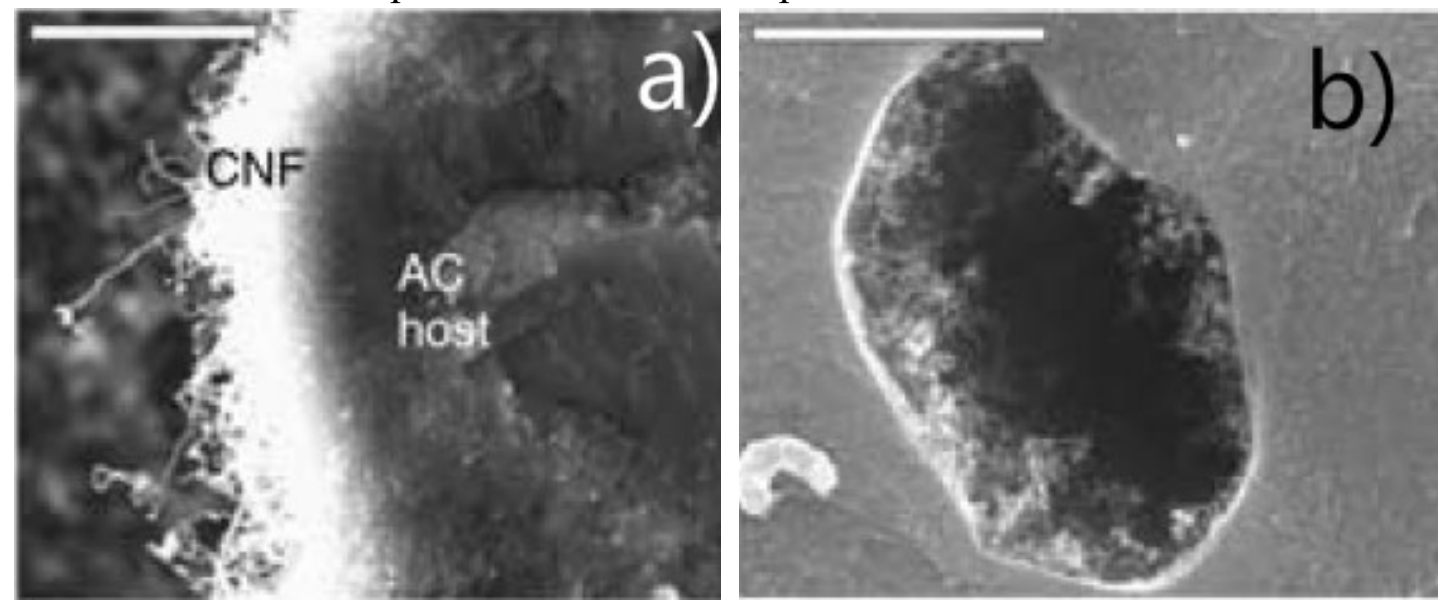

Fig. 9 SEM images of CNFs on AC reported by Su et al. ${ }^{153}$, a) CNFs covered the surface of AC; b) CNFs nested inside AC pore. Reproduced from ${ }^{153}$ with permission from the Wiley.

\subsection{Roles of surface functional groups of biomass-derived carbon}

\section{material on CNMs growth and corresponding growth mechanism}

In addition to pore characteristics, biomass source and growth condition, the surface chemical property of catalyst support was also found to have a significant influence on the dispersion of catalyst and the interaction between support and catalyst, hence remarkably affecting the preparation of CNMs ${ }^{161,162}$. The surface chemical property of biomass-derived support (BC or $\mathrm{AC}$ ) mainly was dominated by the abundant surface functional groups, such as $-\mathrm{C}=\mathrm{O},-\mathrm{OH}, \mathrm{C}=\mathrm{C},-\mathrm{COOH}$, on its surface ${ }^{154,163}$. Some of them, especially for O-containing functional groups, can act as anchoring sites for catalyst incorporation, contributing to the immobilization and dispersion of catalyst ${ }^{164}$. To fulfil the controllable immobilization and the dispersion of catalyst, some researchers paid attention to deliberately modify the surface property of the biomassderived support by oxidation process. For example, Zhou et al. ${ }^{156}$ employed concentrated $\mathrm{HNO}_{3}(68 \%)$ to introduce a large amount of O-containing functional groups on the surface of a bamboo-derived AC (Fig. 10). Combining this process with a microwave-assisted homogeneous deposition-precipitation method, Co catalyst was 
found to be well-dispersed on its surface with a uniform size distribution of 3-9 $\mathrm{nm}$. The uniformly dispersed catalyst was subsequently responsible for the production of CNTs with a uniform and narrow diameter distribution.

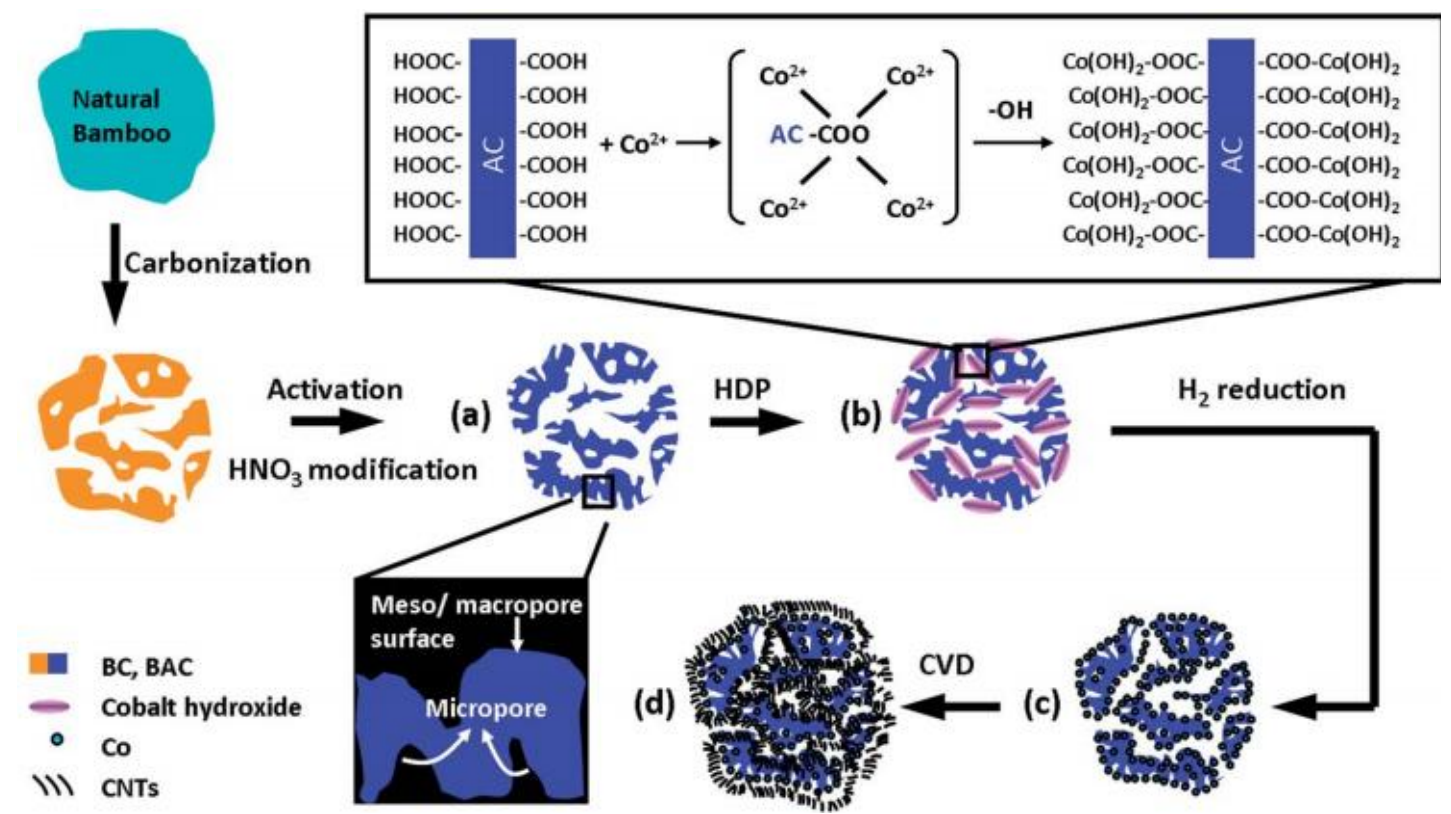

Fig. 10 Illustration of the synthesis of CNTs on bamboo derived AC reported by Zhou et al. ${ }^{156}$ : a) The pore structure of bamboo derived AC, b) Homogeneous nucleation of cobalt hydroxide on the bamboo derived AC support via a homogeneous deposition-precipitation method, c) Co nanoparticles were fixed on the surface of the bamboo derived AC, d) CNTs were bonded onto the bamboo derived AC with Co nanoparticles as the joint points. Reproduced from ${ }^{156}$ with permission from the Royal Society of Chemistry

Su et al. ${ }^{153}$ inferred that the growth of CNFs on AC followed the "tip-growing" model due to most of the Fe catalyst particles were observed on the tips of the CNFs, suggesting that the interactions between AC surface and Fe catalyst were weak ${ }^{79}$. During the synthesis process, Fe catalyst particles dispersed on the surface of AC firstly were reduced by hydrogen, then dissociated from AC surface, acting as a catalyst to decompose carbon source, dissolve carbon atom and precipitate carbon for the growth of CNFs. On the contrary, open-tipped CNTs can be observed in the work from Zhou et al., indicating that CNTs were formed in terms of base growth mechanism which can be briefly stated as follows: at the initial stage, carbon monoxide molecules were pyrolyzed on the surface of fine Co nanoparticles to produce carbon atoms, which simultaneously were dissolved in the Co catalysts ${ }^{156}$. As the carbon was oversaturated, CNTs began to grow out from the surface of the Co catalysts and grew longer until reaching a dynamic equilibrium. The formation of large amounts of CNTs containing catalyst particles on the bottom could be ascribed to the strong binding force between catalyst particles and the support surface. 


\section{Applications of biomass-based CNMs}

It is well-established that conventional CNMs produced from petrochemical hydrocarbons can be applied in various fields such as adsorption, energy storage and catalysis, which have been well reviewed by other studies ${ }^{79,88}$. As fore-mentioned in this review, biomass-based CNMs (biomass providing carbon source, catalyst or catalyst support for CNMs preparation) also presented similar characteristics with the conventional ones, such as diameter, length, morphology and graphitic degree ${ }^{30}$. It is supposed that biomass-based CNMs could be used in the fields where conventional CNMs involved. In addition, as a result of low-cost, eco-friendly and renewable nature of feedstock (biomass) and unique properties such as abundant surface functional groups and minerals, biomass-based CNMs seems to possess more promising potential applications in comparison with conventional CNMs ${ }^{144,165}$.

\subsection{Adsorbents}

It is reported that the effective removal of contaminants such as heavy metal ions (i.e., $\mathrm{Pb}^{2+}, \mathrm{Cd}^{2+}, \mathrm{Cu}^{2+}, \mathrm{CrO}_{3}{ }^{3-}$ ), dyes, organics and nutrient substances (i.e., $\mathrm{PO}_{4}{ }^{3-}, \mathrm{NH}_{4}{ }^{+}$, $\mathrm{NO}_{3}{ }^{-}$) from aqueous solution mainly depended on pore-filling, complexation, electrostatic interaction, ion exchange and precipitation which were greatly attributed to high specific surface area, well-developed porosity, abundant surface functional groups and minerals of the adsorbents ${ }^{166-169}$. Biomass-based CNMs present high specific surface area, abundant surface functional groups and minerals, and have been developed as high-efficient adsorbents 155, 170. For example, Bigdeli and Fatemi considered that the enhancement of specific surface area of CNMs after the formation of CNFs on AC played a vital role in the removal of thiophene and dibenzothiophene from aqueous solution ${ }^{171}$. Multi-walled-CNTs derived from cotton via mechanical activation in a planetary mill for 7-27 h showed a specific surface area of $378-793 \mathrm{~m}^{2} / \mathrm{g}$, which was found to be important for the effective removal of $\mathrm{Ag}^{+} \mathrm{Pb}^{2+}, \mathrm{Cd}^{2+}, \mathrm{Cu}^{2+}$, methylene blue, methyl orange, gelatin and white ${ }^{170}$. Zhang et al. found that a $\mathrm{CNTs} / \mathrm{AC}$ with a specific surface area of $3.2 \mathrm{~m}^{2} / \mathrm{g}$ presented a maximum $\mathrm{Cu}^{2+}$ adsorption capacity of $16.34 \mathrm{mg} / \mathrm{g}$ which was over twice as much as a commercial AC having a specific surface area of $1120 \mathrm{~m}^{2} / \mathrm{g}{ }^{154}$. This result may indicate that the adsorption capability of CNMs was not determined by the specific surface area only. FT-IR and Boehm titration analysis revealed that O-containing surface functional groups such as $-\mathrm{OH}$, - $\mathrm{CO}-\mathrm{O}-$ and $-\mathrm{COOH}$ were extensively existed on the surface of the CNTs/AC. The abundant O-containing surface functional groups provided a large amount of ion-exchange sites and decreased the $\mathrm{pHpzc}$, which were in favor of the ionexchange interactions between $\mathrm{Cu}^{2+}$ and $\mathrm{H}^{+}$of the O-containing surface functional groups and electrostatic attraction, respectively. Therefore, a high uptake of $\mathrm{Cu}^{2+}$ was obtained. Carbon nanospheres prepared from willow leaves showed an excellent adsorption performance toward $\mathrm{Cu}^{2+}, \mathrm{Zn}^{2+}$ and $\mathrm{Cr}^{6+}$ with the adsorption capacity of 
$12.07 \mathrm{mg} / \mathrm{g}$ at $\mathrm{pH} 2,30.48 \mathrm{mg} / \mathrm{g}$ at $\mathrm{pH} 4$ and $372.46 \mathrm{mg} / \mathrm{g}$ at $\mathrm{pH} \mathrm{3}$, respectively. The main reason for this is attributed to the abundant -OH and -CO- surface functional groups as well ${ }^{115}$. The FT-IR spectra of the willow leaves-derived carbon nanospheres before and after rhodamine B adsorption showed that the peaks expected at 1115, 1444, 1797 and $3433 \mathrm{~cm}^{-1}$ shifted to lower wavenumbers after the adsorption process, revealing that in addition to O-containing surface functional groups $(-\mathrm{OH},-\mathrm{CO}-\mathrm{O}-$ and $-\mathrm{COOH})$, aromatic rings played important roles in rhodamine $\mathrm{B}$ adsorption (wavenumber around $1444 \mathrm{~cm}^{-1}$ ) as well ${ }^{115}$. Moreover, the presence of minerals in CNMs was considered to be positive in adsorption procedure ${ }^{65}$. It is reported by Petala group that in addition to surface functional groups, iron particles (iron carbide and metallic iron with sizes of 20-100 nm) buried in the internal carbon matrix of pine tree resin-derived magnetic carbon nanocages can also serve as Fe-oxide layer surface sites ( $\equiv \mathrm{Fe}_{3} \mathrm{C}$ and $\equiv \mathrm{FeOH}_{2}$ ) to make contribution to $\mathrm{AsO}_{2}{ }^{3+}$ adsorption, especially at a $\mathrm{pH}$ higher than 6 based on the mechanism in Eq. 1-2. The maximum adsorption capacity of $\mathrm{AsO}_{2}{ }^{3+}$ at $\mathrm{pH} 7$ was estimated to be $263.9 \mathrm{mg} / \mathrm{g}$ which is believed to be the highest in the literature. Furthermore, $\mathrm{Su}$ et al. reported that the considerable roughness of the outer surface of the CNFs/AC was responsible for the effective adsorption of heteropolymolybdate $\left(\mathrm{H}_{3}\left(\mathrm{PMo}_{12} \mathrm{O}_{40}\right)\right)$ from aqueous solution, while the specific surface area and surface functional groups were less important ${ }^{153}$. They proposed that the highly rough surface of the adsorbent was beneficial for the hydrodynamics of adsorption processes in the liquid phase and provided mechanical and chemical anchoring sites.

$$
\begin{aligned}
& \equiv \mathrm{Fe}_{3} \mathrm{C}+\mathrm{H}_{3} \mathrm{AsO}_{3} \leftrightarrow \equiv \mathrm{Fe}_{3} \mathrm{C}-\left[\mathrm{H}_{3} \mathrm{AsO}_{3}\right](\log \mathrm{K}=0.3) \\
& \equiv \mathrm{FeOH}_{2}+\mathrm{H}_{3} \mathrm{AsO}_{3} \leftrightarrow \mathrm{FeOH}_{2}-\left[\mathrm{H}_{3} \mathrm{AsO} \mathrm{O}_{3}\right](\log \mathrm{K}=3.0)
\end{aligned}
$$

\subsection{Photocatalytic materials}

As a result of favorable conductivity, effective electron accepting and transporting properties, biomass-based CNMs have been widely applied in the domain of photocatalysis ${ }^{172}$. It is reported by Qu et al. that adsorbent cotton-derived CNTs showed about $34 \%$ degradation efficiency toward rhodamine B after a UV light irradiation for $2 \mathrm{~h}$ (initial rhodamine B concentration: $15 \mathrm{mg} / \mathrm{L}$, rhodamine B solution volume: 100 $\mathrm{mL}$, CNTs dosage: $20 \mathrm{mg}){ }^{111}$. Brassica juncea L. shoots-derived CNTs were employed to degrade a bisphenol A solution $(15 \mathrm{mg} / \mathrm{L})$ under a UV light irradiation for $90 \mathrm{~min}^{113}$. The efficiency of photocatalytic degradation reached $48.3 \%$. It is suggested that biomass-based CNMs can be directly applied as effective photocatalysis materials in the degradation of organic pollutants. On the other hand, biomass-based CNMs acted as favorable supports for nanoparticles (semiconductor) to prepare high-efficient photocatalytic materials (biomass-based CNMs/nanoparticle composites) also has been investigated, where were believed to possess many advantages over those derived from typical oxides ${ }^{172}$. For example, the presence of biomass-based CNMs can act as macromolecule photosensitizers to enhance the capability of visible light adsorption, 
resulting in the formation of superoxide radicals. At the same time, biomass-based CNMs provided a new carbon energy level to the band gap of photocatalysis material composites, extending the light adsorption to longer wavelengths. The dispersion of nanoparticles in the photocatalysis material composites was greatly improved due to the large specific surface area of biomass-based CNMs. As a result, corresponding photocatalytic degradation performance of the biomass-based CNMs and nanoparticles composites was enhanced. Qu et al. found that the efficiency of the degradation of rhodamine $\mathrm{B}$ by $\mathrm{CNTs} / \mathrm{ZnO}$ nanocomposites was up to $98 \%$ after a $2 \mathrm{~h}$ UV light irradiation, which was higher than that of adsorbent cotton-derived CNTs and nano ZnO alone ${ }^{111}$. SEM and XRD analysis indicated that $\mathrm{ZnO}$ nanoparticles presented on the surface of CNTs have a diameter around $35.9 \mathrm{~nm}$. CNTs and ZnO nanoparticles were considered to be good electron acceptors and electron donors, respectively. During the photocatalytic degradation process these nanoparticles can effectively impede the recombination of the photo-induced electron and hole, giving rise to the improvement of the photocatalytic degradation performance ${ }^{113}$. As mentioned above, the abundant minerals in biomass played important roles in the formation of CNMs. As a result, the presence of minerals in the as-synthesized biomass-based CNMs also made great influence on the application of the CNMs. It was reported that poplar leaves with abundant minerals such as $\mathrm{K}, \mathrm{Na}, \mathrm{Ca}, \mathrm{Zn}, \mathrm{Cu}$ were directly employed to fabricate metal oxides/CNTs. The formed composites possessed about $74.8 \%$ photocatalytic degradation efficiency for bisphenol A under a solar light irradiation for $180 \mathrm{~min}^{112}$. In the above report, not only an effective photocatalytic degradation material under visible light irradiation was readily obtained, but also the introduction of exogenetic metal oxides as catalytic active sites was avoided. The potential mechanisms of photocatalytic degradation of bisphenol A by the metal oxide/poplar leaves-derived CNTs was proposed as shown in Fig. 11.

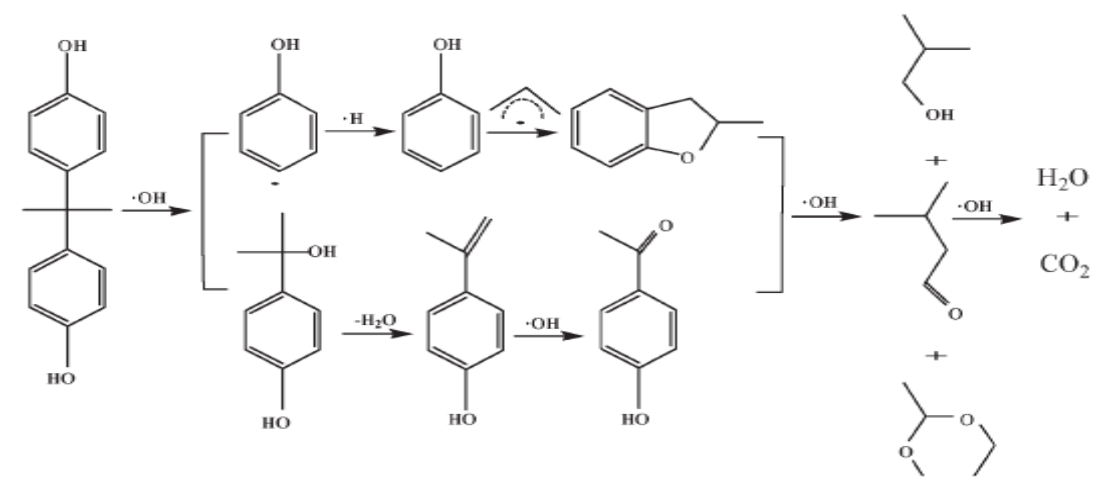

Fig. 11 Proposed photocatalytic degradation mechanism of bisphenol A by metal oxide/poplar leavesderived CNTs reported by Qu group ${ }^{112}$. Reproduced from ${ }^{112}$ with permission from the Royal Society of Chemistry

\subsection{Electrode materials}

Biomass-based CNMs have good potential to be used in the field of electrochemical industrial, as they have unique three-dimensional structure and abundant surface 
functional groups, high specific surface area and abundant porosity. They have been largely employed as electrode materials in energy storage such as supercapacitors (i.e., electronic double layer capacitors and pseudo-capacitance based supercapacitors), $\mathrm{Li}^{+}-$ ion batteries and fuel cells ${ }^{67,72,156}$. Generally, high specific surface area and welldeveloped porosity are favorable for the efficient adsorption, storage, transportation and transmission of electrolyte ${ }^{173}$. Surface functional groups such as O-containing surface functional groups and $\mathrm{N}$-containing surface functional groups could: i) greatly enhance the pseudo-capacitance capability and elevate the amount of energy stored of the supercapacitor; ii) improve the wettability of the CNMs-based electrode, resulting in the enhancement of the specific capacitance; iii) prevent further oxidation of the CNMsbased electrode to ensure a strong cycling stability ${ }^{144}$. Sun et al. investigated the electrochemical properties of spruce bark-based three-dimensional vertically aligned graphene nanosheet arrays prepared via a combined hydrothermal carbonization and $\mathrm{KOH}$ activation approach at 800-1000 ${ }^{\circ} \mathrm{C}$ (VAGNAs) in a three-electrode system with $6 \mathrm{M} \mathrm{KOH}$ aqueous electrolyte. The results are presented in Fig. $12^{70}$. The cycling voltammetry $(\mathrm{CV})$ and galvanostatic charge/discharge (GCD) analyses (Fig. 12a-d) revealed that the as-synthesized CNMs presented both favorable electric double-layer capacitor and pseudo-capacitance behaviors. Particularly, the CNM sample prepared from $900{ }^{\circ} \mathrm{C}$ (VAGNA-900) showed a high specific capacitance of $398 \mathrm{~F} / \mathrm{g}$ at current density of $0.5 \mathrm{~A} / \mathrm{g}$, which was much higher than most of the reported biomass-based CNMs (Fig. 12e). The VAGNA-900 even retained a high specific capacitance of 275 $\mathrm{F} / \mathrm{g}$ at an ultrahigh current density of $50 \mathrm{~A} / \mathrm{g}$. The cycle tests conducting at $10 \mathrm{~A} / \mathrm{g}$ (Fig. 12f) demonstrated that the VAGNA-900 maintained $93.3 \%$ of its initial capacitance after 10000 cycles. It is inferred that the outstanding electrochemical performance of VAGNA-900 was related to its high specific surface area $\left(2385 \mathrm{~m}^{2} / \mathrm{g}\right)$ and open pores which were formed by the nanosheets and three-dimensional graphene structure. In particular, the high specific surface area could supply high accessible surface for adsorbing ions to obtain a high specific capacitance, act as ion buffering reservoirs and provide a short diffusion distance to accelerate the electron transfer and decrease the electric resistance. While the open pores could enhance electric conductivity and electrochemical stability. The unique structure of biomass-based CNMs contributed to the exceptional electrochemical performance in the study from $\mathrm{Su}$ et al. ${ }^{75}$. It was proposed that the hollow activated carbon nanomesh derived from poplar catkins presented a large specific surface area $\left(1893.0 \mathrm{~m}^{2} /\right)$, high total pore volume $(1.495$ $\mathrm{cm}^{3} / \mathrm{g}$ ) and developed meso-macoporous structure (with a uniform pore size distribution of about $4.53 \mathrm{~nm}$ ) giving rise to its high specific capacitance. The poplar catkins-derived carbon nanomesh was practically used in symmetric supercapacitor in a $1.0 \mathrm{M} \mathrm{Na}_{2} \mathrm{SO}_{4}$ aqueous electrolyte. The results showed that a high energy density of $20.86 \mathrm{Wh} / \mathrm{kg}$ was obtained at a power density of $180.13 \mathrm{~W} / \mathrm{kg}$ within a wide voltage rage of $0-1.8 \mathrm{~V}$. An electrochemical stability with $87.6 \%$ capacitance retention after 10000 cycles at $1.0 \mathrm{~A} / \mathrm{g}$ and the coulombic efficiency nearly $100 \%$ of the nanomesh were obtained according to the cycling stability and coulombic efficiency analyses. In addition to the unique structure, surface functional groups were also believed to be responsible for the favorable electrochemical performance of biomass-based CNMs ${ }^{69}$. 
Liu et al. found that carbon nanosheets prepared from Perilla frutescens leaves contained $18.76 \% \mathrm{O}$ and $1.70 \% \mathrm{~N}$ as determined by $\mathrm{X}$-ray photoelectron spectroscopy. These elements mainly existed as corresponding $\mathrm{O} / \mathrm{N}$-containing functional groups such as phenol, carboxylic, carbonyl/quinone, pyrrolic, hydroxypyridine and oxidized pyridine $\mathrm{N}-\mathrm{O}$ moieties ${ }^{55}$. The presence of these abundant $\mathrm{O} / \mathrm{N}$-containing functional groups on the as-prepared CNMs were responsible for its high gravimetric capacitance $(270 \mathrm{~F} / \mathrm{g}$ at $0.5 \mathrm{~A} / \mathrm{g})$ and high volumetric capacitance $\left(287 \mathrm{~F} / \mathrm{cm}^{3}\right.$ at $\left.0.5 \mathrm{~A} / \mathrm{g}\right)$. In detail, the abundant $\mathrm{O} / \mathrm{N}$-containing surface functional groups can i) directly produce pseudocapacitance via redox reaction, ii) endow the as-synthesized CNMs with high affinity to aqueous electrolyte to enhance its wettability, iii) endow the as-synthesized CNMs with acid/base characteristics in aqueous electrolytes, iv) enhance the electrical conductivity of the as-synthesized CNMs. In addition to the $\mathrm{N}$-containing surface functional groups originated from the biomass precursor, surface modification were also beneficial to improve the electrochemical performance of the biomass-based CNMs ${ }^{68}$. Large-size graphene-like porous carbon nanosheets were prepared from combined pyrolysis and activation of sugarcane bagasse pith and chitosan. The obtained CNMs possessed large-size multiscale wrinkled nanosheets architecture, high surface area and appropriate controllable surface $\mathrm{N}$ doping state ${ }^{68}$. The doping of $\mathrm{N}$ on the CNMs enhanced the electrical conductivity and pseudo-capacitance. As a result, the largest specific capacitance of the as-synthesized CNMs was about $339 \mathrm{~F} / \mathrm{g}$ at $0.25 \mathrm{~A} / \mathrm{g}$ which was still as high as $280 \mathrm{~F} / \mathrm{g}$ as the current density increased to $100 \mathrm{~A} / \mathrm{g}$. At the same time, the as-synthesized CNMs also displayed high energy density, power density and excellent cycling stability. 

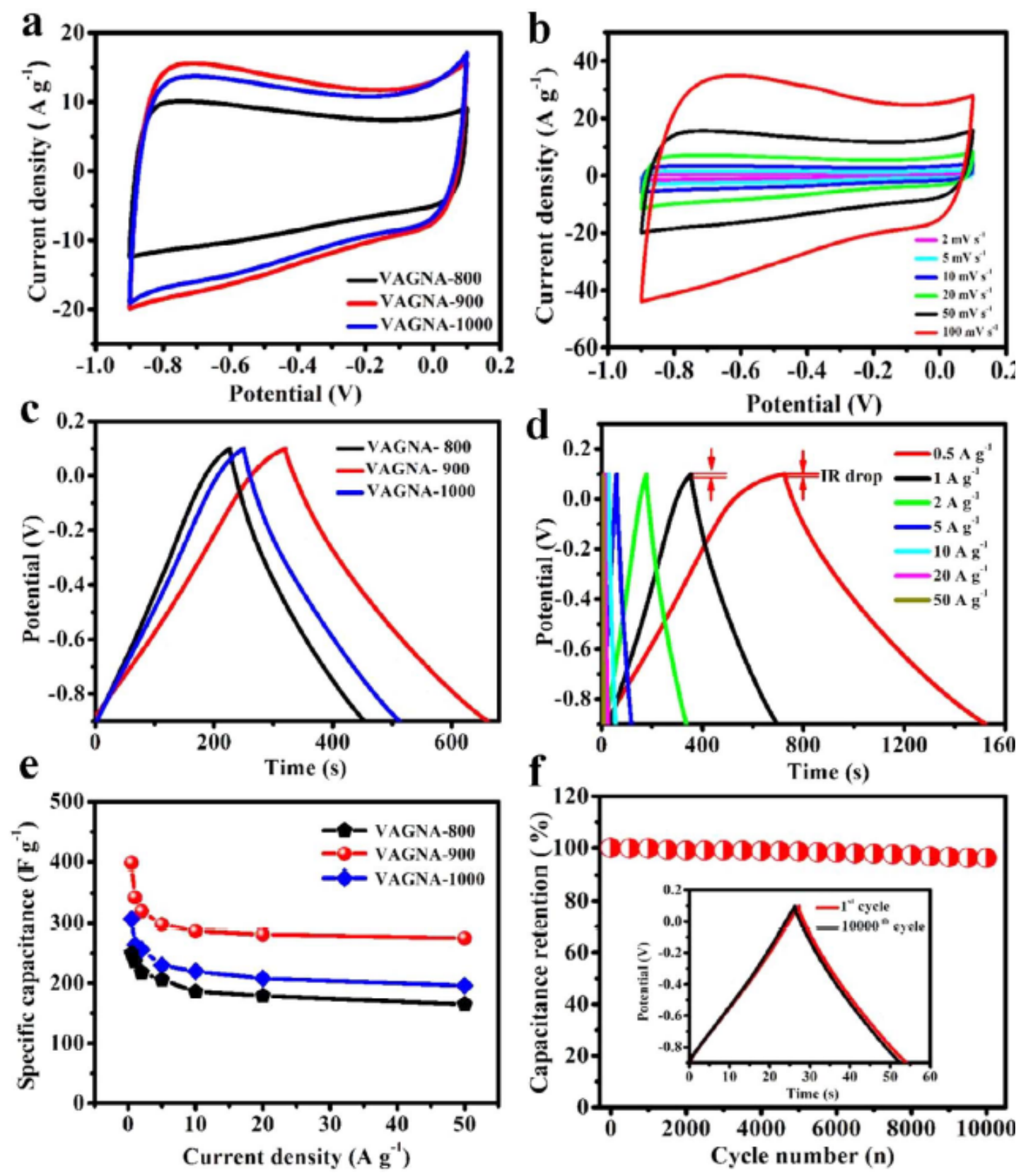

Fig. 12 Electrochemical performance of spruce bark-based three-dimensional vertically aligned graphene nanosheet arrays determined in a three-electrode system with $6.0 \mathrm{M} \mathrm{KOH}$ electrolyte from

Sun et al. ${ }^{70}$. a) CV curves at a scan rate of $50 \mathrm{mV} / \mathrm{s}$, b) CV curves of the spruce bark-based CNM prepared at $900{ }^{\circ} \mathrm{C}$ (VAGNA-900) at different scan rates, c) GCD curves of VAGNAs at a surrent density of 1 A/g, d) GCD curves of VAGNA-900 at different current densities, e) Specific capacitance of VAGNAs at different current densities, f) Cycling stability of VAGNA-900 at a charge/discharge current density of $10 \mathrm{~A} / \mathrm{g}$ for 10000 cycles in a $6.0 \mathrm{M} \mathrm{KOH}$ electrolyte. Inset is the comparison of GCD curves before and after cycling test. Reproduced from ${ }^{70}$ with permission from the Elsevier.

\subsection{Other applications}

Conventional CNMs were considered as effective energy materials for the storage of $\mathrm{H}_{2}$ and $\mathrm{CH}_{4}$ due to the high specific surface area ${ }^{174}$. In order to enhance the capacity 
of gas storage, metal or metal oxide of noble metals, alkaline-earth metals, rare-earth metals and metalloids were introduced into conventional CNMs ${ }^{175-177}$. It seems to that high pressure was essential to promote the diffusion of the targeted gas into the inner structure of conventional CNMs for most of the adsorption/storage processes ${ }^{178}$. However, Onishchenko et al. reported that biomass-based CNTs derived from mechanical activation of rusty peat moss, katerina SV corn, priozernyi-4 cotton and thorny bamboo presented excellent $\mathrm{H}_{2}$ adsorption capability even at a low pressure $(0.5$ $\mathrm{MPa})$ and at room temperature $\left(24{ }^{\circ} \mathrm{C}\right){ }^{179-181}$. It was found that the adsorption capacity of $\mathrm{H}_{2}$ were greatly affected by the type of feedstock, the mechanical activation time, the adsorption pressure and the adsorption temperature. The adsorption capacity of $\mathrm{H}_{2}$ on the CNTs from rusty peat moss, katerina SV corn, priozernyi-4 cotton and thorny bamboo at $0.5 \mathrm{MPa}$ and $24{ }^{\circ} \mathrm{C}$ were $4.7 \mathrm{wt} \%, 4.6 \mathrm{wt} \%, 4.1 \mathrm{wt} \%$ and $3.9 \mathrm{wt} \%$, respectively ${ }^{179}$. At the same time, three-dimensional highly porous graphene derived from bagasse powder through the combination of catalytic graphitization and chemical activation were employed as adsorbents for $\mathrm{CH}_{4}$ adsorption ${ }^{73}$. It was found that the bagasse powder-based porous graphene with a specific surface area of $2720 \mathrm{~m}^{2} / \mathrm{g}$ and a total pore volume of $1.45 \mathrm{~cm}^{3} / \mathrm{g}$ showed a $\mathrm{CH}_{4}$ adsorption capacity up to $193 \mathrm{mg} / \mathrm{g}$ at $298 \mathrm{~K}$ and 35 bar which was superior to most of the reports using conventional CNMs. According to a linear fitting, $\mathrm{CH}_{4}$ adsorption capacity exhibited a well linear relation with the total volume, suggesting that hierarchical pore structure and narrow pore size distribution of the bagasse powder-based porous graphene played important roles in the adsorption process. On the other hand, CNMs were extensively applied as catalyst supports in catalysis for the preparation of chemicals ${ }^{182,183}$. It was reported by Zuo et al. that Pd-involved pemole peel-based nitrogen-doping porous graphene had favorable conversion efficiency for nitrobenzene hydrogenation toward aniline ${ }^{184}$. The Pdinvolved porous graphene fabricated from a mixture of pomelo peel and melamine (1:1) at $800{ }^{\circ} \mathrm{C}$ (PP-1:1-800-Pd) displayed a 100\% convention of nitrobenzene at $50{ }^{\circ} \mathrm{C}$ for $1 \mathrm{~h}$ and high catalytic stability after 10 cycles, which was believed to be related to its high specific surface area $\left(563 \mathrm{~m}^{2} / \mathrm{g}\right)$ and $\mathrm{N}$-content. In detail, high specific surface area of PP-1:1-800-Pd led to the uniform distribution of Pd particles (less than $2 \mathrm{~nm}$ ). Also, the dispersion of $\mathrm{Pd}$ particles was improved and the aggregation was reduced as a result of the high specific surface area. Nitrogen element of the PP-1:1-800-Pd mainly occurred as graphitic $\mathrm{N}$ and pyrrolic $\mathrm{N}$ which were in favor of improving the electronic properties of $\mathrm{Pb}$, thus promoting the conversion of PP-1:1-800-Pd. Liu et al. found that fir sawdust-based $\mathrm{Ni}-\mathrm{NiFe}_{2} \mathrm{O}_{4} / \mathrm{CNF}$ composite had not only high catalytic conversion activity $(100 \%)$ and stability after 7 cycles for the nitrobenzene hydrogenation but high selectivity ${ }^{50}$. No detectable azoxybenzene or azobenzene by-products were determined. These compounds were often observed in other hydrogenation reaction ${ }^{185}$. The Ni$\mathrm{NiFe}_{2} \mathrm{O}_{4} / \mathrm{CNF}$ composite also possessed a favorable separability by an external magnetic field after reaction due to the existence of $\mathrm{NiFe}_{2} \mathrm{O}_{4}$ which endowed a saturation magnetization of $26 \mathrm{emu} / \mathrm{g}$ at 5000 Oe toward the catalyst composite. The above authors considered that high specific surface area of the fir sawdust-derived CNFs was favorable for the dispersion of the Ni nanoparticles, leading to the presence of a large amount of active catalytic sites. High degree of graphitization of the as- 
fabricated CNFs also played an active role in the nitrobenzene hydrogenation due to it was beneficial to electron transport. A proposed potential mechanism for the highly efficient nitrobenzene hydrogenation reaction with the $\mathrm{Ni}-\mathrm{NiFe}_{2} \mathrm{O}_{4} / \mathrm{CNF}$ composite is described in Fig. 13.

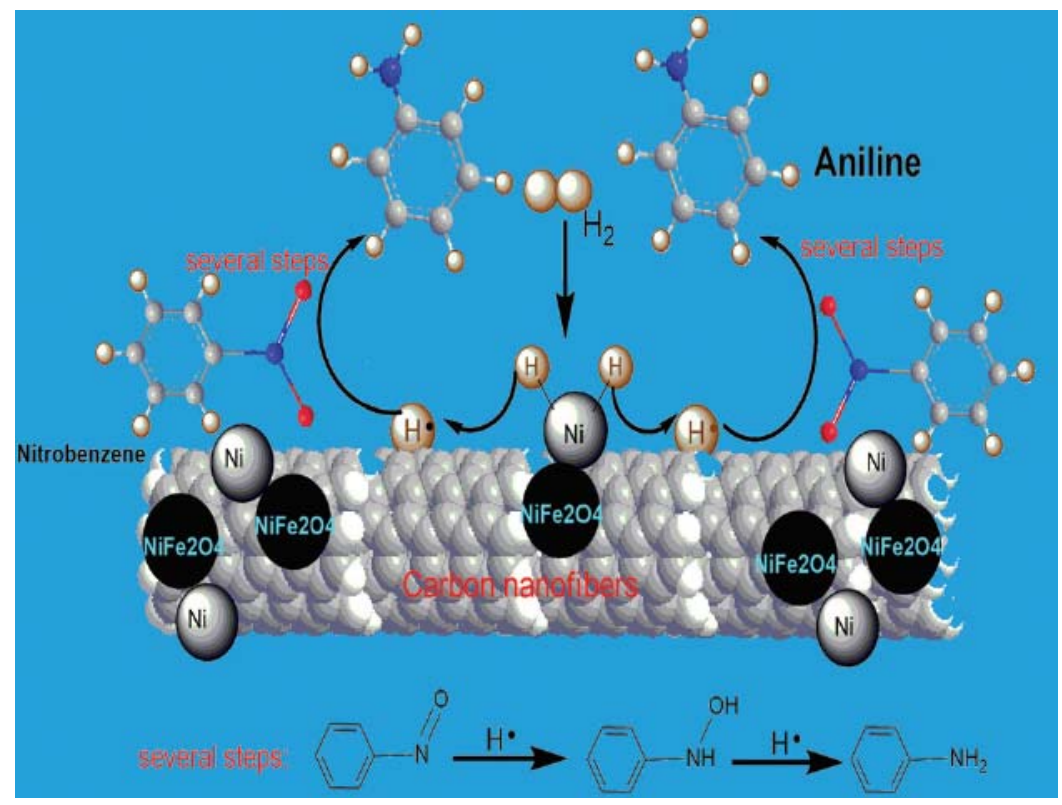

Fig. 13 The proposed possible catalytic mechanism of the Ni-NiFe2O4/CNFs for the hydrogenation of nitrobenzene reported by Liu et al. ${ }^{50}$. Reproduced from ${ }^{50}$ with permission from the Royal Society of

Chemistry

In addition, CNMs were widely developed as additives to incorporate into polymer, concrete and mortar to prepare enhanced composite materials because of their unique structure and outstanding thermal and mechanical properties ${ }^{134,}{ }^{141}$. Gaddam et al. found that the thermal and mechanical properties of polyurethane composites were significantly improved after the addition of Desmostachya bipinnata grass-derived CNMs (0.1-1\%), resulting from the formation of amide linkages between the carboxyl groups of the grass-based CNMs and diisocyanate ${ }^{139}$. Rhee et al. reported that rice husk-derived graphene possessed an extremely high specific surface area of $2274 \mathrm{~m}^{2} / \mathrm{g}$ which was responsible for the improvement of the cementitious mortar compressive strength as they were incorporated ${ }^{142,143}$.

\section{Challenges and way forward}

Biomass has been identified as an alternative, abundant, low cost and renewable carbon source for CNMs preparation, mainly depending on two routes presented in Scheme. 1. One of them is to first convert biomass into amorphous carbons through pyrolysis or combustion and then the amorphous carbons were further converted into CNMs by means of catalytic graphitization, mechanical activation or chemical activation, subjecting to a solid-solid-solid process (Route 1). It is reported that the resulting 
CNMs and their individual characteristics varied from the types of biomass, indicating that biomass and the corresponding amorphous carbons played important roles in the formation of CNMs. Therefore, selecting a suitable biomass and regulating the characteristics of corresponding amorphous carbons to produce more favorable amorphous carbon precursors for the formation of CNMs is the key point. On the other hand, CNMs could be obtained from biomass through a solid-vapor-solid process, in which hydrocarbons and their derivatives (such as $\mathrm{CH}_{4}, \mathrm{C}_{2} \mathrm{H}_{4}, \mathrm{C}_{2} \mathrm{H}_{2}$, naphthalene and benzene) were the precursors of CNMs produced from biomass via pyrolysis (Route 2). It is well-known that the volatiles in gaseous and liquid phase products were composed of water, non-condensable gas, water soluble and insoluble tars. Regulating the generation of effective components (hydrocarbons and their derivatives) and reducing the effects of unrelated components such as O-containing components have a significant effect on the growth of CNMs. This may be achieved by controlling catalyst and the component of biomass.

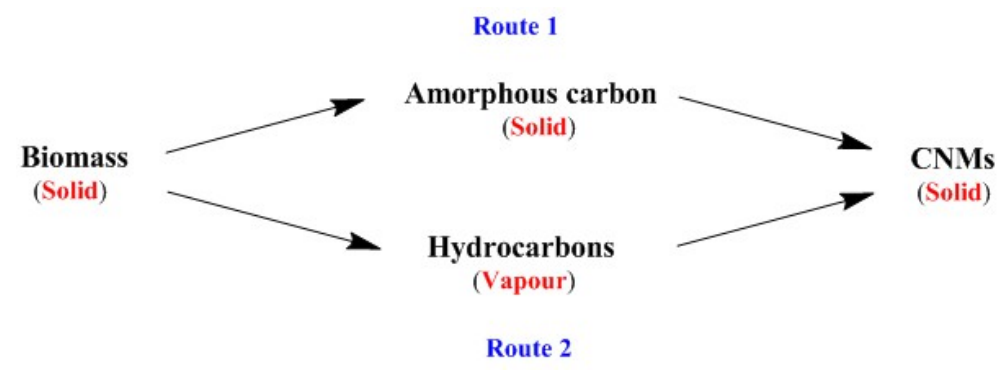

Scheme. 1 The route of biomass towards CNMs

Though biomass can provide minerals as catalysts for CNMs fabrication, it is noted that the concentration of active catalytic components in biomass is very low, and these active sites are usually accompanied with other components or imprisoned in an organic matrix, reducing the availability of active components for CNMs production. It is hence necessary to make sense of the elemental composition as well as the state of individual element in biomass before its utilization.

The thermal conversion of biomass would result in the occurrence of pore structure with varied size distribution. The distribution of BC pores is closely related to the kind of biomass feedstock and the preparation conditions (e.g., temperature, activation treatment). As used as a substrate to support catalyst, mesopores play a key role in liquid-phase adsorption, which are favorable for the impregnation and dispersion of catalyst. Therefore, it seems that the conversion of biomass into carbon-rich material with homogeneous and uniform mesopore distribution is a crucial strategy to enhance the application value of biomass as a catalyst support. In addition to hierarchical pore structure, biomass derived carbon material possesses surface functional groups in rich variety and huge quality. Some of these functional groups, especially for O-containing functional groups, have a great impact on the uptake, dispersion and immobilization of catalyst. Further study hence is to focus on the preparation of biomass derived carbon materials with a large amount of desirable surface functional groups or taking the 
advantage of the surface functional groups of biomass-based carbon material to fulfill the quantitative immobilization and the dispersion of catalyst.

It is well-established that conventional CNMs would present more favorable application after functionalization due to the functionalization process endowed or improved their properties in some special aspects, such as introducing heteroatom surface functional groups and metal/metal oxide active sites, enhancing specific surface area and making structure defects ${ }^{186,187}$. As fore-mentioned in this review, biomass based CNMs possessed a large amount of structure defects, abundant O/N/S-containing surface functional groups, high surface area and developed porosity $55,73,184$. From this point of view, biomass-based CNMs can be considered as functionalized-conventional CNMs. At the same time, due to the low cost, renewable and abundant raw material involved, biomass based-CNMs have been drawing increasing attention. It is worth noting that there are still a great deal of challenge in preparation biomass based-CNMs with tunable physicochemical properties because of the complex structure and composition of biomass precursor. On the other hand, it is also necessary to explore more application fields applicable to biomass based-CNMs.

\section{Conflicts of interest:}

There are no conflicts of interest to declare.

\section{Acknowledgements:}

The authors greatly acknowledge the funding support from the projects supported by National Natural Science Foundation of China (Grant no. 51476034 and 51628601), The Fundamental Research Funds for the Central Universities and Postgraduate Research \& Practice Innovation Program of Jiangsu Province from the Education Department of Jiangsu (KYCX17_0153) and Royal Society International Exchange Scheme (IE150760). The authors gratefully acknowledge financial support from China Scholarship Council.

\section{References:}

1. S. Iijima, nature, 1991, 354, 56-58.

2. A. K. Geim and K. S. Novoselov, Nature Materials, 2007, 6, 183.

3. L. L. Zhang and X. S. Zhao, ChemInform, 2009, 40, no-no.

4. I. Gonzalez-Valls and M. Lira-Cantu, Energy \& Environmental Science, 2009, 2, 19-34.

5. K. Balasubramanian and M. Burghard, Biosensors based on carbon nanotubes, 2006. 
6. Z. Chang, H. Fan, K. Zhao, M. Chen, P. He and Y. Fang, Electroanalysis, 2008, 20, 131-136.

7. M. T. Martínez, Y.-C. Tseng, N. Ormategui, I. Loinaz, R. Eritja and J. Bokor, Nano Letters, 2009, 9, 530-536.

8. H. Hao, P. Liu, J. Tang, Q. Cai and S. Fan, Carbon, 2012, 50, 4203-4208.

9. P. Liu, Y. Wei, K. Liu, L. Liu, K. Jiang and S. Fan, Nano Letters, 2012, 12, 23912396.

10. S. Stobbe, P. E. Lindelof and J. Nygård, Semiconductor Science and Technology, 2006, 21, S10.

11. J. M. Larson, S. C. Bharath, W. G. Cullen and J. E. Reutt-Robey, Small, 2015, $11,4946-4958$.

12. V. Dremov, V. Fedoseev, P. Fedorov and A. Grebenko, Review of Scientific Instruments, 2015, 86, 053703.

13. P.-C. Ma and Y. Zhang, Renewable and Sustainable Energy Reviews, 2014, 30, 651-660.

14. Z. F. Ren, Z. P. Huang, J. W. Xu, J. H. Wang, P. Bush, M. P. Siegal and P. N. Provencio, Science, 1998, 282, 1105-1107.

15. S. Iijima and T. Ichihashi, Nature, 1993, 363, 603-605.

16. A. Thess, R. Lee, P. Nikolaev, H. Dai, P. Petit, J. Robert, C. Xu, Y. H. Lee, S. G. Kim, A. G. Rinzler, D. T. Colbert, G. E. Scuseria, D. Tománek, J. E. Fischer and R. E. Smalley, Science, 1996, 273, 483-487.

17. W. S. Cho, E. Hamada, Y. Kondo and K. Takayanagi, Applied Physics Letters, 
1996, 69, 278-279.

18. E. F. Kukovitskii, L. A. Chernozatonskii, S. G. L'Vov and N. N. Mel'nik, Chemical Physics Letters, 1997, 266, 323-328.

19. T. Kyotani, L.-f. Tsai and A. Tomita, Chemistry of Materials, 1996, 8, 21092113.

20. H. Richter, K. Hernadi, R. Caudano, A. Fonseca, H. N. Migeon, J. B. Nagy, S. Schneider, J. Vandooren and P. J. Van Tiggelen, Carbon, 1996, 34, 427-429.

21. R. L. Vander Wal, G. M. Berger and L. J. Hall, The Journal of Physical Chemistry B, 2002, 106, 3564-3567.

22. R. L. Vander Wal and T. M. Ticich, The Journal of Physical Chemistry B, 2001, $105,10249-10256$.

23. W. K. Hsu, M. Terrones, J. P. Hare, H. Terrones, H. W. Kroto and D. R. M. Walton, Chemical Physics Letters, 1996, 262, 161-166.

24. F. Abnisa and W. M. A. Wan Daud, Energy Conversion and Management, 2014, $87,71-85$.

25. M. N. Satheesh Kumar, A. K. Mohanty, L. Erickson and M. Misra, Journal of Biobased Materials and Bioenergy, 2009, 3, 1-24.

26. S. Gillet, M. Aguedo, L. Petitjean, A. Morais, A. da Costa Lopes, R. Łukasik and P. Anastas, Green Chemistry, 2017, 19, 4200-4233.

27. S. Wang, G. Dai, H. Yang and Z. Luo, Progress in Energy and Combustion Science, 2017, 62, 33-86.

28. L. Sun, C. Tian, M. Li, X. Meng, L. Wang, R. Wang, J. Yin and H. Fu, Journal 
of Materials Chemistry A, 2013, 1, 6462.

29. Z. Wang, H. Ogata, S. Morimoto, J. Ortiz-Medina, M. Fujishige, K. Takeuchi, H. Muramatsu, T. Hayashi, M. Terrones, Y. Hashimoto and M. Endo, Carbon, 2015, 94, 479-484.

30. M.-M. Titirici, R. J. White, N. Brun, V. L. Budarin, D. S. Su, F. del Monte, J. H. Clark and M. J. MacLachlan, Chemical Society Reviews, 2015, 44, 250-290.

31. D. Shen, W. Jin, J. Hu, R. Xiao and K. Luo, Renewable and Sustainable Energy Reviews, 2015, 51, 761-774.

32. T. K. Patra and P. N. Sheth, Renewable and Sustainable Energy Reviews, 2015, $50,583-593$

33. R. Kumar, R. K. Singh and D. P. Singh, Renewable and Sustainable Energy Reviews, 2016, 58, 976-1006.

34. J. Deng, Y. You, V. Sahajwalla and R. K. Joshi, Carbon, 2016, 96, 105-115.

35. Z. Wang, H. Guo, F. Shen, G. Yang, Y. Zhang, Y. Zeng, L. Wang, H. Xiao and S. Deng, Chemosphere, 2015, 119, 646-653.

36. M. Keiluweit, P. S. Nico, M. G. Johnson and M. Kleber, Environmental Science \& Technology, 2010, 44, 1247-1253.

37. M. Zhang, B. Gao, Y. Yao, Y. Xue and M. Inyang, Chemical Engineering Journal, 2012, 210, 26-32.

38. M. Zhang, B. Gao, S. Varnoosfaderani, A. Hebard, Y. Yao and M. Inyang, Bioresource Technology, 2013, 130, 457-462.

39. Z. Wang, H. Guo, F. Shen, G. Yang, Y. Zhang, Y. Zeng, L. Wang, H. Xiao and 
S. Deng, Chemosphere, 2015, 119, 646-653.

40. V. L. Kuznetsov, A. N. Usoltseva, A. L. Chuvilin, E. D. Obraztsova and J.-M. Bonard, Physical Review B, 2001, 64, 235401.

41. S. Maruyama, R. Kojima, Y. Miyauchi, S. Chiashi and M. Kohno, Chemical Physics Letters, 2002, 360, 229-234.

42. N. Q. Zhao, C. N. He, J. Ding, T. C. Zou, Z. J. Qiao, C. S. Shi, X. W. Du, J. J. Li and Y. D. Li, Journal of Alloys and Compounds, 2007, 428, 79-83.

43. L. Yu, Y. Lv, Y. Zhao and Z. Chen, Materials Letters, 2010, 64, 2145-2147.

44. K. Page, M. J. Harbottle, P. J. Cleall and T. R. Hutchings, Science of The Total Environment, 2014, 487, 260-271.

45. C. Keller, C. Ludwig, F. Davoli and J. Wochele, Environmental Science \& Technology, 2005, 39, 3359-3367.

46. L. Zhao, X. Cao, O. Mašek and A. Zimmerman, Journal of Hazardous Materials, 2013, 256-257, 1-9.

47. W.-J. Liu, F.-X. Zeng, H. Jiang and H.-Q. Yu, Bioresource Technology, 2011, $102,3471-3479$.

48. A. Selvam, N. G. Nair and P. Singh, Journal of Materials Science Letters, 1998, $17,57-60$.

49. T. L. Y. Cheung and D. H. L. Ng, Journal of the American Ceramic Society, 2007, 90, 559-564.

50. W.-J. Liu, K. Tian and H. Jiang, Green Chemistry, 2015, 17, 821-826.

51. X. Ye, Q. Yang, Y. Zheng, W. Mo, J. Hu and W. Huang, Materials Research 
Bulletin, 2014, 51, 366-371.

52. Q. Zhang, M.-Q. Zhao, J.-Q. Huang, J.-Q. Nie and F. Wei, Carbon, 2010, 48, 1196-1209.

53. S. B. Sinnott, R. Andrews, D. Qian, A. M. Rao, Z. Mao, E. C. Dickey and F. Derbyshire, Chemical Physics Letters, 1999, 315, 25-30.

54. R. Brukh and S. Mitra, Chemical Physics Letters, 2006, 424, 126-132.

55. B. Liu, Y. Liu, H. Chen, M. Yang and H. Li, Journal of Power Sources, 2017, $341,309-317$.

56. S. S. Shams, L. S. Zhang, R. Hu, R. Zhang and J. Zhu, Materials Letters, 2015, $161,476-479$.

57. G. B. Barin, I. de Fátima Gimenez, L. P. da Costa, A. G. S. Filho and L. S. Barreto, Carbon, 2014, 78, 609-612.

58. M. Sevilla and A. B. Fuertes, Chemical Physics Letters, 2010, 490, 63-68.

59. M. Sevilla, C. Sanchís, T. Valdés-Solís, E. Morallón and A. B. Fuertes, The Journal of Physical Chemistry C, 2007, 111, 9749-9756.

60. A. Ōya and H. Marsh, Phenomena of catalytic graphitization, 1982.

61. A. Ōya and S. Ōtani, Carbon, 1981, 19, 391-400.

62. M. Sevilla, C. Salinas Martinez-de Lecea, T. Valdes-Solis, E. Morallon and A. B. Fuertes, Physical Chemistry Chemical Physics, 2008, 10, 1433-1442.

63. M. Sevilla, C. Sanchís, T. Valdés-Solís, E. Morallón and A. B. Fuertes, Carbon, 2008, 46, 931-939.

64. E. Thompson, A. E. Danks, L. Bourgeois and Z. Schnepp, Green Chem., 2015, 
$17,551-556$.

65. E. Petala, Y. Georgiou, V. Kostas, K. Dimos, M. A. Karakassides, Y. Deligiannakis, C. Aparicio, J. Tuček and R. Zbořil, ACS Sustainable Chemistry \& Engineering, 2017, 5, 5782-5792.

66. C. Chen, D. Yu, G. Zhao, B. Du, W. Tang, L. Sun, Y. Sun, F. Besenbacher and M. Yu, Nano Energy, 2016, 27, 377-389.

67. Y. Li, G. Wang, T. Wei, Z. Fan and P. Yan, Nano Energy, 2016, 19, 165-175.

68. Q. Niu, K. Gao, Q. Tang, L. Wang, L. Han, H. Fang, Y. Zhang, S. Wang and L. Wang, Carbon, 2017, 123, 290-298.

69. D. Zhou, H. Wang, N. Mao, Y. Chen, Y. Zhou, T. Yin, H. Xie, W. Liu, S. Chen and X. Wang, Microporous and Mesoporous Materials, 2017, 241, 202-209.

70. Z. Sun, M. Zheng, H. Hu, H. Dong, Y. Liang, Y. Xiao, B. Lei and Y. Liu, Chemical Engineering Journal, 2018, 336, 550-561.

71. X. Zhou, F. Chen, T. Bai, B. Long, Q. Liao, Y. Ren and J. Yang, Green Chem., 2016, 18, 2078-2088.

72. F. Chen, J. Yang, T. Bai, B. Long and X. Zhou, Journal of Electroanalytical Chemistry, 2016, 768, 18-26.

73. L. Mahmoudian, A. Rashidi, H. Dehghani and R. Rahighi, Chemical Engineering Journal, 2016, 304, 784-792.

74. Y. Cai, Y. Luo, H. Dong, X. Zhao, Y. Xiao, Y. Liang, H. Hu, Y. Liu and M. Zheng, Journal of Power Sources, 2017, 353, 260-269.

75. X.-L. Su, M.-Y. Cheng, L. Fu, J.-H. Yang, X.-C. Zheng and X.-X. Guan, Journal 
of Power Sources, 2017, 362, 27-38.

76. F. J. Derbyshire, A. E. B. Presland and D. L. Trimm, Carbon, 1975, 13, 111-113.

77. Y. Yan, J. Miao, Z. Yang, F.-X. Xiao, H. B. Yang, B. Liu and Y. Yang, Chemical Society Reviews, 2015, 44, 3295-3346.

78. K. A. Shah and B. A. Tali, Materials Science in Semiconductor Processing, 2016, 41, 67-82.

79. J.-P. Tessonnier and D. S. Su, ChemSusChem, 2011, 4, 824-847.

80. X.-j. Xu and S.-m. Huang, Materials Letters, 2007, 61, 4235-4237.

81. C. P. Deck and K. Vecchio, Carbon, 2005, 43, 2608-2617.

82. H. Zhou, C. Wu, J. A. Onwudili, A. Meng, Y. Zhang and P. T. Williams, Energy \& Fuels, 2014, 28, 6371-6379.

83. F. Chen, C. Wu, L. Dong, A. Vassallo, P. T. Williams and J. Huang, Applied Catalysis B: Environmental, 2016, 183, 168-175.

84. W.-J. Liu, K. Tian, Y.-R. He, H. Jiang and H.-Q. Yu, Environmental Science \& Technology, 2014, 48, 13951-13959.

85. B. Debalina, R. B. Reddy and R. Vinu, Journal of Analytical and Applied Pyrolysis, 2017, 124, 310-318.

86. D. M. Le, H. R. Sørensen, N. O. Knudsen, J. K. Schjoerring and A. S. Meyer, Biotechnology for Biofuels, 2014, 7, 141.

87. K. Shi, J. Yan, E. Lester and T. Wu, Industrial \& Engineering Chemistry Research, 2014, 53, 15012-15019.

88. Q. Zhang, J.-Q. Huang, M.-Q. Zhao, W.-Z. Qian and F. Wei, ChemSusChem, 
$2011,4,864-889$.

89. M. C. Hector, A. D. Luisa and V. Wilfred, Nanotechnology, 2012, 23, 105605.

90. S. Sun, X. Yu, B. Han and J. Ou, Construction and Building Materials, 2013, 49, 835-840.

91. N. Mahinpey, P. Murugan, T. Mani and R. Raina, Energy \& Fuels, 2009, 23, 2736-2742.

92. J. Zhang, A. Tahmasebi, J. E. Omoriyekomwan and J. Yu, Journal of Analytical and Applied Pyrolysis, 2018, 130, 142-148.

93. M. G. S. Bernd, S. R. Bragança, N. Heck and L. C. P. d. S. Filho, Journal of Materials Research and Technology, 2017, 6, 171-177.

94. H. H. Nersisyan, T.-H. Lee, K.-H. Lee, D.-Y. Maeng and J.-H. Lee, Materials Letters, 2013, 107, 79-82.

95. J. E. Omoriyekomwan, A. Tahmasebi, J. Zhang and J. Yu, Energy Conversion and Management, 2017, 148, 583-592.

96. J. Prasek, J. Drbohlavova, J. Chomoucka, J. Hubalek, O. Jasek, V. Adam and R. Kizek, Journal of Materials Chemistry, 2011, 21, 15872-15884.

97. J. O. Alves, J. A. Soares Tenório, C. Zhuo and Y. A. Levendis, Journal of Materials Research and Technology, 2012, 1, 31-34.

98. C. Wu, Z. Wang, V. Dupont, J. Huang and P. T. Williams, Journal of Analytical and Applied Pyrolysis, 2013, 99, 143-148.

99. C. Lang, X. Sécordel and C. Courson, Energy \& Fuels, 2017, 31, 12932-12941.

100. C. Wu, J. Huang and P. T. Williams, International Journal of Hydrogen Energy, 
$2013,38,8790-8797$.

101. L. Dong, C. Wu, H. Ling, J. Shi, P. T. Williams and J. Huang, Energy \& Fuels, $2017,31,2118-2127$.

102. L. Dong, C. Wu, H. Ling, J. Shi, P. T. Williams and J. Huang, Fuel, 2017, 188, 610-620.

103. S. Kumagai, J. Alvarez, P. H. Blanco, C. Wu, T. Yoshioka, M. Olazar and P. T. Williams, Journal of Analytical and Applied Pyrolysis, 2015, 113, 15-21.

104. C. E. Efika, C. Wu and P. T. Williams, Journal of Analytical and Applied Pyrolysis, 2012, 95, 87-94.

105. J. O. Alves, C. Zhuo, Y. A. Levendis and J. A. S. Tenório, Applied Catalysis B: Environmental, 2011, 106, 433-444.

106. C. Wu, Z. Wang, J. Huang and P. T. Williams, Fuel, 2013, 106, 697-706.

107. C. Wu and P. T. Williams, Energy \& Fuels, 2009, 23, 5055-5061.

108. Z. Kang, E. Wang, B. Mao, Z. Su, L. Chen and L. Xu, Nanotechnology, 2005, $16,1192$.

109. B. Goodell, X. Xie, Y. Qian, G. Daniel, M. Peterson and J. Jellison, Journal of Nanoscience and Nanotechnology, 2008, 8, 2472-2474.

110. X. Xie, B. Goodell, Y. Qian, Z. Geoffrey, D. Zhang, D. Nagle, M. Peterson and J. Jellison, Forest products journal., 2009, 59, 26-28.

111. J. Qu, C. Luo and Q. Cong, Journal, 2012, 7, 1064-1068.

112. J. Qu, Q. Cong, C. Luo and X. Yuan, RSC Advances, 2013, 3, 961-965.

113. J. Qu, C. Luo and X. Yuan, Environ Sci Pollut Res, 2013, 20, 3688-3695. 
114. J. Qu, C. Luo, Q. Zhang, Q. Cong and X. Yuan, Materials Science and Engineering: B, 2013, 178, 380-382.

115. J. Qu, Q. Zhang, Y. Xia, Q. Cong and C. Luo, Environ Sci Pollut Res, 2015, 22, 1408-1419.

116. X. Xie, B. Goodell, G. Daniel, Y. Qian, J. Jellison and M. Peterson, International Biodeterioration \& Biodegradation, 2009, 63, 933-935.

117. G. Che, B. B. Lakshmi, C. R. Martin, E. R. Fisher and R. S. Ruoff, Chemistry of Materials, 1998, 10, 260-267.

118. X.-W. Chen, O. Timpe, S. B. A. Hamid, R. Schlögl and D. S. Su, Carbon, 2009, 47, 340-343.

119. Y. Chen and L. T. Chadderton, Journal of Materials Research, 2004, 19, 27912794.

120. Y. Chen and J. Yu, Carbon, 2005, 43, 3183-3186.

121. N. Pierard, A. Fonseca, Z. Konya, I. Willems, G. Van Tendeloo and J. B.Nagy, Chemical Physics Letters, 2001, 335, 1-8.

122. Y. Chen and J. Yu, Applied Physics Letters, 2005, 87, 033103.

123. D. V. Onishchenko and V. P. Reva, Production of modern functional materials based on renewable vegetable resources, 2013.

124. D. V. Onishchenko, V. P. Reva, V. V. Chakov, V. G. Kuryavyi and V. V. Petrov, Promising nanocomposite materials based on renewable plant resources, 2013.

125. D. V. Onishchenko, V. P. Reva and V. G. Kuryavyi, Vacuum annealing of carbon nanotubes produced from amorphous carbon, 2013. 
126. D. V. Onishchenko, V. P. Reva, V. G. Kuryavyi, A. E. Protsenko and V. V. Petrov, Coke Chem., 2013, 56, 70-72.

127. V. P. Reva, A. E. Filatenkov, V. U. Yagofarov, D. A. Gulevskii, V. G. Kuryavyi and N. M. Yu, IOP Conference Series: Materials Science and Engineering, 2016, $127,012008$.

128. V. P. Reva, A. É. Filatenkov, Y. N. Mansurov and V. G. Kuryavyi, Refractories and Industrial Ceramics, 2016, 57, 141-145.

129. D. V. Onishchenko, V. P. Reva and B. A. Voronov, Russian Agricultural Sciences, 2013, 39, 540-543.

130. J. Zhu, J. Jia, F. L. Kwong, D. H. L. Ng and S. C. Tjong, Biomass and Bioenergy, 2012, 36, 12-19.

131. K. Mukhopadhyay, K. M. Krishna and M. Sharon, Carbon, 1996, 34, 251-264.

132. K. Mukhopadhyay and M. Sharon, Materials and Manufacturing Processes, $1997,12,541-554$.

133. M. Ozawa, P. Deotaf and E. Osawa, Fullerene Science and Technology, 1999, 7, 387-409.

134. R. R. Gaddam, S. Kantheti, R. Narayan and K. V. S. N. Raju, RSC Advances, 2014, 4, 23043-23049.

135. R. R. Gaddam, D. Vasudevan, R. Narayan and K. V. S. N. Raju, RSC Advances, $2014,4,57137-57143$.

136. M. Kumar and Y. Ando, Diamond and Related Materials, 2003, 12, 998-1002.

137. M. Kumar and Y. Ando, Chemical Physics Letters, 2003, 374, 521-526. 
138. R. J. Andrews, C. F. Smith and A. J. Alexander, Carbon, 2006, 44, 341-347.

139. R. R. Gaddam, S. Kantheti, R. Narayan and K. V. S. N. Raju, Progress in Organic Coatings, 2015, 79, 37-42.

140. H. Muramatsu, Y. A. Kim, K.-S. Yang, R. Cruz-Silva, I. Toda, T. Yamada, M. Terrones, M. Endo, T. Hayashi and H. Saitoh, Small, 2014, 10, 2766-2770.

141. I. Rhee, J. S. Lee, Y. A. Kim, J. H. Kim and J. H. Kim, Construction and Building Materials, 2016, 125, 632-642.

142. I. Rhee, J.-S. Lee, J. H. Kim and Y. A. Kim, Construction and Building Materials, $2017,146,350-359$.

143. I. Rhee, Y. A. Kim, G.-O. Shin, J. H. Kim and H. Muramatsu, Construction and Building Materials, 2015, 96, 189-197.

144. W.-J. Liu, H. Jiang and H.-Q. Yu, Green Chemistry, 2015, 17, 4888-4907.

145. W.-W. Liu, S.-P. Chai, A. R. Mohamed and U. Hashim, Journal of Industrial and Engineering Chemistry, 2014, 20, 1171-1185.

146. Y. Pii, T. Mimmo, N. Tomasi, R. Terzano, S. Cesco and C. Crecchio, Biology and Fertility of Soils, 2015, 51, 403-415.

147. J. Zhao, X. Guo, Q. Guo, L. Gu, Y. Guo and F. Feng, Carbon, 2011, 49, 21552158.

148. C. Zhuo and Y. A. Levendis, Journal of Applied Polymer Science, 2014, 131, n/a-n/a.

149. R. Araga and C. S. Sharma, Materials Letters, 2017, 188, 205-207.

150. J.-H. Lin, C.-S. Chen, H.-L. Ma, C.-W. Chang, C.-Y. Hsu and H.-W. Chen, 
Carbon, 2008, 46, 1619-1623.

151. Z.-Y. Zeng and J.-H. Lin, RSC Adv., 2014, 4, 40251-40258.

152. F. Zhou, Q. Liu, W. Zhang, J. Gu, S. Zhu and D. Zhang, J Mater Sci, 2014, 49, 548-557.

153. D. S. Su, X. Chen, G. Weinberg, A. Klein-Hofmann, O. Timpe, S. B. A. Hamid and R. Schlögl, Angewandte Chemie International Edition, 2005, 44, 54885492.

154. J. Zhang, Z.-H. Huang, R. Lv, Q.-H. Yang and F. Kang, Langmuir, 2009, 25, 269-274.

155. Z.-H. Huang, F. Zhang, M.-X. Wang, R. Lv and F. Kang, Chemical Engineering Journal, 2012, 184, 193-197.

156. F. Zhou, Q. Liu, D. Kang, J. Gu, W. Zhang and D. Zhang, Journal of Materials Chemistry A, 2014, 2, 3505-3512.

157. J. J. Delgado, X. W. Chen, D. S. Su, S. B. A. Hamid and R. Schlögl, Journal of Nanoscience and Nanotechnology, 2007, 7, 3495-3501.

158. X.-W. Chen, D. S. Su, S. B. A. Hamid and R. Schlögl, Carbon, 2007, 45, 895898.

159. J. Y. Gu, K. X. Li, J. Wang and H. W. He, Microporous and Mesoporous Materials, 2010, 131, 393-400.

160. X. W. Chen, D. S. Su and R. Schlögl, physica status solidi (b), 2006, 243, 35333536.

161. C.-T. Hsieh, W.-Y. Chen and Y.-S. Cheng, Electrochimica Acta, 2010, 55, 5294- 
5300.

162. C.-T. Hsieh, H. Teng, W.-Y. Chen and Y.-S. Cheng, Carbon, 2010, 48, 42194229.

163. D. Angın, E. Altintig and T. E. Köse, Bioresource Technology, 2013, 148, $542-$ 549.

164. J. H. Bitter, M. K. van der Lee, A. G. T. Slotboom, A. J. van Dillen and K. P. de Jong, Synthesis of Highly Loaded Highly Dispersed Nickel on Carbon Nanofibers by Homogeneous Deposition-Precipitation, 2003.

165. S. Ravi and S. Vadukumpully, Journal of Environmental Chemical Engineering, $2016,4,835-856$.

166. Z. Wang, D. Shen, F. Shen and T. Li, Chemosphere, 2016, 150, 1-7.

167. Z. Wang, D. Shen, F. Shen, C. Wu and S. Gu, International Biodeterioration \& Biodegradation, 2017, 120, 104-114.

168. Z. Wang, F. Shen, D. Shen, Y. Jiang and R. Xiao, Journal of Environmental Sciences, 2017, 53, 293-300.

169. M. I. Inyang, B. Gao, Y. Yao, Y. Xue, A. Zimmerman, A. Mosa, P. Pullammanappallil, Y. S. Ok and X. Cao, Critical Reviews in Environmental Science and Technology, 2016, 46, 406-433.

170. D. V. Onishchenko and V. P. Reva, Coke Chem., 2013, 56, 262-265.

171. S. Bigdeli and S. Fatemi, Chemical Engineering Journal, 2015, 269, 306-315.

172. M. S. Seyed Dorraji, A. R. Amani-Ghadim, M. H. Rasoulifard, S. Taherkhani and H. Daneshvar, Applied Catalysis B: Environmental, 2017, 205, 559-568. 
173. W.-J. Liu, H. Jiang and H.-Q. Yu, Chemical Reviews, 2015, 115, 12251-12285.

174. S. Ghosh and V. Padmanabhan, International Journal of Energy Research, 2017, 41, 1108-1117.

175. S. Z. Mortazavi, A. Reyhani and S. Mirershadi, International Journal of Hydrogen Energy, 2017, 42, 24885-24896.

176. H. G. Shiraz and M. G. Shiraz, International Journal of Hydrogen Energy, 2017, $42,11528-11533$

177. Z. Tian and S. Dong, International Journal of Hydrogen Energy, 2016, 41, $1053-$ 1059

178. M. Han, Q. Zhao, Z. Zhu, Y. Hu, Z. Tao and J. Chen, Nanoscale, 2015, 7, $18305-$ 18311.

179. D. Onishchenko and V. Reva, Chemistry \& Technology of Fuels \& Oils, 2013, $49,281-286$

180. D. Onishchenko and V. Reva, Chemical \& Petroleum Engineering, 2013, 49, 484-488.

181. D. Onishchenko, V. Reva and V. Kuryavyi, Coke Chem, 2013, 56, 182-185.

182. Z. Sun, Y. Zhao, Y. Xie, R. Tao, H. Zhang, C. Huang and Z. Liu, Green Chemistry, 2010, 12, 1007-1011.

183. P. Chen, F. Yang, A. Kostka and W. Xia, ACS Catalysis, 2014, 4, 1478-1486.

184. P. Zuo, J. Duan, H. Fan, S. Qu and W. Shen, Applied Surface Science, 2018, $435,1020-1028$.

185. A. Nieto-Márquez, S. Gil, A. Romero, J. L. Valverde, S. Gómez-Quero and M. 
A. Keane, Applied Catalysis A: General, 2009, 363, 188-198.

186. J. Xu, Z. Cao, Y. Zhang, Z. Yuan, Z. Lou, X. Xu and X. Wang, Chemosphere, 2018, 195, 351-364.

187. F. W. Low and C. W. Lai, Renewable and Sustainable Energy Reviews, 2018, $82,103-125$. 